\title{
WHAT IF THE UK HAD JOINED THE EURO IN 1999? AN EMPIRICAL EVALUATION USING A GLOBAL VAR
}

\author{
M. HASHEM PESARAN \\ L. VANESSA SMITH \\ RON P. SMITH
}

\author{
CESIFO WORKING PAPER NO. 1477 \\ CATEgory 6: MONETARy POLICY AND INTERNATIONAL FinanCE \\ JUNE 2005
}

\footnotetext{
An electronic version of the paper may be downloaded

- from the SSRN website: Www.SSRN.com

- from the CESifo website: www.CESifo.de
} 


\title{
WHAT IF THE UK HAD JOINED THE EURO IN 1999? AN EMPIRICAL EVALUATION USING A GLOBAL VAR
}

\begin{abstract}
This paper attempts to provide a conceptual framework for the analysis of counterfactual scenarios using macroeconometric models. As an application we consider UK entry to the euro. Entry involves a long-term commitment to restrict UK nominal exchange rates and interest rates to be the same as those of the euro area. We derive conditional probability distributions for the difference between the future realisations of variables of interest (e.g UK and euro area output and prices) subject to UK entry restrictions being fully met over a given period and the alternative realisations without the restrictions. The robustness of the results can be evaluated by also conditioning on variables deemed to be invariant to UK entry, such as oil or US equity prices. Economic interdependence means that such policy evaluation must take account of international linkages and common factors that drive fluctuations across economies. In this paper this is accomplished using the Global VAR recently developed by Dees, di Mauro, Pesaran and Smith (2005). The paper briefly describes the GVAR which has been estimated for 25 countries and the euro area over the period 1979-2003. It reports probability estimates that output will be higher and prices lower in the UK and the euro area as a result of entry. It examines the sensitivity of these results to a variety of assumptions about when and how the UK entered and the observed global shocks and compares them with the effects of Swedish entry.
\end{abstract}

JEL Code: C32, C35, E17, F15, F42.

Keywords: Global VAR (GVAR), counterfactual analysis, UK and Sweden entry to Euro.

\author{
M. Hashem Pesaran \\ University of Cambridge \\ Sidgwick Avenue \\ UK-Cambridge, CB3 9DD \\ mhp1@cam.ac.uk
}

\author{
L. Vanessa Smith \\ University of Cambridge \\ Sidgwick Avenue \\ UK-Cambridge, CB3 9DD \\ lvs21@cam.ac.uk
}

\author{
Ron P. Smith \\ Birkbeck College/University of London \\ Malet Street \\ UK - London WC1E 7HX \\ rsmith@econ.bbk.ac.uk
}

This is a much revised and corrected version of a paper presented at the Conference "Macroeconomics and Reality, 25 Years Later", Barcelona, April 1-2, 2005. We are grateful to Stephane Dees and Filippo di Mauro of ECB for helpful discussions on the development of the GVAR model used in the present exercise. We have also benefitted from comments by the discussants at the conference, Tom Doan and Marco Del Negro, and by Jagjit Chadha, Mardi Dungey, Sean Holly, Pravin Trivedi, and Stephen Wright. 


\section{Introduction}

In economic analysis it is usually assumed that agents are capable of evaluating alternative potential outcomes: to answer 'what if' questions. Agents often make decisions by conducting a counterfactual analysis, judging what would happen under alternative states of the economy. This ability is taken for granted in strategic games, and in arriving at arbitrage conditions in financial markets. Similarly in economic policy-making, a monetary authority will ask what will be the outcome if interest rates are left unchanged compared to the outcome if they are raised or lowered by a certain number of basis points. In policy-making, such scenarios are usually constructed using an econometric model and the outcomes may be described in terms of point, interval or probability forecasts. This paper attempts to provide a conceptual framework for the analysis of such counterfactuals. The approach is illustrated with a specific example that has caused considerable controversy, the debate as to whether the UK or Sweden should adopt the euro. A natural question to ask in this context is whether output in the UK (Sweden) and euro area (EA), would be higher and prices lower if the UK had joined the euro in 1999. Given a global econometric model this is a well defined question that has not, to our knowledge, been given a quantified answer. The model we shall use is the Global Vector Autoregression, GVAR, described in Dees, di Mauro, Pesaran and Smith (2005), DdPS, which is estimated for 25 countries plus the euro area over the period 1979Q4 to 2003Q4.

Our approach to the counterfactual analysis involves deriving the conditional probability distributions for the differences between the future realisations of variables of interest subject to the restrictions implied by the counterfactual under consideration and the alternative realisations without such restrictions. Given a complete econometric model, i.e. with no exogenous variables, with a vector of endogenous variables $\mathbf{x}_{t}$, one can calculate the multi-period probability distribution for $\mathbf{x}_{T+h}$ conditional on information at time $T: f\left(\mathbf{x}_{T+h} \mid \mathcal{I}_{T}\right)$, for $h=1,2, \ldots H$, where $H$ is the forecast horizon. The counterfactual scenario, say the UK or Sweden euro entry, can be viewed as imposing restrictions on the space of the endogenous variables, $\boldsymbol{\Psi}_{\mathbf{x}_{T+j}}=\mathbf{d}_{T+j}, j=1,2, \ldots, \bar{H}$, where $\boldsymbol{\Psi}$ and $\mathbf{d}_{T+j}$ are specified such as to ensure that UK (Sweden) and EA nominal exchange rates and interest rates are equalised for a certain number of periods after entry, and $\bar{H}$ is the commitment horizon (typically assumed to be much larger than $H)$. One can then calculate the probability distribution of $\mathbf{x}_{T+h}$ subject to the long-term entry restrictions, $f\left(\mathbf{x}_{T+h} \mid \mathcal{I}_{T}, \mathbf{\Psi}_{\mathbf{x}_{T+j}}=\mathbf{d}_{T+j}, j=1,2, \ldots, \bar{H}\right)$, for $h=1,2, . ., H<\bar{H}$.

The effect of the entry can then be derived as the probability distribution of the difference between the two counterfactuals. Our baseline case looks at the effect of UK entry in 1999Q1 at par, namely the exchange rate prevailing in 1998Q4, on output and prices in the UK and EA over the five years 1999Q12003Q4. To model long-term commitment we impose the entry restrictions for 10 years, and consider the effects of the UK entry over the period 1999Q12003Q4 (five years). We examine the robustness of our results to a variety of other assumptions about how the UK joined, when it joined and to the 
realisations of oil prices and US equity and interest rates. A similar analysis is also carried out for Sweden.

There is a large literature on conditional probability forecasts, e.g. Doan, Litterman and Sims (1984) and Waggoner and Zha (1999), but our approach is rather different. For instance, when a Central Bank fixes a future path for interest rates to investigate a particular scenario, it usually does this by fixing the errors in the model so that the required interest path is achieved, but ignores the covariances between those assumed errors and the errors of the other equations, which will change other variables. In contrast, our approach allows for the possibility of non-zero covariances. It differs from impulse response function analysis because it puts the restrictions on the observable variables not the unobservable shocks, whose interpretation can be problematic. Like conditional forecasting, the counterfactual analysis can be carried out using the reduced form model, which renders the analysis invariant to the different schemes discussed in the literature for exact identification of the structural shocks.

The issue we are dealing with is similar to that dealt with by models of potential outcomes introduced in the design of experiments by Neyman (1935) and used in the treatment effect literature. The UK did not join the euro in 1999 and we cannot observe what would have happened had it done so any more than we can observe what would have happened to Italy had it not joined. The relation between models of potential outcomes and econometric models is discussed by Heckman (2000). However, our approach differs in that it examines alternative distributions generated by a parametric model rather than making non-parametric comparisons between the observations on those treated and those not treated. The very small sample means that it is not sensible to compare the outcomes of the twelve EU members who joined the euro with the three who stayed out.

Our approach also differs from the type of counterfactuals that are often contemplated in historical discourses. For example, Fogel (1964) asked: what might have happened to the US economy if the railroad had not been brought into use? The standard counterfactual compares the outcome of the hypothetical alternative scenario to what actually happened. The former can be viewed as restricted forecasts, and as with all forecasts can be subject to significant errors, thus making it difficult to distinguish the effects of the restrictions (the counterfactuals) from the forecasts errors associated with the econometric model. Our approach avoids this problem by evaluating the probability distribution of the difference between two counterfactuals, one with and one without the restrictions imposed. The particular aspect of the probability distribution that we look at is the probability that GDP in the UK and the EA would have been higher and prices lower had the UK joined the euro at the beginning of 1999 . We phrase this question in terms of probabilities rather than point forecasts because measurement of such effects is inherently uncertain.

There is a vast literature on various aspects of the euro, including the massive research project conducted by the UK Treasury involving many independent academics published as HMT (2003), but none of it seems to address the particular question we pose. Much of the analysis has been preoccupied with the 
effects on the UK. We look at the effects on both the UK and the EA, since they are very interdependent. The EA is the UK's largest trading partner accounting for $53.7 \%$ of its trade, compared to $18 \%$ for the US, but the UK is also the EA's largest trading partner, accounting for $23.8 \%$ of its trade as compared with $22.7 \%$ for the US, see Table 1 . Thus UK entry could have important effects on the EA.

Table 1: Trade Weights Based on Direction of Trade Statistics

\begin{tabular}{lccccccccc}
\hline \hline Country/ & & & & & \multicolumn{4}{c}{ Rest of W. Europe } & Rest* $^{*}$ \\
Region & US & EA & China & Japan & UK & Sweden & Switz. & Norway & \\
\hline US & 0.000 & 0.155 & 0.073 & 0.124 & 0.052 & 0.008 & 0.012 & 0.004 & 0.571 \\
EA & 0.227 & 0.000 & 0.056 & 0.072 & 0.238 & 0.057 & 0.090 & 0.028 & 0.232 \\
China & 0.236 & 0.164 & 0.000 & 0.248 & 0.029 & 0.010 & 0.007 & 0.003 & 0.304 \\
Japan & 0.319 & 0.132 & 0.128 & 0.000 & 0.032 & 0.007 & 0.009 & 0.003 & 0.371 \\
UK & 0.180 & 0.537 & 0.020 & 0.042 & 0.000 & 0.027 & 0.028 & 0.023 & 0.143 \\
Sweden & 0.104 & 0.517 & 0.025 & 0.035 & 0.115 & 0.000 & 0.017 & 0.099 & 0.088 \\
Switz. & 0.113 & 0.670 & 0.015 & 0.039 & 0.066 & 0.015 & 0.000 & 0.004 & 0.079 \\
Norway & 0.090 & 0.449 & 0.020 & 0.030 & 0.181 & 0.132 & 0.008 & 0.000 & 0.089 \\
\hline
\end{tabular}

Note: Trade weights are computed as shares of exports and imports displayed in rows by region such that a row, but not a column, sums to one. * Rest" gathers the remaining countries. This Table has been reproduced from Table 2 in Dees, di Mauro, Pesaran and Smith (2005).

Economic interdependence means that policy evaluation of alternative scenarios must take account of international linkages and common factors which drive business cycle fluctuations. Thus, to conduct the counterfactual that we have in mind requires a global macroeconometric model which contains specific models for the euro area and the UK, allows for nominal exchange rates and interest rates to be equalised and can calculate the probability distributions for the endogenous variables multiple periods ahead, with and without the restrictions implied by the counterfactuals. The GVAR described in detail in DdPS allows us to do this. It is estimated over 1979Q4 to 2003Q4, so the parameter estimates embody information after the introduction of the euro. It is exactly the version described there. It has not been adjusted for this particular exercise. An earlier version of the GVAR is described in Pesaran, Schuermann and Weiner (2004).

To examine the effect of entry on levels of output and prices in the UK and the EA, a model which distinguishes between the EA and other countries is essential since we need to fix the UK nominal interest rate and exchange rate relative to the ones in EA, while letting the EA (now including the UK) interest rate and exchange rate to vary against other economies. Models which are based on indices of effective exchange rates are not suitable for this purpose. The experience of the EA would have been different under UK entry, because 
the UK has strong trading links with the EA. Therefore changes in UK economic performance would have feedback effects on the EA. The GVAR allows for this, so the impact on the EA of UK entry can be computed.

The approach developed in this paper could be used to examine a range of other counterfactuals, e.g. the new entrants to the EU joining the euro, the possibility of China pegging her currency to the yen rather than to the US dollar, or the effects of a policy committed to holding interest rates unchanged over a given period.

In the rest of the paper we briefly describe the historical background to the creation of the euro, provide an overview of the GVAR, present a framework for the analysis of counterfactuals starting with a simple illustration. We explain how we model entry and derive the probability distribution of the effects of entry under different scenarios, and finally preset the main results for the effects of UK and Sweden entries, separately.

\section{Historical Background}

A central theme in European economic policy in the last quarter of the twentieth century was the need to reduce exchange rate volatility. After the breakdown of Bretton Woods, there were various attempts to reduce exchange rate fluctuations between European countries, culminating in June 1988, when the European Council confirmed the objective of Economic and Monetary Union, EMU. It established the Delors Committee which proposed a three stage process to EMU. Stage 1 started on 1 July 1990, Stage 2, with an embryonic Central Bank, the European Monetary Institute, started on 1 January 1994. Stage 3 started with the adoption of the euro as a virtual currency on 1 January 1999. Eleven countries fixed their exchange rates to the euro and adopted common interest rates. Greece joined on 1 January 2001. Euro notes and coins entered circulation in January 2002.

During the same period, a central theme in UK economic policy was the control of inflation. Money supply targeting was tried in the late 1970s and early 1980s but failed. The target then switched to the exchange rate, first informally under Chancellor Lawson who shadowed the DM, then formally after October 1990 through membership of the European Exchange Rate Mechanism, ERM. The UK and Italy were ejected from the ERM by a large speculative attack in September 1992. Italy later returned to the ERM and joined the euro while the UK began a period of inflation targeting.

The Labour Party was elected in 1997. In opposition, it knew that if elected to government it would have to establish credibility. Keegan (2003) provides an account of the development of Labour party economic policy. During the election campaign, Labour had tried to establish that it would follow a prudent fiscal policy by committing itself to the public expenditure plans of the previous Conservative government. It also needed to establish that it would follow a prudent monetary policy. There were two obvious routes: rejoining the ERM and subsequently the euro or making the Bank of England independent. Neither 
could have been put in the election manifesto and either could in economic terms be regarded as providing a plausible nominal anchor. In the event, it chose Bank of England independence. To join the euro the UK would have had to meet a set of five convergence criteria. Four of them it easily met: government deficit below $3 \%$ of GDP, government debt below $60 \%$ of GDP, inflation less than $1.5 \%$ above the three best performing states, and long interest rates less than $2 \%$ above the three best performing states. The fifth, membership of the exchange rate mechanism without severe tensions for at least two years, would have been more difficult to meet, but might have been waived by the other members.

To determine policy towards the euro, the Labour Chancellor of the Exchequer, Gordon Brown, in a Statement on Economic and Monetary Union on October 271997 (available on http://www.hm-treasury.gov.uk) proposed five economic tests:

"1. Whether there can be sustainable convergence between Britain and the economies of a single currency;

2. Whether there is sufficient flexibility to cope with economic change;

3. The effect on investment;

4. The impact on our financial services industry, and;

5. Whether it is good for employment."

Some questioned the economic coherence, as distinct from the political rationale, of these tests and in any event they were about conditions for entry, not about what the outcome would be if the UK did enter, which is the question that concerns us in this paper.

\section{An Overview of the GVAR}

Suppose there are $N+1$ countries indexed by $i=0,1,2, \ldots, N$, with country 0 , the US, as the reference country. The DdPS version of the GVAR covers 33 countries, 25 treated separately, the remainder grouped into the euro area. For simplicity we will refer to the EA as a country. A second-order country-specific $\operatorname{VARX}^{*}(2,2)$ model with deterministic trends can be written as

$$
\stackrel{\circ}{\mathbf{x}}_{i t}=\boldsymbol{\alpha}_{i}+\boldsymbol{\beta}_{i} t+\boldsymbol{\Phi}_{i 1} \stackrel{\circ}{\mathbf{x}}_{i, t-1}+\boldsymbol{\Phi}_{i 2} \stackrel{\circ}{\mathbf{x}}_{i, t-2}+\boldsymbol{\Psi}_{i 0} \stackrel{\circ}{\mathbf{x}}_{i t}^{*}+\boldsymbol{\Psi}_{i 1} \stackrel{\circ}{\mathbf{x}}_{i, t-1}^{*}+\boldsymbol{\Psi}_{i 2} \stackrel{\circ}{\mathbf{x}}_{i, t-2}^{*}+\stackrel{\circ}{\mathbf{u}}_{i t},
$$

for $i=0,1, \ldots, N$, where $\stackrel{\circ}{\mathbf{x}}_{i t}$ is a $k_{i} \times 1$ (usually five or six) vector of countryspecific variables, $\stackrel{\mathrm{x}}{i t}_{i t}^{*}$, a $k_{i}^{*} \times 1$ vector of foreign variables specific to country $i$, $\boldsymbol{\Phi}_{i 1}$ and $\boldsymbol{\Phi}_{i 2}$ are $k_{i} \times k_{i}$ matrix of lagged coefficients, $\boldsymbol{\Psi}_{i 0}, \boldsymbol{\Psi}_{i 1}$ and $\boldsymbol{\Psi}_{i 2}$ are $k_{i} \times k_{i}^{*}$ matrix of coefficients associated with the foreign-specific variables, and $\stackrel{\mathbf{u}}{i t}_{i}$ is a $k_{i} \times 1$ vector of idiosyncratic country-specific shocks. All the 26 country-specific models in the GVAR are estimated over the period 1979Q4-2003Q4.

The variables $\stackrel{\circ}{\mathbf{x}}_{i t}$ are a $k_{i} \times 1$ subset of the logarithm of real output, $y_{i t}$; inflation, $\pi_{i t}=p_{i t}-p_{i t-1}$, where $p_{i t}$ is the logarithm of a price index; the real exchange rate, which we define as $e_{i t}-p_{i t}$, where $e_{i t}$ is the logarithm of the nominal exchange rate against the dollar; a short interest rate, $r_{i t}^{S}=$ $0.25 \log \left(1+R_{i t}^{S} / 100\right)$, where $R_{i t}^{S}$ is a short interest rate measured in percent per annum; a long interest rate, $r_{i t}^{L}=0.25 \log \left(1+R_{i t}^{L} / 100\right)$; and the logarithm of 
real equity prices, $q_{i t}$. The variables included in the different country models are not always the same, e.g. there are no equity price or long-term interest rate data for some.

The lag orders are selected by AIC separately for each country up to a maximum of 2. The US, the reference country, is treated differently. Oil prices are included in the US model as an endogenous variable but included in other country models as weakly exogenous. In contrast, exchange rates (in terms of US dollars) are included as endogenous variables in all country models except for the US model. Also all foreign variables are included in the non-US models as weakly exogenous variables, but only foreign real output and foreign inflation are included as weakly exogenous in the US model.

The country specific models in the GVAR could be derived from structural models. Most theoretical models have VARs as reduced forms. For example, solution of Dynamic Stochastic General Equilibrium (DSGE) models can be approximated by VAR's with restrictions on the coefficients. But a formal link up of the GVAR with multi-country DSGE models will be beyond the scope of the present paper.

The foreign variables $\dot{\mathbf{x}}_{i t}^{*}$ are calculated as country specific trade weighted averages of the corresponding variables of the other countries

$$
\stackrel{\circ}{\mathbf{x}}_{i t}^{*}=\sum_{j=0}^{N} w_{i j} \stackrel{\circ}{\mathbf{x}}_{j t}, \text { with } w_{i i}=0
$$

where $w_{i j}$ is the share of country $j$ in the trade (exports plus imports) of country $i$. The $\stackrel{\mathbf{x}}{i t}_{i t}^{*}$ are treated as weakly exogenous, an assumption found acceptable, when tested. A summary of the trade-weight matrix is given in Table 1. The VARX* models can be estimated separately for each country, taking into account the possibility of cointegration between $\stackrel{\circ}{i t}_{i t}$ and $\stackrel{\circ}{\mathbf{x}}_{i t}^{*}$. Including the country specific world averages, $\mathbf{x}_{i t}^{*}$, also reduces between-groups dependence in the errors. In the $\mathrm{VARX}^{*}$ only the just identifying restrictions are imposed on the cointegrating vectors. It is worth noting that the outcome does not depend on the precise form of the just identifying restrictions.

Although estimation is done on a country by country basis, the GVAR model is solved for the world as a whole, taking account of the fact that all the variables are endogenous to the system as a whole. To do this (1) can be written as

$$
\mathbf{A}_{i 0} \stackrel{\circ}{\mathbf{z}}_{i t}=\mathbf{h}_{i 0}+\mathbf{h}_{i 1} t+\mathbf{A}_{i 1} \stackrel{\circ}{\mathbf{z}}_{i t-1}+\mathbf{A}_{i 2} \stackrel{\circ}{\mathbf{z}}_{i t-2}+\stackrel{\circ}{\mathbf{u}}_{i t},
$$

for $i=0,1,2, \ldots, N$ where $\stackrel{\circ}{\mathbf{z}}_{i t}$

$$
\stackrel{\circ}{\mathbf{z}}_{i t}=\left(\begin{array}{c}
\stackrel{\circ}{\mathbf{x}}_{i t} \\
\stackrel{\circ}{\mathbf{x}}_{i t}^{*}
\end{array}\right)
$$

and

$$
\mathbf{A}_{i 0}=\left(\mathbf{I}_{k_{i}},-\boldsymbol{\Psi}_{i 0}\right), \quad \mathbf{A}_{i 1}=\left(\boldsymbol{\Phi}_{i 1}, \boldsymbol{\Psi}_{i 1}\right), \quad \mathbf{A}_{i 2}=\left(\boldsymbol{\Phi}_{i 2}, \boldsymbol{\Psi}_{i 2}\right) .
$$


The dimensions of $\mathbf{A}_{i 0}, \mathbf{A}_{i 1}$ and $\mathbf{A}_{i 2}$ are $k_{i} \times\left(k_{i}+k_{i}^{*}\right)$ and $\mathbf{A}_{i 0}$ has full column rank, namely $\operatorname{Rank}\left(\mathbf{A}_{i 0}\right)=k_{i}$. Also note that

$$
\stackrel{\circ}{\mathbf{z}}_{i t}=\mathbf{W}_{i} \stackrel{\circ}{\mathbf{x}}_{t}
$$

where $\stackrel{\circ}{\mathbf{x}}_{t}=\left(\stackrel{\circ}{\mathbf{x}}_{0 t}^{\prime}, \stackrel{\circ}{\mathbf{x}}_{1 t}^{\prime}, \ldots, \stackrel{\circ}{\mathbf{x}}_{N t}^{\prime}\right)^{\prime}$ is the $k \times 1$ vector which collects all the endogenous variables of the system, and $\mathbf{W}_{i}$ is the $\left(k_{i}+k_{i}^{*}\right) \times k$ matrix defined by the trade weights $w_{i j}$. Using this (2) can be written as

$$
\mathbf{A}_{i 0} \mathbf{W}_{i} \stackrel{\circ}{\mathrm{x}}_{t}=\mathbf{h}_{i 0}+\mathbf{h}_{i 1} t+\mathbf{A}_{i 1} \mathbf{W}_{i} \stackrel{\circ}{\mathbf{x}}_{t-1}+\mathbf{A}_{i 2} \mathbf{W}_{i} \stackrel{\circ}{\mathbf{x}}_{t-2}+\stackrel{\circ}{\mathbf{u}}_{i t}, \text { for } i=0,1,2, \ldots, N,
$$

and the systems stacked to yield the model for $\stackrel{\circ}{\mathbf{x}}_{\mathbf{t}}$

$$
\mathbf{H}_{0} \stackrel{\circ}{\mathbf{x}}_{t}=\mathbf{h}_{0}+\mathbf{h}_{1} \mathbf{t}+\mathbf{H}_{1} \stackrel{\circ}{\mathbf{x}}_{t-1}+\mathbf{H}_{2} \stackrel{\circ}{\mathbf{x}}_{t-2}+\stackrel{\circ}{\mathbf{u}}_{t},
$$

where

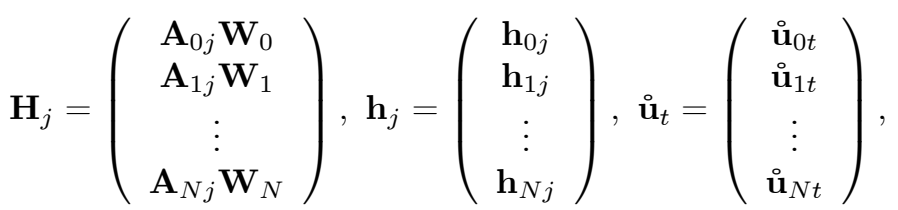

for $j=0,1,2$. Since $\mathbf{H}_{0}$ is a known non-singular matrix that depends on the trade weights and parameter estimates, we can obtain the GVAR

$$
\stackrel{\circ}{\mathbf{x}}_{t}=\mathbf{a}_{0}+\mathbf{a}_{1} \mathbf{t}+\mathbf{G}_{1} \stackrel{\circ}{\mathbf{x}}_{t-1}+\mathbf{G}_{2} \stackrel{\circ}{\mathbf{x}}_{t-2}+\stackrel{\circ}{\mathbf{v}}_{t}
$$

where $\mathbf{G}_{j}=\mathbf{H}_{0}^{-1} \mathbf{H}_{j}, \mathbf{a}_{j}=\mathbf{H}_{0}^{-1} \mathbf{h}_{j}$, for $j=0,1,2$, and $\stackrel{\circ}{\mathbf{v}}_{t}=\mathbf{H}_{0}^{-1} \stackrel{\circ}{\mathbf{u}}_{t}$. The GVAR can be solved recursively and used for a variety of purposes.

There are no restrictions on the covariance matrix $\boldsymbol{\Sigma}=\mathbf{E}\left(\dot{\mathbf{v}}_{t} \stackrel{\circ}{\mathbf{v}}_{t}^{\prime}\right)$. For each

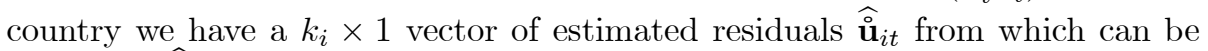
calculated $\widehat{\hat{\mathbf{v}}}_{i t}$ and the elements of the covariance matrix are estimated freely by the $k_{i} \times k_{j}$ matrix $\widehat{\boldsymbol{\Sigma}}_{i j}=\sum_{t} \widehat{\stackrel{\mathbf{v}}{i t}}_{i t} \widehat{\stackrel{\mathrm{v}}{\mathbf{v}}}_{j t}^{\prime} / T$.

The model has 134 endogenous variables 71 stochastic trends and 63 cointegrating relations. A full description of the model properties including an analysis of its stability is given in DdPS. Although linear with a simple overall structure, this is a large and complicated model which allows for a large degree of interdependence. There are two routes for between country interdependence, through the impact of the $\dot{\mathrm{x}}_{i t}^{*}$ variables and through the covariances. The effects through the $\dot{\mathbf{x}}_{i t}^{*}$ are generally large, shocks to one country have marked effects on other countries. The between country covariances are quite small, with the exception of those for the real exchange rate equations, perhaps because of the base-country effect, since they are all expressed against the US dollar.

\section{A Framework for Counterfactual Analysis}

\subsection{A Simple Illustration}

Before presenting our counterfactual framework for the analysis of UK entry it might be helpful to consider a simple illustration where we focus only on two 
variables, $x_{1}$ and $x_{2}$ in the context of a one-period commitment problem. Suppose that in the absence of interventions the variables $\left(x_{1}, x_{2}\right)$ have a bivariate normal distribution with means $\left(\mu_{1}, \mu_{2}\right)$ and variance matrix

$$
\left(\begin{array}{cc}
\sigma_{1}^{2} & \rho \sigma_{1} \sigma_{2} \\
\rho \sigma_{1} \sigma_{2} & \sigma_{2}^{2}
\end{array}\right)
$$

Denote the corresponding random variables after the intervention by $x_{1}^{*}$ and $x_{2}^{*}$, and suppose that the objective of the intervention is to ensure $x_{1}^{*}=x_{2}^{*},{ }^{1}$ with the post-intervention variables being no more volatile than the pre-intervention ones, namely $V\left(x_{1}^{*}\right) \leq V\left(x_{1}\right)$ and $V\left(x_{2}^{*}\right) \leq V\left(x_{2}\right){ }^{2}$ To clarify the role of these optimality conditions in deriving our proposed solution we introduce the intervention variables $\eta_{1}$ and $\eta_{2}$ so that

$$
\begin{aligned}
& x_{1}^{*}=\mu_{1}+\eta_{1}+u_{1}, \\
& x_{2}^{*}=\mu_{2}+\eta_{2}+u_{2},
\end{aligned}
$$

and $\eta_{1}$ and $\eta_{2}$ are such that

$$
\eta_{1}-\eta_{2}=\mu_{2}-\mu_{1}+u_{2}-u_{1} .
$$

Clearly, without further restrictions, there are many possible forms of interventions that could satisfy (5). For example, intervention could only affect $x_{2}$ and not $x_{1}$, with $x_{1}$ realised first and then $x_{2}$ set to equal $x_{1}$. Under this set up $\eta_{1}=0$, and $\eta_{2}=\mu_{1}-\mu_{2}+u_{1}-u_{2}$ so that $x_{1}^{*}$ and $x_{2}^{*}$ both will be distributed as $N\left(\mu_{1}, \sigma_{1}^{2}\right)$. But such an intervention need not be optimal since it does not necessarily ensure that $V\left(x_{1}^{*}\right) \leq V\left(x_{1}\right)$ and $V\left(x_{2}^{*}\right) \leq V\left(x_{2}\right)$.

Under the above set up and noting that $x_{1}$ and $x_{2}$ are jointly normally distributed, the mean and variance of $x_{1}^{*}$ ( or $x_{2}^{*}$ ) are given by ${ }^{3}$

$$
E\left(x_{1}^{*}\right)=E\left(x_{1} \mid x_{1}-x_{2}=0\right)=\mu_{1}+\frac{\operatorname{Cov}\left(x_{1}, x_{1}-x_{2}\right)}{V\left(x_{1}-x_{2}\right)}\left[0-\left(\mu_{1}-\mu_{2}\right)\right],
$$

and

$$
V\left(x_{1}^{*}\right)=V\left(x_{1} \mid x_{1}-x_{2}=0\right)=V\left(x_{1}\right)-\frac{\operatorname{Cov}\left(x_{1}, x_{1}-x_{2}\right) \operatorname{Cov}\left(x_{1}-x_{2}, x_{1}\right)}{V\left(x_{1}-x_{2}\right)},
$$

which can be simplified to

$$
E\left(x_{1}^{*}\right)=E\left(x_{2}^{*}\right)=\frac{\mu_{1}\left(\sigma_{2}^{2}-\rho \sigma_{1} \sigma_{2}\right)+\mu_{2}\left(\sigma_{1}^{2}-\rho \sigma_{2} \sigma_{1}\right)}{\sigma_{1}^{2}+\sigma_{2}^{2}-2 \rho \sigma_{1} \sigma_{2}},
$$

${ }^{1}$ Note that by construction $x_{1}^{*}=x_{2}^{*}=x^{*}$, where $x^{*}$ is also normally distributed under our assumptions.

${ }^{2}$ In the context of more structured problems, one could also employ utility-based optimality conditions. However, to the extent that lower volatilities are welfare enhancing our statistical approach can be reconciled with alternative utility-based procedures.

${ }^{3}$ Recall that for normally distributed random variables we have

$$
E(\mathbf{y} \mid \mathbf{x}=\mathbf{d})=E(\mathbf{y})+\operatorname{Cov}(\mathbf{y}, \mathbf{x}) \mathbf{V}(\mathbf{x})^{-1}(\mathbf{d}-E(\mathbf{x})) .
$$


and

$$
V\left(x_{1}^{*}\right)=V\left(x_{2}^{*}\right)=\frac{\sigma_{1}^{2} \sigma_{2}^{2}\left(1-\rho^{2}\right)}{\sigma_{1}^{2}+\sigma_{2}^{2}-2 \rho \sigma_{1} \sigma_{2}} .
$$

It is also easily verified that $V\left(x_{i}^{*}\right) \leq V\left(x_{i}\right)$ for $i=1,2$, as required.

Finally, for future reference we note that $\operatorname{Cov}\left(x_{1}, x_{1}^{*}\right)=\operatorname{Cov}\left(x_{2}, x_{1}^{*}\right)=$ $V\left(x_{1}^{*}\right)$. To prove this result consider the following convex combination of the random variables $x_{1}$ and $x_{1}^{*}$

$$
z=\lambda x_{1}+(1-\lambda) x_{1}^{*},
$$

where $\lambda$ is a scalar in the range $0 \leq \lambda \leq 1$. Since under our intervention rule $V\left(x_{1}^{*}\right) \leq V\left(x_{1}\right)$, hence the value of $\lambda$ that minimizes $V(z)$ must be zero. From the first order condition for the minimization of $V(z)$ with respect to $\lambda$, the optimal value of $\lambda$, say $\lambda^{*}$, is given by

$$
\lambda^{*}=\frac{V\left(x_{1}^{*}\right)-\operatorname{Cov}\left(x_{1}, x_{1}^{*}\right)}{V\left(x_{1}-x_{1}^{*}\right)}=0,
$$

and hence $\operatorname{Cov}\left(x_{1}, x_{1}^{*}\right)=V\left(x_{1}^{*}\right)$, as required.

\subsection{Modeling of Entry}

The illustrative model of the above section is static and focuses on a single period where the forecast and the commitment periods are the same. But in the case of dynamic models, as noted in the introduction, it is important that a distinction is made between the forecast horizon and the commitment period. Let $H$ denote the forecast horizon, $h=1,2, \ldots, H$, and $\bar{H}$ the commitment horizon, $j=1,2, \ldots, \bar{H}$, such that $H<\bar{H}$. The choice of $\bar{H}$ would typically depend on the nature and the expected durability of the commitment. In what follows we take $H$ and $\bar{H}$ as given. In the empirical applications we ensure that $\bar{H}$ is sufficiently large relative to $H$.

Also the GVAR includes as endogenous variables in $\stackrel{\circ}{x}_{t}$ the real exchange rates and rates of inflation of the various countries. To analyse the effect of UK entry we need to transform the model to explain a new set of endogenous variables $\mathbf{x}_{t}$ which include the levels of prices and nominal exchange rates. We treat a counterfactual as a restriction on the space of endogenous variables, $\mathbf{x}_{t}$. In this case the restriction is the equality between UK and EA nominal exchange rates and interest rates. For entry at the end of period $T$ (e.g. 1998Q4), the restrictions can be written in the form: $\mathbf{\Psi x}_{T+j}=\mathbf{d}_{T+j}, j=1,2, \ldots, \bar{H}$. where the restrictions embodied in $\boldsymbol{\Psi}$ and $\mathbf{d}_{T+j}$ are defined by the counterfactual. UK entry imposes two restrictions on the endogenous variables. We can then calculate the unrestricted expected values $\boldsymbol{\mu}_{h}=E\left(\mathbf{x}_{T+h} \mid \mathcal{I}_{T}\right)$ and the restricted expected values $\boldsymbol{\mu}_{h}^{*}=E\left(\mathbf{x}_{T+h} \mid \mathcal{I}_{T}, \mathbf{\Psi}_{\mathbf{x}_{T+j}}=\mathbf{d}_{T+j}, j=1,2, \ldots, \bar{H}\right)$, for $h=$ $1,2, \ldots, H<\bar{H}$. The difference in these expected values is our point estimate 
of the effects of the counterfactual, UK entry. We also derive the variancecovariance matrix of the difference for each horizon. Assuming joint normality, this allows us to make probability statements about the effects of entry on events, for example that UK GDP will be higher, and joint probability statements, e.g. that UK GDP will be higher and UK prices lower across the different horizons.

The advantage of the GVAR in this exercise is that it can consistently allow for a large degree of interdependence through a variety of channels within a coherent structure. One disadvantage for exposition is that the linkages in the GVAR are complex. We assume that the parameters of the model remain constant at the values estimated from the historical sample. The stochastic trends in the model mean that the variance of the forecast $\mathbf{x}_{T+h}$ increases at the rate, $h$, thus the forecasts themselves are likely to have large standard errors which will increase with the horizon. The estimates of the effect of entry, the difference between two forecasts, will have smaller variances than the forecasts, but the variance of the effect of entry will also increase at the rate, $h$. To allow for this uncertainty we will focus on the probability of particular events. Specifically, we consider the probability that output in the UK and EA will be higher with entry, that prices will be lower and the joint probability of higher output and lower prices.

With the above considerations in mind, suppose that UK joins euro at the end of date $T$ with the commitment (agreed by the euro area and UK authorities jointly) that UK's nominal exchange rate, $E_{2, T+j}$, and short term interest rate, $r_{2, T+j}^{S}$, will be fixed at the corresponding euro values over the commitment period $j=1,2, \ldots, \bar{H}^{4}$. Since in the GVAR all exchange rates are measured with respect to the US dollar, the alignment of nominal exchange rates between UK and euro can be achieved by setting

$$
\frac{E_{2, T+j}}{E_{1, T+j}}=\gamma \frac{E_{2, T}}{E_{1, T}}
$$

where $\gamma$ denotes the $£$ /euro rate at which UK joins the euro. The case of $\gamma=1$ implies entry at par, i.e nominal £/euro rate being equivalent to that at the end of period $T$. Clearly entry at a different exchange rate can also be entertained. In the case, for example, of a UK entry with a rate which is $10 \%$ (say) below the $£ /$ euro at the end of period $T, \gamma=0.90$. Taking logs, (6) may also be written

$$
e_{2, T+j}-e_{1, T+j}=e_{2 T}-e_{1 T}+\ln (\gamma), \text { for } j=1,2, \ldots, \bar{H} .
$$

For short term interest rates we have

$$
r_{2, T+j}^{S}=r_{1, T+j}^{S} \text { for } j=1,2, \ldots, \bar{H} .
$$

To work out the effects of UK entry we shall consider two multi-period forecast scenarios: (i) the forecasts of $\mathbf{x}_{T+h}, h=1,2, \ldots, H$ in the absence of a UK entry, (ii) forecasts in the presence of a UK entry. This could be done either in terms of point or probability forecasts that allow for parameter

\footnotetext{
${ }^{4}$ In what follows we denote UK and euro variables by the subscripts ' 2 ' and ' 1 ', respectively.
} 
and/or model uncertainty. Under entry at 1999Q1, we further consider forecasts conditional on the realisations of four variables namely, oil prices (endogenous to the US model), US equity prices and US short and long term interest rates. As mentioned at the outset, it is unlikely that UK entry would have any effect on these particular variables.

As noted earlier, the GVAR uses real exchange rates as a variable, but to model entry we need to fix nominal exchange rates. The solution of the GVAR given by (4) can be expressed in terms of the price level and the nominal exchange rate yielding the equation

$$
\mathbf{x}_{t}=\mathbf{b}_{0}+\mathbf{b}_{1} t+\mathbf{F}_{1} \mathbf{x}_{t-1}+\mathbf{F}_{2} \mathbf{x}_{t-2}+\mathbf{F}_{3} \mathbf{x}_{t-3}+\mathbf{v}_{t},
$$

where

$$
\mathbf{b}_{0}=\mathcal{B} \mathbf{a}_{0}, \mathbf{b}_{1}=\mathcal{B} \mathbf{a}_{1}
$$

and

$$
\mathbf{F}_{1}=\left(\mathcal{C}+\mathcal{B} \mathbf{G}_{1} \mathcal{B}^{-1}\right), \mathbf{F}_{2}=\mathcal{B}\left(\mathbf{G}_{2} \mathcal{B}^{-1}-\mathbf{G}_{1} \mathcal{B}^{-1} \mathcal{C}\right), \mathbf{F}_{3}=-\mathcal{B} \mathbf{G}_{2} \mathcal{B}^{-1} \mathcal{C}
$$

The details of this procedure and the precise relationship between $\mathbf{x}_{t}$ and $\stackrel{\circ}{x}_{t}$, defined by (1), can be found in the Appendix where for expositional convenience the first three countries in the $k \times 1$ vector $\mathbf{x}_{t}=\left(\mathbf{x}_{0 t}^{\prime}, \mathbf{x}_{1 t}^{\prime}, \ldots, \mathbf{x}_{N t}^{\prime}\right)^{\prime}$ are ordered as US, EA and UK respectively, followed by the remaining. Similarly, in all country models, $\mathbf{x}_{i t}$, the first variable is the price level $p_{i t}$ and, with the exception of the US, the second and third entries in $\mathbf{x}_{i t}$ are the nominal exchange rate, $e_{i t}$, and the short term interest rate, $r_{i t}^{S}$, followed by the remaining.

Using (9), the point forecasts under (i) (in the absence of UK entry) are given recursively by

$$
\boldsymbol{\mu}_{h}=\hat{\mathbf{b}}_{0}+\hat{\mathbf{b}}_{1}(T+h)+\hat{\mathbf{F}}_{1} \boldsymbol{\mu}_{h-1}+\hat{\mathbf{F}}_{2} \boldsymbol{\mu}_{h-2}+\hat{\mathbf{F}}_{3} \boldsymbol{\mu}_{h-3}, \text { for } h=1,2, \ldots, H
$$

with the initial values $\boldsymbol{\mu}_{0}=\mathbf{x}_{T}, \boldsymbol{\mu}_{-1}=\mathbf{x}_{T-1}$ and $\boldsymbol{\mu}_{-2}=\mathbf{x}_{T-2}$, where

$$
\begin{aligned}
\hat{\mathbf{F}}_{1} & =\left(\mathcal{C}+\mathcal{B} \hat{\mathbf{G}}_{1} \mathcal{B}^{-1}\right), \hat{\mathbf{F}}_{2}=\mathcal{B}\left(\hat{\mathbf{G}}_{2} \mathcal{B}^{-1}-\hat{\mathbf{G}}_{1} \mathcal{B}^{-1} \mathcal{C}\right), \hat{\mathbf{F}}_{3}=-\mathcal{B} \hat{\mathbf{G}}_{2} \mathcal{B}^{-1} \mathcal{C} \\
\hat{\mathbf{b}}_{0} & =\mathcal{B} \hat{\mathbf{a}}_{0}, \hat{\mathbf{b}}_{1}=\mathcal{B} \hat{\mathbf{a}}_{1}
\end{aligned}
$$

and $\hat{\mathbf{a}}_{0}, \hat{\mathbf{a}}_{1}, \hat{\mathbf{G}}_{1}$ and $\hat{\mathbf{G}}_{2}$ are obtained from the individual country estimates using the GVAR modeling framework (described in Section 3).

It is also convenient to work with the companion form of (9) and so we have

$$
\left(\begin{array}{c}
\mathbf{x}_{t} \\
\mathbf{x}_{t-1} \\
\mathbf{x}_{t-2}
\end{array}\right)=\left(\begin{array}{ccc}
\mathbf{F}_{1} & \mathbf{F}_{2} & \mathbf{F}_{3} \\
\mathbf{I}_{k} & \mathbf{0} & \mathbf{0} \\
\mathbf{0} & \mathbf{I}_{k} & \mathbf{0}
\end{array}\right)\left(\begin{array}{c}
\mathbf{x}_{t-1} \\
\mathbf{x}_{t-2} \\
\mathbf{x}_{t-3}
\end{array}\right)+\left(\begin{array}{c}
\mathbf{b}_{0}+\mathbf{b}_{1} t \\
\mathbf{0} \\
\mathbf{0}
\end{array}\right)+\left(\begin{array}{c}
\mathbf{v}_{t} \\
\mathbf{0} \\
\mathbf{0}
\end{array}\right),
$$

or

$$
\mathbf{X}_{t}=\mathbf{F X}_{t-1}+\mathbf{D}_{t}+\mathbf{V}_{t}
$$

Hence

$$
\mathbf{X}_{T+h}=\mathbf{F}^{h} \mathbf{X}_{T}+\sum_{s=0}^{h-1} \mathbf{F}^{s} \mathbf{D}_{T+h-s}+\sum_{s=0}^{h-1} \mathbf{F}^{s} \mathbf{V}_{T+h-s}
$$


and

$$
\mathbf{x}_{T+h}=\mathbf{E}_{1} \mathbf{X}_{T+h}
$$

where $\mathbf{E}_{1}=\left(\begin{array}{ccc}\mathbf{I}_{k} & \mathbf{0}_{k \times k} & \mathbf{0}_{k \times k}\end{array}\right)$.

Therefore, conditional on the initial values, $\mathbf{X}_{T}$, and in the absence of entry

$$
\mathbf{x}_{T+h} \mid \mathcal{I}_{T} \sim N\left(\boldsymbol{\mu}_{h}, \boldsymbol{\Omega}_{h h}\right)
$$

where $\boldsymbol{\mu}_{h}$ is given by ${ }^{5}$

$$
\boldsymbol{\mu}_{h}=\mathbf{E}_{1} \mathbf{F}^{h} \mathbf{X}_{T}+\sum_{s=0}^{h-1} \mathbf{E}_{1} \mathbf{F}^{s} \mathbf{D}_{T+h-s}
$$

and

$$
\boldsymbol{\Omega}_{h h}=\mathbf{E}_{1} \sum_{s=0}^{h-1} \mathbf{F}^{s} \tilde{\mathbf{\Sigma}} \mathbf{F}^{\prime s} \mathbf{E}_{1}^{\prime}
$$

in which

$$
\tilde{\Sigma}=\left(\begin{array}{lll}
\Sigma & 0 & 0 \\
0 & 0 & 0 \\
0 & 0 & 0
\end{array}\right)
$$

and $\boldsymbol{\Sigma}=\mathcal{B C o v}\left(\stackrel{\circ}{\mathbf{v}}_{T+h-i}\right) \mathcal{B}^{\prime}$. The covariance of $\stackrel{\circ}{\mathbf{v}}_{t}$ can be estimated using the residuals of the global model, (4).

\subsection{Point and Probability Forecasts Conditional on UK Entry}

Under UK entry, forecasts of the global model must be obtained subject to the entry restrictions (7) and (8) which can also be written more generally as

$$
\boldsymbol{\Psi}_{\mathbf{x}_{T+j}}=\mathbf{d}_{T+j}, j=1,2, \ldots, \bar{H}
$$

where $\boldsymbol{\Psi}$ is a suitably defined $l \times k$ matrix and $\mathbf{d}_{T+j}$ is a $l \times 1$ vector of known constants. In the case of the entry restrictions (7) and (8) we have $l=2$,

$$
\mathbf{d}_{T+j}=\left(\begin{array}{c}
e_{2 T}-e_{1 T}+\ln (\text { rate of appreciation/depreciation }) \\
0
\end{array}\right)=d_{T}\left(\begin{array}{l}
1 \\
0
\end{array}\right),
$$

for $j=1,2, \ldots, \bar{H}$, where $d_{T}=e_{2 T}-e_{1 T}+\ln$ (rate of appreciation/depreciation), and

$\underset{2 \times k}{\mathbf{\Psi}}=\left(\begin{array}{llllllllll}\mathbf{0}_{1 \times k_{0}} & 0 & -1 & 0 & \mathbf{0}_{1 \times\left(k_{1}-3\right)} & 0 & 1 & 0 & \mathbf{0}_{1 \times\left(k_{2}-3\right)} & \mathbf{0}_{1 \times\left(k-k_{0}-k_{1}-k_{2}\right)} \\ \mathbf{0}_{1 \times k_{0}} & 0 & 0 & -1 & \mathbf{0}_{1 \times\left(k_{1}-3\right)} & 0 & 0 & 1 & \mathbf{0}_{1 \times\left(k_{2}-3\right)} & \mathbf{0}_{1 \times\left(k-k_{0}-k_{1}-k_{2}\right)}\end{array}\right)$.

\footnotetext{
${ }^{5} \boldsymbol{\mu}_{h}$ can can also be computed using the recursions (10).
} 
Point forecasts of $\mathbf{x}_{T+h}$ under UK entry restrictions (16) are given by, for $h=$ $1,2, \ldots, H$,

$$
\mu_{h}^{*}=E\left(\mathbf{x}_{T+h} \mid \mathcal{I}_{T}, \mathbf{\Psi}_{\mathbf{x}_{T+j}}=\mathbf{d}_{T+j}, j=1,2, \ldots, \bar{H}\right) .
$$

In deriving these expectations we assume that the announcement of the entry restrictions does not affect the GVAR parameters, $\mathbf{F}_{i}, i=1,2,3$ and $\boldsymbol{\Sigma}^{6}$

First note that, using (11), we have

$$
\mathbf{x}_{T+h}=\boldsymbol{\mu}_{h}+\boldsymbol{\xi}_{T+h},
$$

where

$$
\boldsymbol{\xi}_{T+h}=\sum_{s=0}^{h-1} \mathbf{E}_{1} \mathbf{F}^{s} \mathbf{V}_{T+h-s}
$$

Also

$$
\boldsymbol{\xi}_{T+h} \mid \mathcal{I}_{T} \sim N\left(\mathbf{0}, \boldsymbol{\Omega}_{h h}\right),
$$

where $\boldsymbol{\Omega}_{h h}$ is given by (14). The entry restrictions now imply that

$$
\boldsymbol{\Psi} \boldsymbol{\xi}_{T+j}=\mathbf{d}_{T+j}-\boldsymbol{\Psi} \boldsymbol{\mu}_{j} \text { for } j=1,2, \ldots, \bar{H} .
$$

Setting $\mathbf{g}_{j}=\mathbf{d}_{T+j}-\mathbf{\Psi} \boldsymbol{\mu}_{j} \forall j$, (19) can be written as

$$
\left(\mathbf{I}_{\bar{H}} \otimes \boldsymbol{\Psi}\right) \tilde{\boldsymbol{\xi}}_{\bar{H}}=\tilde{\mathbf{g}}_{\bar{H}},
$$

where $\tilde{\boldsymbol{\xi}}_{\bar{H}}=\left(\boldsymbol{\xi}_{T+1}^{\prime}, \boldsymbol{\xi}_{T+2}^{\prime}, \ldots, \boldsymbol{\xi}_{T+\bar{H}}^{\prime}\right)^{\prime}$ and $\tilde{\mathbf{g}}_{\bar{H}}=\left(\mathbf{g}_{1}^{\prime}, \mathbf{g}_{2}^{\prime}, \ldots, \mathbf{g}_{\bar{H}}^{\prime}\right)^{\prime}$.

Under joint normality of the shocks, we have, for $h=1, \ldots, H<\bar{H}$

$$
\begin{aligned}
& E\left(\boldsymbol{\xi}_{T+h} \mid \mathcal{I}_{T}, \mathbf{\Psi}_{\mathbf{x}_{T+j}}=\mathbf{d}_{T+j}, j=1, \ldots, \bar{H}\right) \\
= & E\left(\boldsymbol{\xi}_{T+h} \mid \mathcal{I}_{T},\left(\mathbf{I}_{\bar{H}} \otimes \mathbf{\Psi}\right) \tilde{\boldsymbol{\xi}}_{\bar{H}}=\tilde{\mathbf{g}}_{\bar{H}}\right) \\
= & \left(\mathfrak{s}_{h \bar{H}}^{\prime} \otimes \mathbf{I}_{k}\right) \tilde{\boldsymbol{\Omega}}_{\bar{H}}\left(\mathbf{I}_{\bar{H}} \otimes \boldsymbol{\Psi}^{\prime}\right)\left[\left(\mathbf{I}_{\bar{H}} \otimes \boldsymbol{\Psi}\right) \tilde{\boldsymbol{\Omega}}_{\bar{H}}\left(\mathbf{I}_{\bar{H}} \otimes \boldsymbol{\Psi}^{\prime}\right)\right]^{-1} \tilde{\mathbf{g}}_{\bar{H}},
\end{aligned}
$$

where $\mathfrak{s}_{h \bar{H}}$ is a $\bar{H} \times 1$ selection vector with unity as its $h^{\text {th }}$ element and zeros elsewhere, and $\tilde{\boldsymbol{\Omega}}_{\bar{H}}$ is the $k \bar{H} \times k \bar{H}$ matrix

$$
\tilde{\boldsymbol{\Omega}}_{\bar{H}}=\left(\begin{array}{cccc}
\boldsymbol{\Omega}_{11} & \boldsymbol{\Omega}_{12} & \cdots & \boldsymbol{\Omega}_{1 \bar{H}} \\
\boldsymbol{\Omega}_{21} & \boldsymbol{\Omega}_{22} & \cdots & \boldsymbol{\Omega}_{2 \bar{H}} \\
\vdots & \vdots & \ddots & \vdots \\
\boldsymbol{\Omega}_{\bar{H} 1} & \boldsymbol{\Omega}_{\bar{H} 2} & \cdots & \boldsymbol{\Omega}_{\bar{H} \bar{H}}
\end{array}\right) .
$$

The diagonal elements of $\tilde{\boldsymbol{\Omega}}_{\bar{H}}$, that is $\left\{\boldsymbol{\Omega}_{i i}\right\}_{i=1}^{\bar{H}}$, are given by (14), while the off-diagonal elements can be expressed as

$$
\boldsymbol{\Omega}_{i j}= \begin{cases}\mathbf{E}_{1}\left(\sum_{s=0}^{i-1} \mathbf{F}^{s} \tilde{\boldsymbol{\Sigma}} \mathbf{F}^{\prime s}\right) \mathbf{F}^{\prime(j-i)} \mathbf{E}_{1}^{\prime}, \quad i<j \\ \mathbf{E}_{1} \mathbf{F}^{(i-j)}\left(\sum_{s=0}^{j-1} \mathbf{F}^{s} \tilde{\boldsymbol{\Sigma}} \mathbf{F}^{s}\right) \mathbf{E}_{1}^{\prime}, \quad i>j\end{cases}
$$

\footnotetext{
${ }^{6}$ Other possibilities can also be entertained. But we do not believe there are sufficient grounds to make a priori assumptions about the way some of the parameters might change as a result of the UK entry. The general issue of parameter and model uncertainty does, however, deserve further attention.
} 
where $\tilde{\boldsymbol{\Sigma}}$ is defined by (15).

Hence, point forecasts under UK entry restrictions are given by

$$
\boldsymbol{\mu}_{h}^{*}=\boldsymbol{\mu}_{h}+\left(\mathfrak{s}_{h \bar{H}}^{\prime} \otimes \mathbf{I}_{k}\right) \tilde{\boldsymbol{\Omega}}_{\bar{H}}\left(\mathbf{I}_{\bar{H}} \otimes \Psi^{\prime}\right)\left[\left(\mathbf{I}_{\bar{H}} \otimes \mathbf{\Psi}\right) \tilde{\boldsymbol{\Omega}}_{\bar{H}}\left(\mathbf{I}_{\bar{H}} \otimes \boldsymbol{\Psi}^{\prime}\right)\right]^{-1} \tilde{\mathbf{g}}_{\bar{H}} .
$$

It is easily seen that $\boldsymbol{\mu}_{h}^{*}$ satisfy the entry restrictions, namely $\boldsymbol{\Psi} \boldsymbol{\mu}_{h}^{*}=\mathbf{d}_{T+h}$. To see this note that

$$
\boldsymbol{\Psi}\left(\mathfrak{s}_{h \bar{H}}^{\prime} \otimes \mathbf{I}_{k}\right)=(1 \otimes \boldsymbol{\Psi})\left(\mathfrak{s}_{h \bar{H}}^{\prime} \otimes \mathbf{I}_{k}\right)=\left(\mathfrak{s}_{h \bar{H}}^{\prime} \otimes \mathbf{\Psi}\right)=\left(\mathfrak{s}_{h \bar{H}}^{\prime} \otimes \mathbf{I}_{2}\right)\left(\mathbf{I}_{\bar{H}} \otimes \mathbf{\Psi}\right),
$$

and $\left(\mathfrak{s}_{h \bar{H}}^{\prime} \otimes \mathbf{I}_{2}\right) \tilde{\mathbf{g}}_{\bar{H}}=\mathbf{g}_{h}=\mathbf{d}_{T+h}-\mathbf{\Psi} \boldsymbol{\mu}_{h}$. Recall that under UK entry restrictions $\boldsymbol{\Psi}$ is $2 \times k$.

For future reference also note that the mean effects of UK entry are given by

$$
\boldsymbol{\mu}_{h}^{*}-\boldsymbol{\mu}_{h}=\left(\mathfrak{s}_{h \bar{H}}^{\prime} \otimes \mathbf{I}_{k}\right) \tilde{\boldsymbol{\Omega}}_{\bar{H}}\left(\mathbf{I}_{\bar{H}} \otimes \Psi^{\prime}\right)\left[\left(\mathbf{I}_{\bar{H}} \otimes \mathbf{\Psi}\right) \tilde{\boldsymbol{\Omega}}_{\bar{H}}\left(\mathbf{I}_{\bar{H}} \otimes \boldsymbol{\Psi}^{\prime}\right)\right]^{-1} \tilde{\mathbf{g}}_{\bar{H}} .
$$

\subsection{Probability Distribution of the Effects of UK Entry}

Let $\mathbf{x}_{T+h}^{*}$ be the values of $\mathbf{x}_{T+h}$ under UK entry

$$
\mathbf{x}_{T+h}^{*}=\boldsymbol{\mu}_{h}+\boldsymbol{\xi}_{T+h}^{*}, h=1,2, \ldots, H
$$

where $\boldsymbol{\mu}_{h}$ is given by (13) and $\boldsymbol{\xi}_{T+h}^{*}$ is the random variable defined by the probability distribution of $\boldsymbol{\xi}_{T+h}$ conditional on $\left(\mathbf{I}_{\bar{H}} \otimes \mathbf{\Psi}\right) \tilde{\boldsymbol{\xi}}_{\bar{H}}=\tilde{\mathbf{g}}_{\bar{H}}$. More specifically,

$$
\boldsymbol{\xi}_{T+h}^{*}=\sum_{s=0}^{h-1} \mathbf{E}_{1} \mathbf{F}^{s} \mathbf{V}_{T+h-s} \mid\left(\mathbf{I}_{\bar{H}} \otimes \mathbf{\Psi}\right) \tilde{\boldsymbol{\xi}}_{\bar{H}}=\tilde{\mathbf{g}}_{\bar{H}},
$$

for $h=1,2, \ldots, H<\bar{H} \cdot{ }^{7}$ The effects of UK entry in this case are given by

$$
\boldsymbol{\delta}_{T+h}=\mathbf{x}_{T+h}^{*}-\mathbf{x}_{T+h}=\boldsymbol{\xi}_{T+h}^{*}-\boldsymbol{\xi}_{T+h}
$$

The mean effects are

$$
E\left(\boldsymbol{\delta}_{T+h} \mid \mathcal{I}_{T}\right)=\boldsymbol{\mu}_{h}^{*}-\boldsymbol{\mu}_{h} .
$$

The variance $\mathbf{V}\left(\boldsymbol{\delta}_{T+h} \mid \mathcal{I}_{T}\right)$ is given by

$$
\begin{aligned}
\mathbf{V}\left(\boldsymbol{\delta}_{T+h} \mid \mathcal{I}_{T}\right)= & \mathbf{V}\left(\boldsymbol{\xi}_{T+h}^{*} \mid \mathcal{I}_{T}\right)+\mathbf{V}\left(\boldsymbol{\xi}_{T+h} \mid \mathcal{I}_{T}\right) \\
& -\operatorname{Cov}\left(\boldsymbol{\xi}_{T+h}^{*}, \boldsymbol{\xi}_{T+h} \mid \mathcal{I}_{T}\right)-\operatorname{Cov}\left(\boldsymbol{\xi}_{T+h}, \boldsymbol{\xi}_{T+h}^{*} \mid \mathcal{I}_{T}\right)
\end{aligned}
$$

where ${ }^{8}$

$$
\mathbf{V}\left(\boldsymbol{\xi}_{T+h}^{*} \mid \mathcal{I}_{T}\right)=\boldsymbol{\Omega}_{h h}^{*}
$$

with

$\boldsymbol{\Omega}_{h h}^{*}=\boldsymbol{\Omega}_{h h}-\left(\mathfrak{s}_{h \bar{H}}^{\prime} \otimes \mathbf{I}_{k}\right) \tilde{\boldsymbol{\Omega}}_{\bar{H}}\left(\mathbf{I}_{\bar{H}} \otimes \boldsymbol{\Psi}^{\prime}\right)\left[\left(\mathbf{I}_{\bar{H}} \otimes \Psi\right) \tilde{\boldsymbol{\Omega}}_{\bar{H}}\left(\mathbf{I}_{\bar{H}} \otimes \Psi^{\prime}\right)\right]^{-1}\left(\mathbf{I}_{\bar{H}} \otimes \mathbf{\Psi}\right) \tilde{\boldsymbol{\Omega}}_{\bar{H}}\left(\mathfrak{s}_{h \bar{H}} \otimes \mathbf{I}_{k}\right)$,

\footnotetext{
${ }^{7}$ To simplify the notations we are suppressing the dependence of $\boldsymbol{\xi}_{T+h}^{*}$ on $\bar{H}$. Strictly speaking, we should write $\boldsymbol{\xi}_{T+h, \bar{H}}^{*}$.

${ }^{8}$ Similarly, we suppress the dependence of $\boldsymbol{\Omega}_{h h}^{*}$ on $\bar{H}$.
} 
and $\boldsymbol{\Psi}$ defined by (17).

To obtain $\operatorname{Cov}\left(\boldsymbol{\xi}_{T+h}^{*}, \boldsymbol{\xi}_{T+h} \mid \mathcal{I}_{T}\right)$, recall that conditional on $\mathcal{I}_{T}$ the $k \times 1$ random vector $\boldsymbol{\xi}_{T+h}^{*}$ defined by (22) is dependently distributed with mean $\boldsymbol{\mu}_{h}^{*}$ and variance $\mathbf{V}\left(\boldsymbol{\xi}_{T+h}^{*} \mid \mathcal{I}_{T}\right)=\boldsymbol{\Omega}_{h h}^{*}$. Let $\tilde{\mathbf{\Psi}}_{\bar{H}}^{\prime}=\tilde{\boldsymbol{\Omega}}_{\bar{H}}^{1 / 2}\left(\mathbf{I}_{\bar{H}} \otimes \mathbf{\Psi}^{\prime}\right)$ and note that $\boldsymbol{\Omega}_{h h}^{*}$ defined by (25) can alternatively be expressed as

$$
\boldsymbol{\Omega}_{h h}^{*}=\boldsymbol{\Omega}_{h h}-\left(\mathfrak{s}_{h \bar{H}}^{\prime} \otimes \mathbf{I}_{k}\right) \tilde{\boldsymbol{\Omega}}_{\bar{H}}^{1 / 2} \mathbf{P}_{\bar{H}} \tilde{\boldsymbol{\Omega}}_{\bar{H}}^{1 / 2}\left(\mathfrak{s}_{h \bar{H}} \otimes \mathbf{I}_{k}\right),
$$

where

$$
\mathbf{P}_{\bar{H}}=\tilde{\mathbf{\Psi}}_{\bar{H}}^{\prime}\left(\tilde{\mathbf{\Psi}}_{\bar{H}} \tilde{\mathbf{\Psi}}_{\bar{H}}^{\prime}\right)^{-1} \tilde{\mathbf{\Psi}}_{\bar{H}},
$$

is a projection matrix which is symmetric, idempotent and positive semi-definite. Hence,

$$
\boldsymbol{\Omega}_{h h}-\boldsymbol{\Omega}_{h h}^{*}=\left(\mathfrak{s}_{h \bar{H}}^{\prime} \otimes \mathbf{I}_{k}\right) \tilde{\boldsymbol{\Omega}}_{\bar{H}}^{1 / 2} \mathbf{P}_{\bar{H}} \tilde{\mathbf{\Omega}}_{\bar{H}}^{1 / 2}\left(\mathfrak{s}_{h \bar{H}} \otimes \mathbf{I}_{k}\right) .
$$

is a positive semi-definite matrix.

As illustrated in Section 4.1, by considering the convex combination of the random variables $\mathbf{q}^{\prime} \boldsymbol{\xi}_{T+h}$ and $\mathbf{q}^{\prime} \boldsymbol{\xi}_{T+h}^{*}$ for any non-zero $k \times 1$ vector of constants q we obtain

$$
\operatorname{Cov}\left(\boldsymbol{\xi}_{T+h}, \boldsymbol{\xi}_{T+h}^{*} \mid \mathcal{I}_{T}\right)=\mathbf{V}\left(\boldsymbol{\xi}_{T+h}^{*} \mid \mathcal{I}_{T}\right) .
$$

Using this result in (26) the variance of the effects of UK entry is derived as

$$
\mathbf{V}\left(\boldsymbol{\delta}_{T+h} \mid \mathcal{I}_{T}\right)=\boldsymbol{\Omega}_{h h}-\boldsymbol{\Omega}_{h h}^{*} \geq 0
$$

which is a positive semi-definite matrix. Hence,

$$
\boldsymbol{\delta}_{T+h} \mid \mathcal{I}_{T} \sim N\left(\boldsymbol{\mu}_{h}^{*}-\boldsymbol{\mu}_{h}, \boldsymbol{\Omega}_{h h}-\boldsymbol{\Omega}_{h h}^{*}\right) .
$$

\subsection{Conditioning on US variables}

When conditioning on the realisations of the four variables in the US model, a new $4 \times k$ restriction matrix $\boldsymbol{\Psi}_{a}$ is defined and imposed under both the case of no entry and UK entry. If the rest of the variables in the US are ordered as $\mathbf{x}_{0 t}^{r e s t}=\left(y_{0 t}, q_{0 t}, r_{0 t}^{L}, o i l_{t}\right)^{\prime}$, then we have $\left(k_{0}=4\right)$

$$
\underset{4 \times k}{\mathbf{\Psi}_{a}}=\left(\begin{array}{cccc}
0 & 1 & \mathbf{0}_{1 \times\left(k_{0}-2\right)} & \mathbf{0}_{1 \times\left(k-k_{0}\right)} \\
\mathbf{0}_{\left(k_{0}-3\right) \times\left(k_{0}-3\right)} & \mathbf{I}_{k_{0}-3} & \mathbf{0}_{1 \times\left(k-k_{0}\right)}
\end{array}\right) .
$$

Unlike the entry restrictions that are committed to extend beyond the forecast horizon, $H$, conditioning on the realisations of $\mathbf{x}_{0 t}^{\text {rest }}$ is only possible when such realisations are in fact available. Therefore, the analysis of this section is only applicable when the entry date is assumed to be prior to the end of the available sample.

Assuming that the observations $\mathbf{x}_{0 t}^{r e s t}, t=T+1, \ldots ., T+h$ are given, the associated restrictions can be written as

$$
\left(\mathbf{I}_{H} \otimes \boldsymbol{\Psi}_{a}\right) \tilde{\boldsymbol{\xi}}_{H}=\tilde{\mathbf{g}}_{a H},
$$


where $\tilde{\boldsymbol{\xi}}_{H}=\left(\boldsymbol{\xi}_{T+1}^{\prime}, \boldsymbol{\xi}_{T+2}^{\prime}, \ldots, \boldsymbol{\xi}_{T+H}^{\prime}\right)^{\prime}$ and $\tilde{g}_{a H}=\left(\mathbf{g}_{a 1}^{\prime}, \mathbf{g}_{a 2}^{\prime}, \ldots, \mathbf{g}_{a H}^{\prime}\right)^{\prime}$, where $\mathbf{g}_{a h}=$ $\mathbf{d}_{a, T+h}-\boldsymbol{\Psi}_{a} \boldsymbol{\mu}_{h}, \mathbf{d}_{a, T+h}=\left(r_{0, T+h}^{S}, q_{0, T+h}^{S}, r_{0, T+h}^{L}, o i l_{T+h}\right)^{\prime}$. For these set of restrictions the point forecasts under no entry are given by

$$
\boldsymbol{\mu}_{a h}^{*}=\boldsymbol{\mu}_{h}+\left(\mathfrak{s}_{h H}^{\prime} \otimes \mathbf{I}_{k}\right) \tilde{\boldsymbol{\Omega}}_{H}\left(\mathbf{I}_{H} \otimes \mathbf{\Psi}_{a}^{\prime}\right)\left[\left(\mathbf{I}_{H} \otimes \mathbf{\Psi}_{a}\right) \tilde{\boldsymbol{\Omega}}_{H}\left(\mathbf{I}_{H} \otimes \mathbf{\Psi}_{a}^{\prime}\right)\right]^{-1} \tilde{\mathbf{g}}_{a H},
$$

where $\mathfrak{s}_{h H}$ is a $H \times 1$ vector of zeros with its $h^{t h}$ element set to unity.

Point forecasts under UK entry plus the US restrictions are given by

$$
\boldsymbol{\mu}_{b h}^{*}=\boldsymbol{\mu}_{h}+\left(\mathfrak{s}_{h \bar{H}}^{\prime} \otimes \mathbf{I}_{k}\right) \tilde{\boldsymbol{\Omega}}_{\bar{H}} \tilde{\mathbf{\Psi}}_{b}^{\prime}\left(\tilde{\mathbf{\Psi}}_{b} \tilde{\boldsymbol{\Omega}}_{\bar{H}} \tilde{\mathbf{\Psi}}_{b}^{\prime}\right)^{-1} \tilde{\mathbf{g}}_{b}
$$

where $\tilde{\mathbf{g}}_{b}=\left(\mathbf{g}_{b 1}^{\prime}, \mathbf{g}_{b 2}^{\prime}, \ldots, \mathbf{g}_{b H}^{\prime}, \mathbf{g}_{H+1}^{\prime}, \mathbf{g}_{H+2}^{\prime}, \ldots, \mathbf{g}_{\bar{H}}^{\prime}\right)^{\prime}$,

$$
\tilde{\boldsymbol{\Psi}}_{b}=\left(\begin{array}{cc}
\mathbf{I}_{H} \otimes \boldsymbol{\Psi}_{\mathbf{b}} & \mathbf{0} \\
\mathbf{0} & \mathbf{I}_{\bar{H}-H} \otimes \boldsymbol{\Psi}
\end{array}\right),
$$

and

$$
\mathbf{\Psi}_{b}=\left(\begin{array}{c}
\boldsymbol{\Psi}_{a} \\
\mathbf{\Psi}
\end{array}\right), \mathbf{g}_{b h}=\left(\begin{array}{c}
\mathbf{g}_{a h} \\
\mathbf{g}_{h}
\end{array}\right) .
$$

The mean effects of committed UK entry are then given by the difference $\boldsymbol{\mu}_{b h}^{*}-\boldsymbol{\mu}_{a h}^{*}$. Conditional on the realisations of the variables in the US model, denoting $\mathbf{x}_{a, T+h}^{*}$ and $\mathbf{x}_{b, T+h}^{*}$ the values of $\mathbf{x}_{T+h}$ under no entry and UK entry, respectively, we have

$$
\mathbf{x}_{i, T+h}^{*}=\boldsymbol{\mu}_{h}+\boldsymbol{\xi}_{i, T+h}^{*}, \text { for } i=a, b,
$$

where $\boldsymbol{\mu}_{h}$ is given by (13), $\boldsymbol{\xi}_{a, T+h}^{*}$ is the random variables defined by the probability distribution of $\boldsymbol{\xi}_{T+h}$ conditional on

$$
\left\{\boldsymbol{\Psi}_{a} \boldsymbol{\xi}_{T+j}=\mathbf{d}_{a, T+j}-\boldsymbol{\Psi}_{a} \boldsymbol{\mu}_{j}=\mathbf{g}_{a j}, \text { for } j=1,2, \ldots, H\right\},
$$

and $\boldsymbol{\xi}_{b, T+h}^{*}$ is the vector of random variables defined by $\boldsymbol{\xi}_{T+h}$ conditional on $\tilde{\mathbf{\Psi}}_{b} \tilde{\boldsymbol{\xi}}_{\bar{H}}=\tilde{\mathbf{g}}_{b}$, where $\tilde{\mathbf{\Psi}}_{b}$ and $\tilde{\mathbf{g}}_{b}$ are as defined above.

The difference between the two counterfactuals, is given by $\boldsymbol{\delta}_{T+h}=\boldsymbol{\xi}_{b, T+h}^{*}-$ $\boldsymbol{\xi}_{a, T+h}^{*}$ and we have

$$
E\left(\boldsymbol{\delta}_{T+h} \mid \mathcal{I}_{T}\right)=\boldsymbol{\mu}_{b h}^{*}-\boldsymbol{\mu}_{a h}^{*}
$$

Also

$$
\begin{aligned}
\mathbf{V}\left(\boldsymbol{\delta}_{T+h} \mid \mathcal{I}_{T}\right)= & \mathbf{V}\left(\boldsymbol{\xi}_{b, T+h}^{*} \mid \mathcal{I}_{T}\right)+\mathbf{V}\left(\boldsymbol{\xi}_{a, T+h}^{*} \mid \mathcal{I}_{T}\right) \\
& -\operatorname{Cov}\left(\boldsymbol{\xi}_{b, T+h}^{*}, \boldsymbol{\xi}_{a, T+h}^{*} \mid \mathcal{I}_{T}\right)-\operatorname{Cov}\left(\boldsymbol{\xi}_{a, T+h}^{*}, \boldsymbol{\xi}_{b, T+h}^{*} \mid \mathcal{I}_{T}\right),
\end{aligned}
$$

where

$$
\mathbf{V}\left(\boldsymbol{\xi}_{i, T+h}^{*} \mid \mathcal{I}_{T}\right)=\boldsymbol{\Omega}_{i h}^{*}, \text { for } i=a, b,
$$

with

$$
\boldsymbol{\Omega}_{a h}^{*}=\boldsymbol{\Omega}_{h h}-\left(\mathfrak{s}_{h H}^{\prime} \otimes \mathbf{I}_{k}\right) \tilde{\boldsymbol{\Omega}}_{H} \tilde{\mathbf{\Psi}}_{a}^{\prime}\left(\tilde{\mathbf{\Psi}}_{a} \tilde{\mathbf{\Omega}}_{H} \tilde{\mathbf{\Psi}}_{a}^{\prime}\right)^{-1} \tilde{\mathbf{\Psi}}_{a} \tilde{\mathbf{\Omega}}_{H}\left(\mathfrak{s}_{h H} \otimes \mathbf{I}_{k}\right),
$$


where $\tilde{\mathbf{\Psi}}_{a}=\left(\mathbf{I}_{H} \otimes \mathbf{\Psi}_{a}\right)$, and

$$
\boldsymbol{\Omega}_{b h}^{*}=\boldsymbol{\Omega}_{h h}-\left(\mathfrak{s}_{h \bar{H}}^{\prime} \otimes \mathbf{I}_{k}\right) \tilde{\boldsymbol{\Omega}}_{\bar{H}} \tilde{\mathbf{\Psi}}_{b}^{\prime}\left(\tilde{\mathbf{\Psi}}_{b} \tilde{\boldsymbol{\Omega}}_{\bar{H}} \tilde{\mathbf{\Psi}}_{b}^{\prime}\right)^{-1} \tilde{\mathbf{\Psi}}_{b} \tilde{\boldsymbol{\Omega}}_{\bar{H}}\left(\mathfrak{s}_{h \bar{H}} \otimes \mathbf{I}_{k}\right) .
$$

Following similar lines of reasoning as above, we also have

$$
\mathbf{V}\left(\boldsymbol{\delta}_{T+h} \mid \mathcal{I}_{T}\right)=\boldsymbol{\Omega}_{a h}^{*}-\boldsymbol{\Omega}_{b h}^{*},
$$

which can be shown to be a positive semi-definite matrix. Hence,

$$
\boldsymbol{\delta}_{T+h} \mid \mathcal{I}_{T} \sim N\left(\boldsymbol{\mu}_{b h}^{*}-\boldsymbol{\mu}_{a h}^{*}, \boldsymbol{\Omega}_{a h}^{*}-\boldsymbol{\Omega}_{b h}^{*}\right) .
$$

\section{Estimates of the Effects of UK Entry}

\subsection{Interest and Exchange Rate Co-movements}

Euro entry involves restricting UK and EA interest rates and the rate of change of their exchange rate to be equal. To judge the feasibility of such a scenario it is worth examining the co-movements of interest rates and exchange rates of UK and the EA, particularly before the euro was formed. Figures 1 and 2 plot UK and EA short interest rates (in percent per annum) and exchange rate changes (in percent) from 1979Q1 to 2003Q4. Before 1999 the EA measures are PPP GDP weighted average of values for the largest eight EA members. The exchange rate measures are quarterly percentage changes of the EA and UK exchange rate against the US dollar. The UK and the EA series follow each other quite closely. The rate of change of exchange rates are $\mathrm{I}(0)$. But using a variety of tests, including the GLS and Weighted Symmetric versions of the ADF, one cannot reject a unit root in the UK and EA interest rates. However, they cointegrate, one can reject a unit root in the difference between interest rates. There has clearly been strong historical relationships between the interest rates and exchange rates of the two economies, and the patterns of these co-movements do not indicate any fundamental difficulty with equalization of either interest rates or exchange rates. 
Figure 1: UK and EA Nominal Short-Term Interest Rates at Annual Percentage Rates

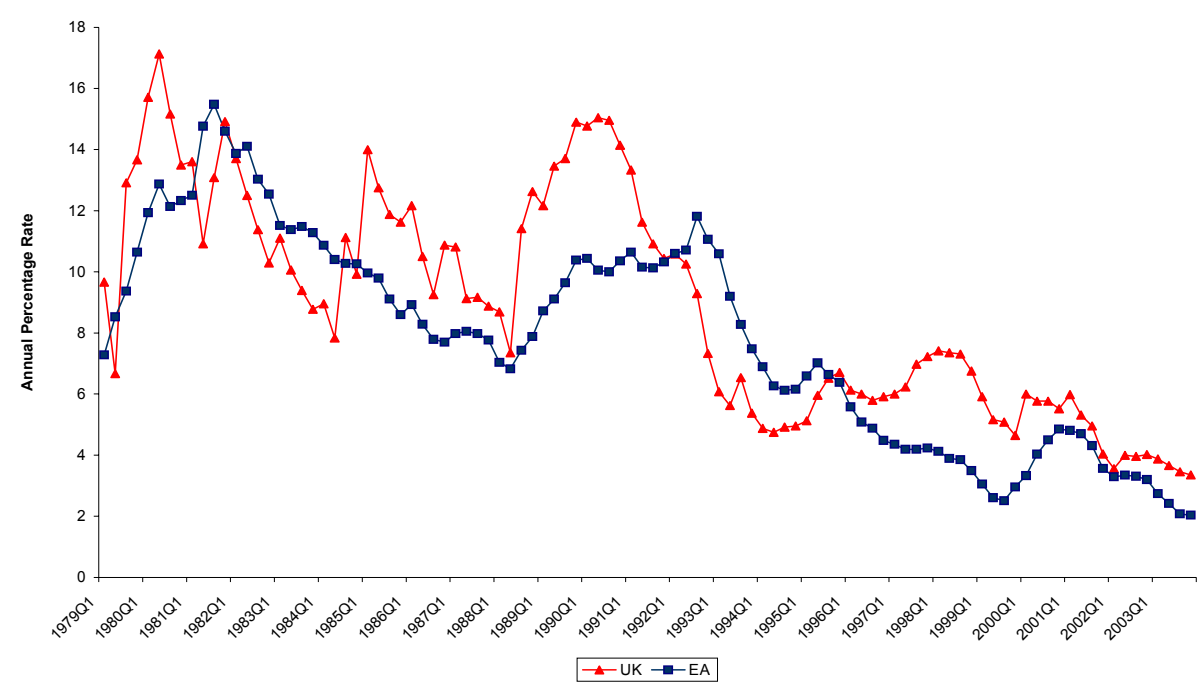

Figure 2: Quarterly Percentage Changes in UK and EA Exchange Rates

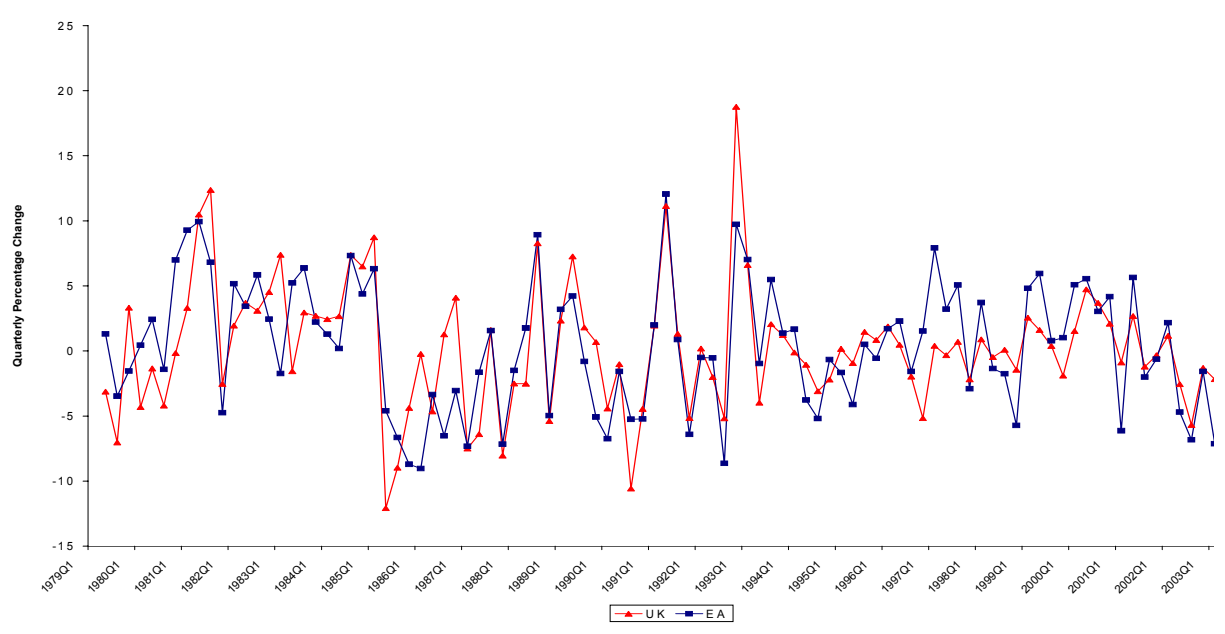

As can be seen from the graphs UK short-term interest rates were above euro area rates from the establishment of the euro, ranging from above $3 \%$ higher 
at the start of the euro, dropping to a quarter of a percent higher in 2002Q4 increasing to one percent higher by 2003Q4, and 2.75\% higher in 2005 . The euro-sterling rate in January 1999 was 1.4, and stayed above this rate for the whole of the subsequent period; exceeding 1.7 in parts of 2000, then falling back towards 1.4.

\subsection{Alternative Scenarios for the UK}

Our base-line case considers entry in 1999Q1 and uses the GVAR to calculate probability distributions for the 5 years ahead to 2003Q4, with and without UK entry. We focus on output and the price level in the EA and UK. EA always refers to the existing euro area. Entry is assumed to be at par, the exchange rate prevailing in 1998Q4, with a long-term commitment to euro membership. We model the long-term commitment by imposing the restrictions for ten years, 40 quarters, at least twice the forecast horizon. Extending it to 56 quarters (the maximum number of quarters our computer codes can run on our pc) makes virtually no difference to the results. For practical considerations, as a first approximation, it is assumed that the parameters of the model are invariant to the nature of the commitment. The nature of the commitment does, however, affect the conditional forecasts (and expectations). Given that joining is such a major decision, it is not something that one would commit to on a period by period basis. ${ }^{9}$

We describe our results in terms of the probability of the effect of entry, $\delta_{T+h}=x_{T+h}^{*}-x_{T+h}$, having a particular sign. This takes account both of the size of the effect and its standard error. We are examining the probability distribution of the difference between two counterfactuals from the GVAR. We are not comparing our estimates with what actually happened over the period 1999Q1-2003Q4 to the UK and EA. Although we can estimate the shocks to the UK and EA without UK entry from the residuals of the model, we do not know what they would be with entry. There is no reason to suppose that they would be the same as without entry. This exercise is quite different from standard approaches such as impulse response analysis, and prior expectations based on such approaches may not be appropriate.

We compare this base-line case with various other scenarios. The first alternative considers entry at par in 1999Q1, but conditions on observed values of oil prices, US interest rates and US equity prices over the period 1999Q1-2003Q4. The second alternative has the UK entering the euro in 2004Q1 at par, the exchange rate in 2003Q4, and calculates the effects from 2004Q1 to 2008Q4 to examine the effect of initial conditions. The third alternative considers the effects different patterns of appreciation or depreciation have on entry in 1999Q1. Finally, for comparison we consider Swedish entry.

\footnotetext{
${ }^{9}$ As noted earlier these results are invariant to identification, in the sense that they would be exactly the same whatever set of just identifying set of restrictions one chose to impose on the underlying country-specific models.
} 


\subsection{UK Entry at Par}

Our base-line case has the UK entering the euro from the start at parity, the exchange rate prevailing in 1998Q4. In 1998Q4 UK short interest rates were $6.75 \%$ per annum compared to euro area short rates of $3.5 \%$ per annum. Table 2 and Figure 3 show the probability that UK and EA interest rates would have been lower with entry than without entry. The probability that UK short interest rates are lower with entry than without starts at almost exactly one and drifts down steadily to $76 \%$ in 2003Q4. The probability that EA interest rates are lower as a result of entry starts at zero (interest rates are certain to have been higher), rises sharply to peak at $94 \%$ in 2000Q1, then falls steadily to $44 \%$ in 2003Q4. The lower UK interest rates would tend to cause output to rise but this is offset by the exchange rate effect. Under no entry the UK is expected to depreciate against the euro, so relative to no entry sterling appreciates against the euro. We examine the exchange rate effects further below.

Table 2: Probability Estimates that UK and EA Short-Term Interest Rates are Lower under Entry at par at Beginning of 1999Q1

\begin{tabular}{rll}
\hline \hline & \multicolumn{2}{l}{ Probability } \\
\cline { 2 - 3 } Year & UK & EA \\
\hline 1999Q1 & 1.00 & 0.02 \\
Q2 & 0.99 & 0.12 \\
Q3 & 0.98 & 0.39 \\
Q4 & 0.97 & 0.76 \\
2000Q1 & 0.96 & 0.94 \\
Q2 & 0.95 & 0.94 \\
Q3 & 0.93 & 0.89 \\
Q4 & 0.91 & 0.83 \\
2001Q1 & 0.89 & 0.76 \\
Q2 & 0.87 & 0.69 \\
Q3 & 0.86 & 0.63 \\
Q4 & 0.84 & 0.58 \\
2002Q1 & 0.82 & 0.55 \\
Q2 & 0.81 & 0.51 \\
Q3 & 0.80 & 0.49 \\
Q4 & 0.79 & 0.47 \\
2003Q1 & 0.78 & 0.46 \\
Q2 & 0.77 & 0.45 \\
Q3 & 0.77 & 0.44 \\
Q4 & 0.76 & 0.44 \\
\hline
\end{tabular}


Figure 3: Probability Estimates that UK and EA Short-Term Interest Rates are Lower under Entry at par at Beginning of 1999Q1

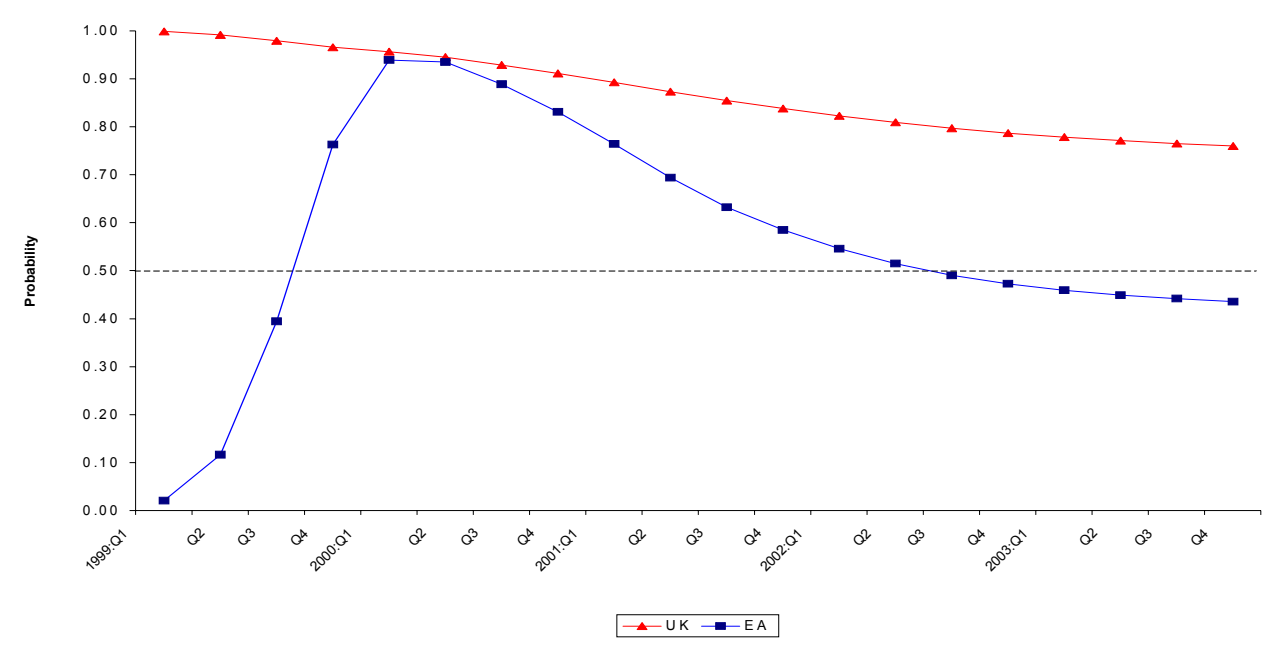

The effects on GDP and prices are shown in Table 3. Figure 4 shows estimates of the probability that UK and EA GDP are higher, Figure 5 the probability that prices are lower. The probability that UK GDP is higher as a result of entry starts very small, then increases peaking after four years at $62 \%$, then starting to fall again to $58 \%$ in 2003Q4. The probability that EA GDP is higher as a result of entry also starts very small then increases steadily, reaching $46 \%$ in 2003Q4. The probability that UK prices will be lower with entry starts high, then falls steadily, reaching $66 \%$ in $2003 \mathrm{Q} 4$. The probability that EA prices will be lower starts at $47 \%$, falls to $7 \%$ after a year, then rises to $17 \%$ by $2003 \mathrm{Q} 4$. The joint probability of higher GDP and lower prices in the UK starts close to zero and rises rapidly at first and then more slowly, finishing at $53 \%$. The joint probability of higher output and lower prices is close to zero in the EA throughout. 
Table 3: Probability Estimates that Output is Higher and Prices are Lower, separately and jointly in UK and EA under Entry at par at Beginning of 1999Q1

\begin{tabular}{|c|c|c|c|c|c|c|}
\hline \multirow[b]{2}{*}{ Year } & \multicolumn{2}{|c|}{ Output } & \multicolumn{2}{|c|}{ Prices } & \multicolumn{2}{|c|}{ Output \& Prices } \\
\hline & UK & EA & UK & EU & UK & EU \\
\hline 1999Q1 & 0.03 & 0.00 & 0.99 & 0.47 & 0.03 & 0.00 \\
\hline Q2 & 0.00 & 0.00 & 0.99 & 0.22 & 0.00 & 0.00 \\
\hline Q3 & 0.02 & 0.01 & 0.95 & 0.10 & 0.01 & 0.00 \\
\hline Q4 & 0.06 & 0.03 & 0.94 & 0.08 & 0.04 & 0.00 \\
\hline 2000Q1 & 0.11 & 0.07 & 0.93 & 0.07 & 0.08 & 0.00 \\
\hline Q2 & 0.15 & 0.11 & 0.90 & 0.07 & 0.12 & 0.00 \\
\hline Q3 & 0.24 & 0.16 & 0.87 & 0.08 & 0.20 & 0.00 \\
\hline Q4 & 0.37 & 0.21 & 0.85 & 0.09 & 0.32 & 0.00 \\
\hline 2001Q1 & 0.49 & 0.26 & 0.83 & 0.10 & 0.43 & 0.01 \\
\hline Q2 & 0.56 & 0.30 & 0.80 & 0.10 & 0.49 & 0.01 \\
\hline Q3 & 0.60 & 0.34 & 0.78 & 0.11 & 0.53 & 0.01 \\
\hline Q4 & 0.62 & 0.37 & 0.76 & 0.12 & 0.54 & 0.01 \\
\hline 2002Q1 & 0.62 & 0.39 & 0.74 & 0.13 & 0.55 & 0.01 \\
\hline Q2 & 0.62 & 0.41 & 0.73 & 0.14 & 0.55 & 0.01 \\
\hline Q3 & 0.62 & 0.43 & 0.71 & 0.15 & 0.55 & 0.01 \\
\hline Q4 & 0.61 & 0.44 & 0.70 & 0.15 & 0.55 & 0.01 \\
\hline 2003Q1 & 0.60 & 0.44 & 0.69 & 0.16 & 0.54 & 0.02 \\
\hline Q2 & 0.60 & 0.45 & 0.68 & 0.16 & 0.54 & 0.02 \\
\hline Q3 & 0.59 & 0.45 & 0.67 & 0.17 & 0.54 & 0.02 \\
\hline Q4 & 0.58 & 0.46 & 0.66 & 0.17 & 0.53 & 0.02 \\
\hline
\end{tabular}

Figure 4: Probability Estimates that UK and EA Output is Higher under Entry at par at Beginning of 1999Q1

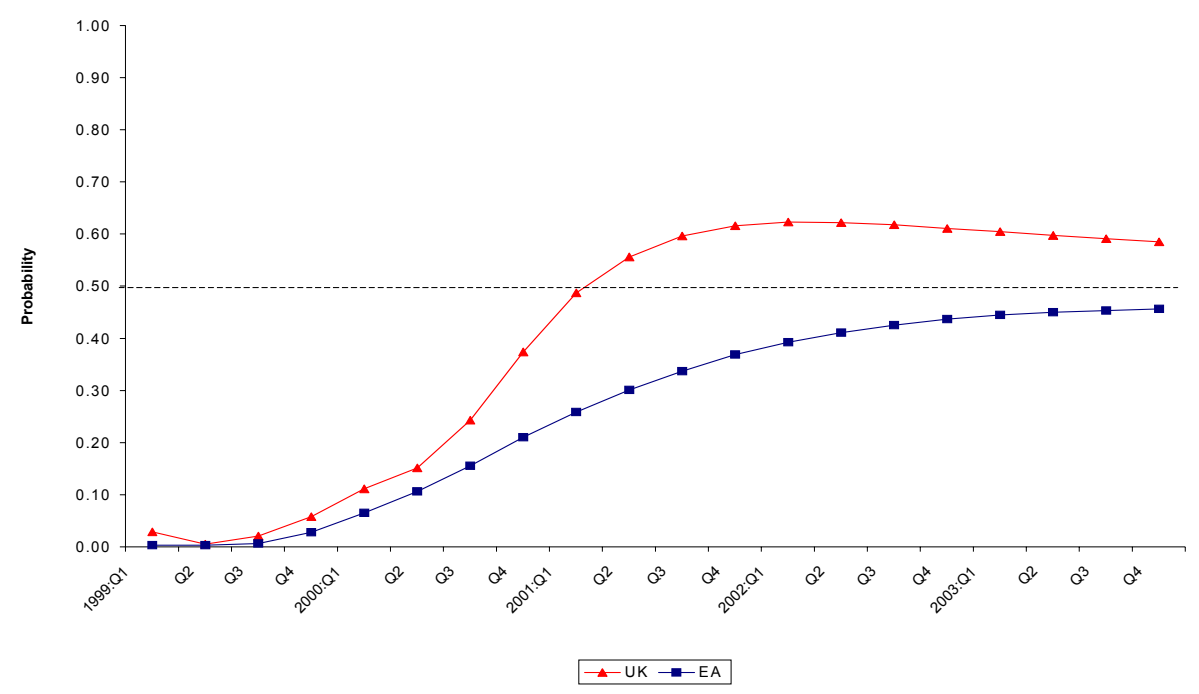


Figure 5: Probability Estimates that UK and EA Prices are Lower under Entry at par at Beginning of 1999Q1

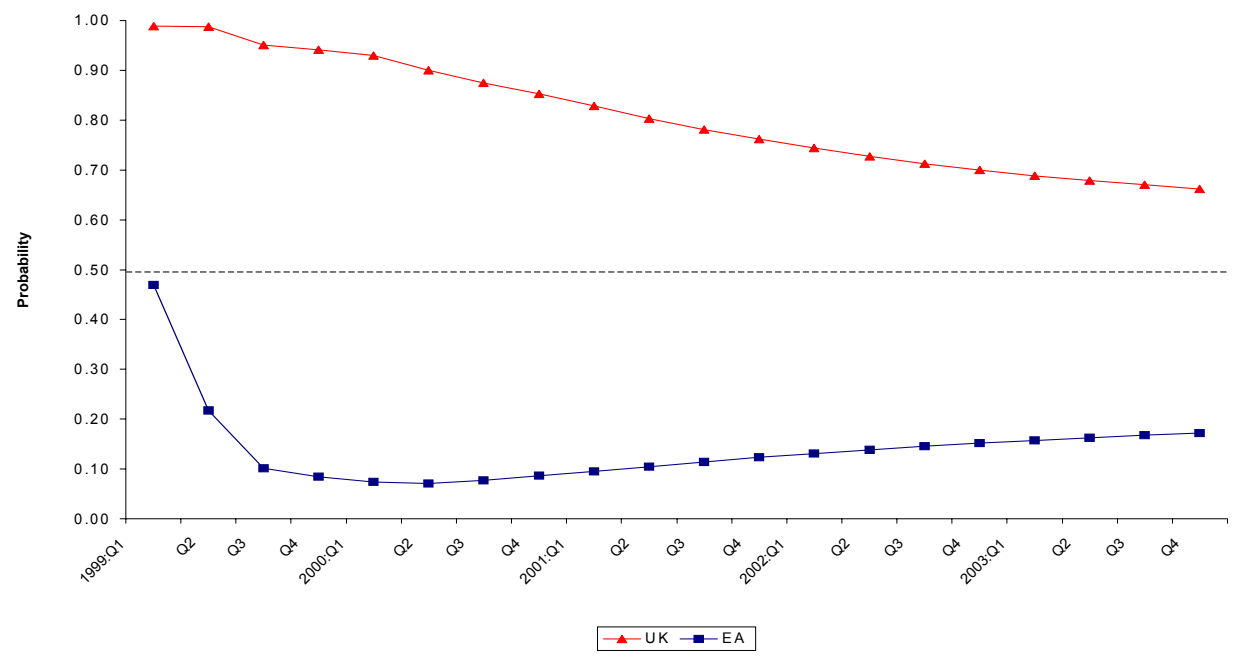

In terms of output the UK initially would have lost from the entry, but gained in the medium term with higher output levels and lower prices. The EA would have experienced lower output and higher prices throughout the period. Thus UK entry seems likely to have generated welfare losses for the EA. For the UK the welfare effects are ambiguous depending on the relative weights given to output and inflation and the discount rate.

To check the robustness of this conclusion we considered a more general base line model where the forecasts are obtained conditional on the observed values of the oil price, US interest rates and US equity prices over the period 1999Q1-2003Q4. Since entry imposes restrictions on the model, the effect of these variables can be different in the restricted and unrestricted cases. This will be reflected in the measure of the effect of entry. Table 4 gives the probabilities that interest rates are lower as a result of entry. In the base-line case, the probability of UK interest rates being lower declines smoothly. With the global shocks included, the pattern is quite similar, but with some extra volatility. The probability that the EA interest rate is lower conditional on observed variables is similar for the first two years, rising from zero to a maximum of $98 \%$ then falling, but more slowly in the conditional case than the unconditional case being $67 \%$ in $2003 \mathrm{Q} 4$. 
Table 4: Conditional Probability Estimates that UK and EA Short-Term Interest Rates are Lower under Entry at par at Beginning of 1999Q1

\begin{tabular}{rll}
\hline \hline & \multicolumn{2}{l}{ Probability } \\
\cline { 2 - 3 } Year & UK & EA \\
\hline 1999Q1 & 1.00 & 0.01 \\
Q2 & 0.99 & 0.36 \\
Q3 & 0.97 & 0.87 \\
Q4 & 0.94 & 0.96 \\
2000Q1 & 0.92 & 0.98 \\
Q2 & 0.91 & 0.97 \\
Q3 & 0.88 & 0.96 \\
Q4 & 0.88 & 0.94 \\
2001Q1 & 0.85 & 0.94 \\
Q2 & 0.81 & 0.93 \\
Q3 & 0.82 & 0.91 \\
Q4 & 0.79 & 0.89 \\
2002Q1 & 0.75 & 0.86 \\
Q2 & 0.75 & 0.80 \\
Q3 & 0.72 & 0.78 \\
Q4 & 0.68 & 0.77 \\
2003Q1 & 0.66 & 0.76 \\
Q2 & 0.68 & 0.75 \\
Q3 & 0.64 & 0.73 \\
Q4 & 0.69 & 0.67 \\
\hline
\end{tabular}

Note: The probability estimates are obtained conditional on the realised values of oil prices, US equity prices and US short and long-term interest rates over the period 1999Q12003Q4.

Table 5 shows the probabilities that GDP is higher or prices lower in the two areas as a result of UK entry at par, conditional on the observed values of oil prices, US equity prices and interest rates over the period 1999Q1-2003Q4. Figure 6 plots the unconditional and conditional probabilities that GDP is higher for the EA and UK. Conditioning on the observed values introduces some volatility and the UK conditional probabilities are rather higher than the unconditional probabilities. The EA conditional probabilities are somewhat lower, but the time profile of the effects are rather similar. These results suggest that we do not need to be able to forecast these four variables in order to measure the overall effects of the UK joining the euro. 
Table 5: Conditional Probability Estimates that Output is Higher and Prices are Lower, separately in UK and EA under Entry at par

\begin{tabular}{|c|c|c|c|c|}
\hline \multirow[b]{2}{*}{ Year } & \multicolumn{2}{|c|}{ Output } & \multicolumn{2}{|c|}{ Prices } \\
\hline & UK & EA & UK & EA \\
\hline 1999Q1 & 0.06 & 0.00 & 1.00 & 0.81 \\
\hline Q2 & 0.01 & 0.01 & 1.00 & 0.59 \\
\hline Q3 & 0.05 & 0.02 & 0.98 & 0.34 \\
\hline Q4 & 0.13 & 0.05 & 0.96 & 0.28 \\
\hline 2000Q1 & 0.28 & 0.10 & 0.94 & 0.25 \\
\hline Q2 & 0.28 & 0.13 & 0.91 & 0.23 \\
\hline Q3 & 0.37 & 0.15 & 0.89 & 0.21 \\
\hline Q4 & 0.46 & 0.18 & 0.86 & 0.20 \\
\hline 2001Q1 & 0.54 & 0.22 & 0.83 & 0.20 \\
\hline Q2 & 0.64 & 0.25 & 0.80 & 0.20 \\
\hline Q3 & 0.65 & 0.30 & 0.78 & 0.21 \\
\hline Q4 & 0.66 & 0.34 & 0.76 & 0.23 \\
\hline 2002Q1 & 0.69 & 0.37 & 0.74 & 0.23 \\
\hline Q2 & 0.70 & 0.40 & 0.72 & 0.24 \\
\hline Q3 & 0.68 & 0.41 & 0.71 & 0.25 \\
\hline Q4 & 0.69 & 0.42 & 0.68 & 0.25 \\
\hline 2003Q1 & 0.69 & 0.44 & 0.67 & 0.26 \\
\hline Q2 & 0.66 & 0.46 & 0.66 & 0.27 \\
\hline Q3 & 0.66 & 0.47 & 0.65 & 0.28 \\
\hline Q4 & 0.64 & 0.48 & 0.64 & 0.29 \\
\hline
\end{tabular}

Note: The probability estimates are obtained conditional on the realised values of oil prices, US equity prices and US short and long-term interest rates over the period 1999Q12003Q4. 
Figure 6: Conditional and Unconditional Probability Estimates that UK and EA Output is Higher under Entry at par at Beginning of 1999Q1

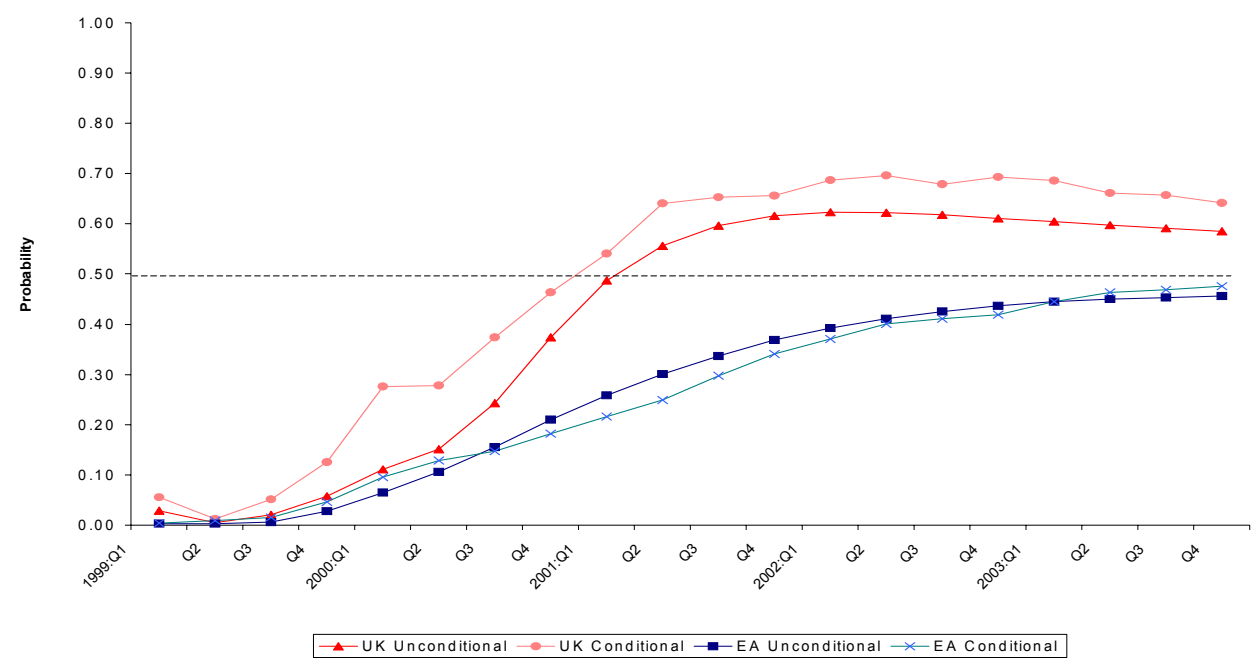

Note: The probability estimates are obtained conditional on the realised values of oil prices, US equity prices and US short and long-term interest rates over the period 1999Q1-2003Q4.

Table 6 shows the results for entry in 2004. Figure 7 plots the probability that GDP is higher for the EA and UK for 1999 entry and 2004 entry, superimposed. For GDP the time patterns are very similar, with the differences being larger at the beginning of the period, when the probability of both EA and UK output being higher is larger with 2004 entry than with 1999 entry, but the differences are very small by the end. For prices, the patterns over time are again similar, with the probability that prices are lower being rather smaller for the UK and, except for the first two periods, rather higher for the EA. The qualitative conclusions are thus almost identical whether one starts from 1999 or 2004. This may be partly because sterling and euro rates against the dollar were similar in 1998Q4 and 2003Q4 and the UK euro interest differential was quite similar, but other initial conditions were very different at the two entry dates. Thus our conclusions seem to be robust to initial conditions.

Conditioning on the realisations of observed variables and different initial conditions has quite small effects on the quantitative results and does not change the qualitative conclusions. 
Table 6: Probability Estimates that Output is Higher and Prices are Lower, separately in UK and EA under Entry at par at Beginning of 2004Q1

\begin{tabular}{rccccc}
\hline \hline & \multicolumn{3}{c}{ Output } & & \multicolumn{2}{c}{ Prices } \\
\cline { 2 - 3 } \cline { 6 - 7 } Year & UK & EA & & UK & EA \\
\hline 2004Q1 & 0.11 & 0.05 & & 0.84 & 0.25 \\
Q2 & 0.05 & 0.05 & & 0.79 & 0.15 \\
Q3 & 0.10 & 0.09 & & 0.74 & 0.11 \\
Q4 & 0.15 & 0.15 & & 0.74 & 0.10 \\
2005Q1 & 0.20 & 0.21 & & 0.73 & 0.10 \\
Q2 & 0.25 & 0.26 & & 0.71 & 0.11 \\
Q3 & 0.33 & 0.29 & & 0.69 & 0.12 \\
Q4 & 0.42 & 0.33 & & 0.68 & 0.13 \\
2006Q1 & 0.50 & 0.36 & & 0.67 & 0.14 \\
Q2 & 0.55 & 0.38 & & 0.66 & 0.16 \\
Q3 & 0.58 & 0.40 & & 0.64 & 0.17 \\
Q4 & 0.60 & 0.42 & & 0.63 & 0.18 \\
2007Q1 & 0.60 & 0.44 & & 0.63 & 0.19 \\
Q2 & 0.60 & 0.45 & & 0.62 & 0.20 \\
Q3 & 0.60 & 0.46 & & 0.61 & 0.21 \\
Q4 & 0.60 & 0.47 & & 0.60 & 0.21 \\
2008Q1 & 0.59 & 0.47 & & 0.60 & 0.22 \\
Q2 & 0.59 & 0.48 & & 0.59 & 0.23 \\
Q3 & 0.58 & 0.48 & & 0.59 & 0.23 \\
Q4 & 0.57 & 0.49 & & 0.58 & 0.24 \\
\hline
\end{tabular}


Figure 7: Probability Estimates that UK and EA Output is Higher under Entry at par at Beginning of 1999Q1 and at Beginning of 2004Q1, by Quarters after Entry

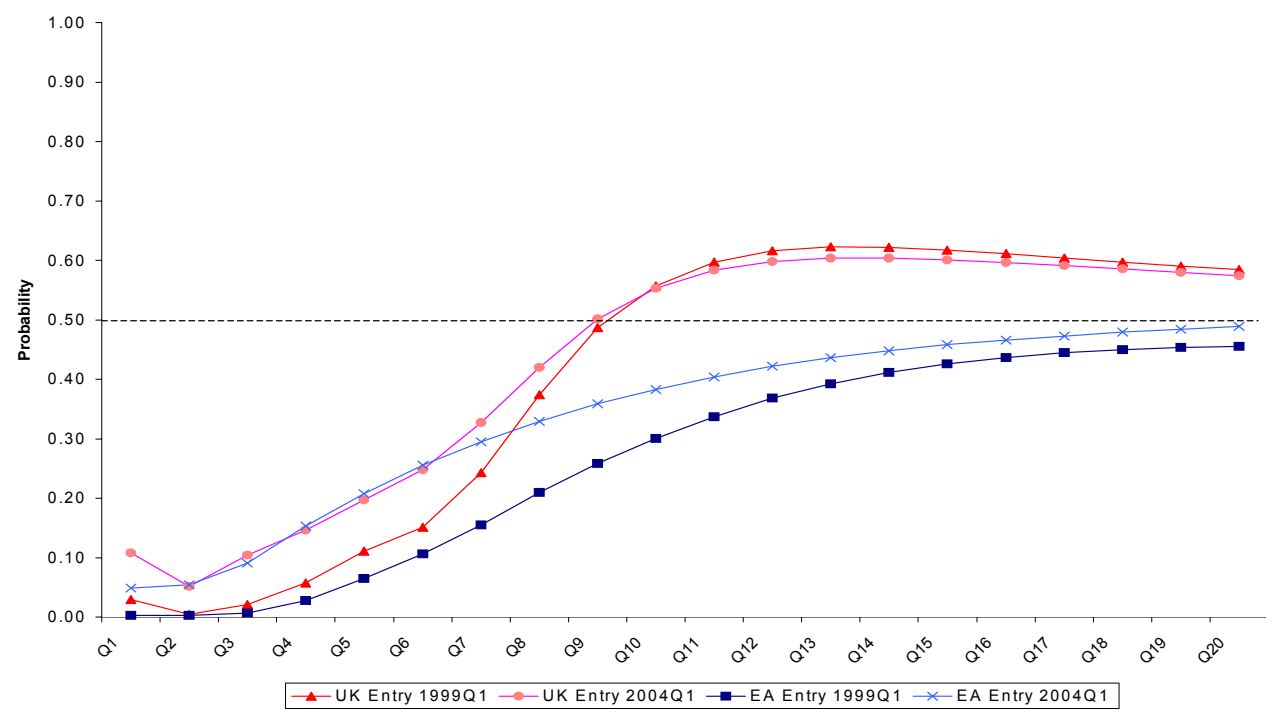

\subsection{UK Entry with Appreciation or Depreciation}

In much of the discussion of euro entry a central issue has been what would be the right rate at which to join. To examine this issue we return to the baseline case, entry in 1999Q1 without conditioning on the four US variables. However, rather than assuming that entry was at par, the exchange rate prevailing in 1998Q4, we assume that the UK was able to appreciate or depreciate on entry and lock itself into the euro at a higher or lower rate. One might question whether the other members would have allowed such a move, but analysis of the effects allows us to judge the significance of the joining rate. We consider four cases: an appreciation of $10 \%$, parity, depreciation of $10 \%$ and a depreciation of $30 \%$.

Table 7 shows the probability that interest rates are lower as a result of entry in the UK and EA for the four cases. In the UK the probability of lower interest rates starts out at one and declines roughly linearly in all four cases. The speed of decline is fastest in the case of $10 \%$ appreciation, slowest in the case of $30 \%$ depreciation, with probabilities of lower interest rates between $70 \%$ (10\% appreciation) and $88 \%$ (30\% depreciation). In the EA the probability of lower interest rates as a result of entry starts at zero in all four cases. In the $10 \%$ appreciation and parity cases, these probabilities rise to a maximum of $73 \%$ 
and $94 \%$, respectively, in $2000 \mathrm{Q} 1$, then decline to $28 \%$ and $44 \%$ by $2003 \mathrm{Q} 4$. In the two depreciation cases, the probability of lower interest rates starts at zero reaching a maximum of $99 \%$ (10\% depreciation) $100 \%$ (30\% depreciation) in 2001Q1 then decline to $59 \%$ and $81 \%$ by the end of 2003 . Thus for both the EA and UK entry with depreciation makes lower interest rates more likely.

Table 7: Probability Estimates that UK and EA Short-Term Interest Rates are Lower under Entry at par at Beginning of 1999Q1 for Alternative Exchange Rates

\begin{tabular}{|c|c|c|c|c|c|c|c|c|}
\hline \multirow[b]{3}{*}{ Year } & \multicolumn{4}{|c|}{$\overline{\mathrm{UK}}$} & \multicolumn{4}{|c|}{$\mathbf{E A}$} \\
\hline & \multirow{2}{*}{$\begin{array}{c}\text { Appreciation } \\
10 \%\end{array}$} & \multirow{2}{*}{$\begin{array}{c}\text { At par } \\
0 \%\end{array}$} & \multicolumn{2}{|c|}{ Depreciation } & \multirow{2}{*}{$\begin{array}{c}\text { Appreciation } \\
10 \%\end{array}$} & \multirow{2}{*}{$\begin{array}{c}\text { At par } \\
0 \%\end{array}$} & \multicolumn{2}{|c|}{ Depreciation } \\
\hline & & & $10 \%$ & $30 \%$ & & & $10 \%$ & $30 \%$ \\
\hline 1999Q1 & 1.00 & 1.00 & 1.00 & 1.00 & 0.05 & 0.02 & 0.01 & 0.00 \\
\hline Q2 & 0.99 & 0.99 & 0.99 & 1.00 & 0.04 & 0.12 & 0.25 & 0.59 \\
\hline Q3 & 0.97 & 0.98 & 0.98 & 0.99 & 0.17 & 0.39 & 0.63 & 0.92 \\
\hline Q4 & 0.96 & 0.97 & 0.97 & 0.98 & 0.54 & 0.76 & 0.90 & 0.99 \\
\hline 2000Q1 & 0.94 & 0.96 & 0.97 & 0.98 & 0.73 & 0.94 & 0.99 & 1.00 \\
\hline Q2 & 0.92 & 0.95 & 0.96 & 0.98 & 0.68 & 0.94 & 0.99 & 1.00 \\
\hline Q3 & 0.90 & 0.93 & 0.95 & 0.97 & 0.60 & 0.89 & 0.98 & 1.00 \\
\hline $\mathrm{Q} 4$ & 0.88 & 0.91 & 0.94 & 0.97 & 0.53 & 0.83 & 0.96 & 1.00 \\
\hline 2001Q1 & 0.85 & 0.89 & 0.92 & 0.96 & 0.46 & 0.76 & 0.93 & 1.00 \\
\hline Q2 & 0.82 & 0.87 & 0.91 & 0.95 & 0.40 & 0.69 & 0.88 & 0.99 \\
\hline Q3 & 0.80 & 0.86 & 0.90 & 0.94 & 0.36 & 0.63 & 0.83 & 0.98 \\
\hline Q4 & 0.78 & 0.84 & 0.88 & 0.94 & 0.33 & 0.58 & 0.79 & 0.96 \\
\hline 2002Q1 & 0.76 & 0.82 & 0.87 & 0.93 & 0.31 & 0.55 & 0.74 & 0.95 \\
\hline Q2 & 0.75 & 0.81 & 0.86 & 0.92 & 0.30 & 0.51 & 0.71 & 0.93 \\
\hline Q3 & 0.73 & 0.80 & 0.85 & 0.91 & 0.29 & 0.49 & 0.68 & 0.90 \\
\hline $\mathrm{Q} 4$ & 0.72 & 0.79 & 0.84 & 0.90 & 0.28 & 0.47 & 0.65 & 0.88 \\
\hline $2003 \mathrm{Q} 1$ & 0.72 & 0.78 & 0.83 & 0.90 & 0.28 & 0.46 & 0.63 & 0.86 \\
\hline Q2 & 0.71 & 0.77 & 0.82 & 0.89 & 0.28 & 0.45 & 0.61 & 0.85 \\
\hline Q3 & 0.70 & 0.77 & 0.81 & 0.88 & 0.28 & 0.44 & 0.60 & 0.83 \\
\hline Q4 & 0.70 & 0.76 & 0.81 & 0.88 & 0.28 & 0.44 & 0.59 & 0.81 \\
\hline
\end{tabular}


Table 8 shows the probability that GDP would be higher under the different entry rates. Figure 8 plots the four cases for UK GDP. One might expect that UK entry with appreciation would reduce the probability that entry increases UK GDP and depreciation increase it. One gets the expected ordering before 200Q1 and after 2002Q2, but in between the ordering is reversed. Figure 9 plots the probability EA GDP would be higher for the four cases. The EA probabilities show a single crossing point in late 1999, and after that the probabilities are in the expected order with UK appreciation making higher EA GDP most likely and UK 30\% depreciation making it least likely. With a 10\% UK appreciation the probability that EA GDP is higher is over $50 \%$ from 2002 onwards.

Table 8: Probability Estimates that UK and EA Output is Higher under Entry at par at Beginning of 1999Q1 for Alternative Exchange Rates

\begin{tabular}{|c|c|c|c|c|c|c|c|c|}
\hline \multirow[b]{3}{*}{ Year } & \multicolumn{4}{|c|}{$\overline{\text { UK }}$} & \multicolumn{4}{|c|}{$\overline{\text { EA }}$} \\
\hline & \multirow{2}{*}{$\begin{array}{c}\text { Appreciation } \\
10 \% \\
\end{array}$} & \multirow{2}{*}{$\frac{\text { At par }}{0 \%}$} & \multicolumn{2}{|c|}{ Depreciation } & \multirow{2}{*}{$\begin{array}{c}\text { Appreciation } \\
10 \% \\
\end{array}$} & \multirow{2}{*}{$\frac{\text { At par }}{0 \%}$} & \multicolumn{2}{|c|}{ Depreciation } \\
\hline & & & $10 \%$ & $30 \%$ & & & $10 \%$ & $30 \%$ \\
\hline 1999Q1 & 0.00 & 0.03 & 0.32 & 0.98 & 0.00 & 0.00 & 0.02 & 0.27 \\
\hline Q2 & 0.00 & 0.00 & 0.03 & 0.27 & 0.00 & 0.00 & 0.01 & 0.07 \\
\hline Q3 & 0.01 & 0.02 & 0.03 & 0.08 & 0.01 & 0.01 & 0.00 & 0.00 \\
\hline Q4 & 0.05 & 0.06 & 0.07 & 0.09 & 0.06 & 0.03 & 0.01 & 0.00 \\
\hline 2000Q1 & 0.11 & 0.11 & 0.12 & 0.13 & 0.12 & 0.07 & 0.04 & 0.01 \\
\hline Q2 & 0.17 & 0.15 & 0.14 & 0.11 & 0.18 & 0.11 & 0.06 & 0.02 \\
\hline Q3 & 0.29 & 0.24 & 0.21 & 0.15 & 0.25 & 0.16 & 0.09 & 0.03 \\
\hline Q4 & 0.43 & 0.37 & 0.33 & 0.25 & 0.32 & 0.21 & 0.13 & 0.05 \\
\hline 2001Q1 & 0.54 & 0.49 & 0.44 & 0.37 & 0.38 & 0.26 & 0.17 & 0.07 \\
\hline Q2 & 0.59 & 0.56 & 0.52 & 0.46 & 0.42 & 0.30 & 0.21 & 0.09 \\
\hline Q3 & 0.62 & 0.60 & 0.57 & 0.53 & 0.46 & 0.34 & 0.24 & 0.12 \\
\hline Q4 & 0.63 & 0.62 & 0.60 & 0.58 & 0.49 & 0.37 & 0.27 & 0.14 \\
\hline 2002Q1 & 0.63 & 0.62 & 0.62 & 0.61 & 0.51 & 0.39 & 0.30 & 0.16 \\
\hline Q2 & 0.62 & 0.62 & 0.62 & 0.62 & 0.52 & 0.41 & 0.32 & 0.18 \\
\hline Q3 & 0.61 & 0.62 & 0.62 & 0.63 & 0.53 & 0.43 & 0.33 & 0.20 \\
\hline Q4 & 0.60 & 0.61 & 0.62 & 0.63 & 0.54 & 0.44 & 0.35 & 0.21 \\
\hline 2003Q1 & 0.59 & 0.60 & 0.62 & 0.63 & 0.54 & 0.44 & 0.36 & 0.22 \\
\hline Q2 & 0.58 & 0.60 & 0.61 & 0.63 & 0.55 & 0.45 & 0.37 & 0.23 \\
\hline Q3 & 0.57 & 0.59 & 0.61 & 0.63 & 0.55 & 0.45 & 0.37 & 0.24 \\
\hline Q4 & 0.57 & 0.58 & 0.60 & 0.63 & 0.55 & 0.46 & 0.37 & 0.25 \\
\hline
\end{tabular}


Figure 8: Probability Estimates that UK Output is Higher under Entry at Beginning of 1999Q1 for Alternative Exchange Rates

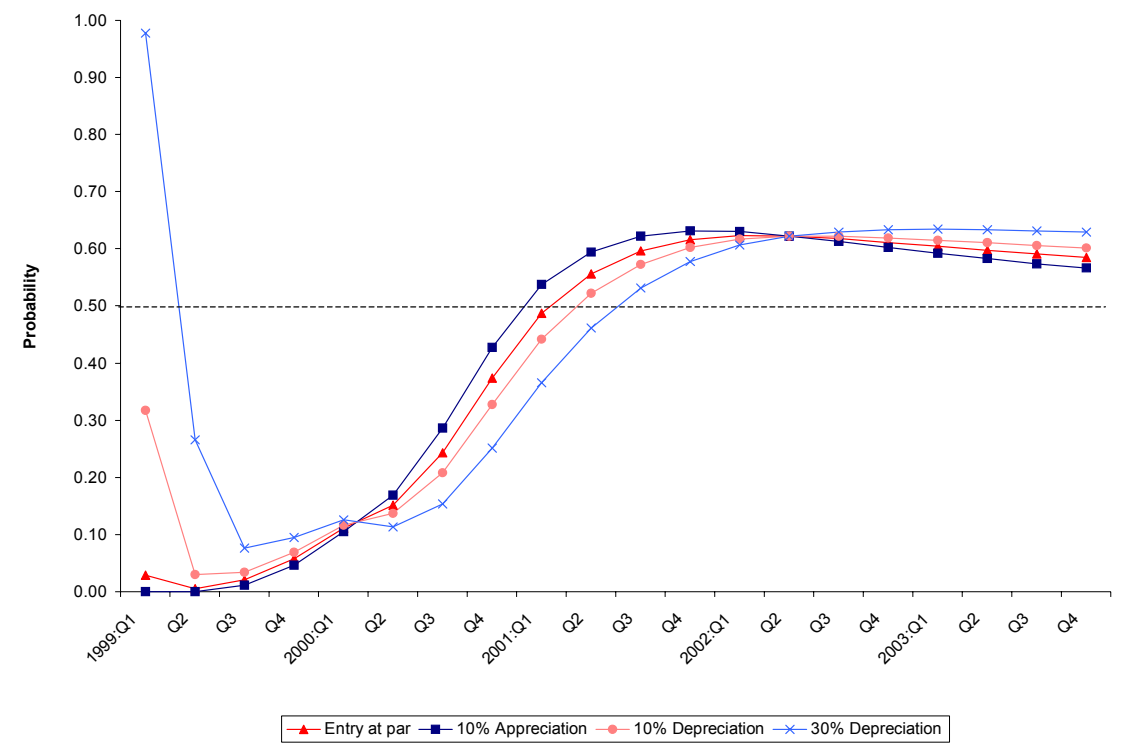

Figure 9: Probability Estimates that EA Output is Higher under Entry at Beginning of 1999Q1 for Alternative Exchange Rates

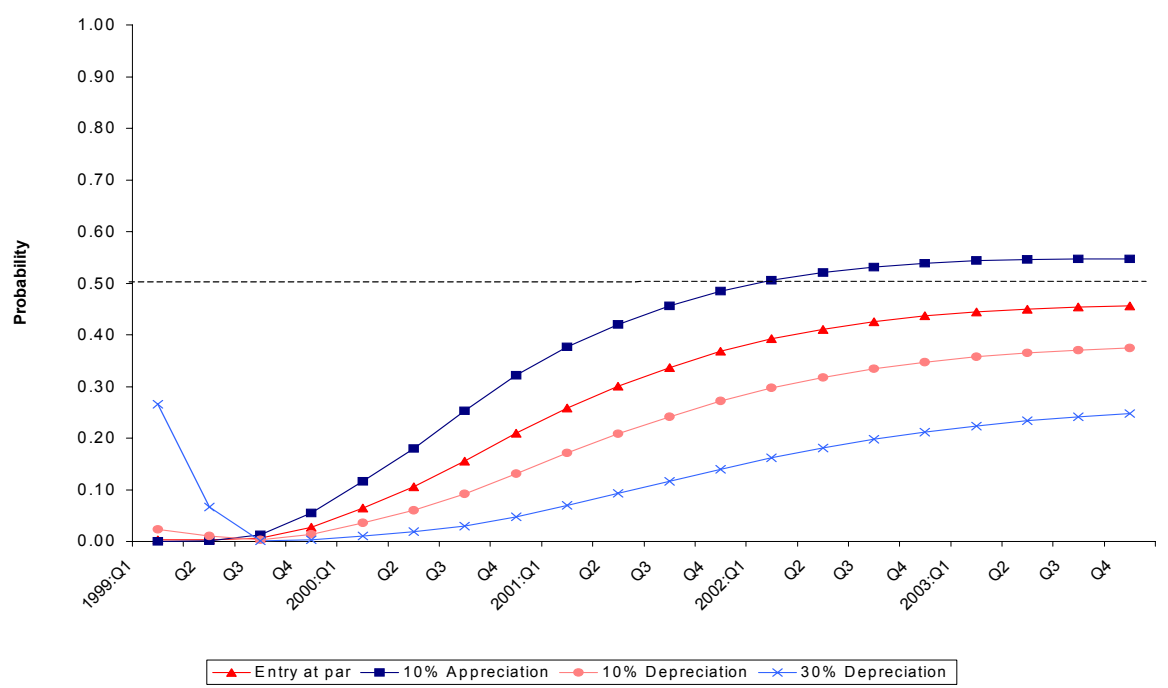


Table 9 shows the probability that prices are lower. For the UK the probabilities that prices will be lower start large and decline, but are always greater than $50 \%$. The ordering is the reverse of what one might expect. UK prices are most likely to be lower with entry with a $30 \%$ depreciation and least likely with a $10 \%$ appreciation. For the EA the probability of prices being lower first declines and then rises, except for the $30 \%$ depreciation where the probability falls continually. The EA shows the same ordering as the UK, prices are most likely to be lower with an initial depreciation and least likely to be lower with an initial appreciation.

Table 9: Probability Estimates that UK and EA Prices are Lower under Entry at par at Beginning of 1999Q1 for Alternative

\section{Exchange Rates}

\begin{tabular}{|c|c|c|c|c|c|c|c|c|}
\hline \multirow[b]{3}{*}{ Year } & \multicolumn{4}{|c|}{ UK } & \multicolumn{4}{|c|}{ EA } \\
\hline & \multirow{2}{*}{$\begin{array}{c}\text { Appreciation } \\
10 \%\end{array}$} & \multirow{2}{*}{$\frac{\text { At par }}{0 \%}$} & \multicolumn{2}{|c|}{ Depreciation } & \multirow{2}{*}{$\begin{array}{c}\text { Appreciation } \\
10 \%\end{array}$} & \multirow{2}{*}{$\frac{\text { At par }}{0 \%}$} & \multicolumn{2}{|c|}{ Depreciation } \\
\hline & & & $10 \%$ & $30 \%$ & & & $10 \%$ & $30 \%$ \\
\hline 1999Q1 & 0.82 & 0.99 & 1.00 & 1.00 & 0.02 & 0.47 & 0.96 & 1.00 \\
\hline Q2 & 0.89 & 0.99 & 1.00 & 1.00 & 0.01 & 0.22 & 0.73 & 1.00 \\
\hline Q3 & 0.85 & 0.95 & 0.99 & 1.00 & 0.01 & 0.10 & 0.42 & 0.96 \\
\hline Q4 & 0.86 & 0.94 & 0.98 & 1.00 & 0.01 & 0.08 & 0.36 & 0.92 \\
\hline 2000Q1 & 0.83 & 0.93 & 0.97 & 1.00 & 0.01 & 0.07 & 0.31 & 0.88 \\
\hline $\mathrm{Q} 2$ & 0.78 & 0.90 & 0.96 & 0.99 & 0.01 & 0.07 & 0.27 & 0.82 \\
\hline Q3 & 0.75 & 0.87 & 0.94 & 0.99 & 0.01 & 0.08 & 0.27 & 0.79 \\
\hline Q4 & 0.72 & 0.85 & 0.93 & 0.98 & 0.01 & 0.09 & 0.27 & 0.76 \\
\hline 2001Q1 & 0.70 & 0.83 & 0.91 & 0.98 & 0.02 & 0.10 & 0.27 & 0.74 \\
\hline Q2 & 0.67 & 0.80 & 0.89 & 0.97 & 0.02 & 0.10 & 0.28 & 0.72 \\
\hline Q3 & 0.64 & 0.78 & 0.87 & 0.96 & 0.03 & 0.11 & 0.28 & 0.70 \\
\hline $\mathrm{Q} 4$ & 0.63 & 0.76 & 0.86 & 0.95 & 0.04 & 0.12 & 0.28 & 0.68 \\
\hline 2002Q1 & 0.61 & 0.74 & 0.84 & 0.94 & 0.04 & 0.13 & 0.29 & 0.66 \\
\hline Q2 & 0.59 & 0.73 & 0.82 & 0.93 & 0.05 & 0.14 & 0.29 & 0.65 \\
\hline Q3 & 0.58 & 0.71 & 0.81 & 0.92 & 0.05 & 0.15 & 0.29 & 0.63 \\
\hline $\mathrm{Q} 4$ & 0.57 & 0.70 & 0.80 & 0.91 & 0.06 & 0.15 & 0.29 & 0.62 \\
\hline 2003Q1 & 0.56 & 0.69 & 0.79 & 0.91 & 0.06 & 0.16 & 0.29 & 0.61 \\
\hline Q2 & 0.56 & 0.68 & 0.77 & 0.90 & 0.07 & 0.16 & 0.30 & 0.60 \\
\hline Q3 & 0.55 & 0.67 & 0.76 & 0.89 & 0.07 & 0.17 & 0.30 & 0.59 \\
\hline Q4 & 0.55 & 0.66 & 0.76 & 0.88 & 0.08 & 0.17 & 0.30 & 0.58 \\
\hline
\end{tabular}

\subsection{Point Estimates of the Effects of UK Entry}

We have emphasised probabilities because we think they provide a more useful way of conveying results that can be quite uncertain. However, to give some indication of the orders of magnitude of the effects, Table 10 shows the effect 
of entry (the point estimate with entry less the associated point estimate without entry) for UK and EA interest rates (percent annualised), the sterling-euro exchange rate and the UK and EA effective rates, expressed as percentage differences between the case with entry and without entry. These effects are for the case of entry at par in 1999 conditioning on oil prices, US interest rates and US equity prices. Entry makes UK short rates over $2 \%$ lower initially though the size of the reduction varies over time. Entry initially raises EA rates and then lowers them by around half a percentage point. Entry causes sterling to be generally stronger relative to the euro than it would have been without entry. UK entry causes the UK effective rate to appreciate relative to what it would have been without entry and the EA effective rate to depreciate. Towards the end of the period the EA effective exchange rate depreciates by about $15 \%$ as a result of the UK entry.

Table 10: Conditional Point Estimates of the Effects of UK Entry on UK and EA Short-Term Interest Rate, the £/Euro Rate and Effective Exchange Rate under Entry at par at Beginning of 1999Q1

\begin{tabular}{|c|c|c|c|c|c|}
\hline \multirow{3}{*}{ Year } & \multicolumn{2}{|c|}{ Short-Term } & \multicolumn{3}{|c|}{ Exchange Rate (\%) } \\
\hline & Inte & Rate $(\%)$ & \multirow{2}{*}{$\begin{array}{c}\text { Spot Rate } \\
£ / \text { Euro }\end{array}$} & \multicolumn{2}{|c|}{ Effective Rate } \\
\hline & UK & EA & & UK & EA \\
\hline 1999Q1 & -2.35 & 0.26 & -0.21 & 0.13 & 0.72 \\
\hline Q2 & -2.49 & 0.06 & -0.97 & 0.54 & 2.90 \\
\hline Q3 & -2.55 & -0.20 & -0.26 & 1.67 & 3.80 \\
\hline Q4 & -2.36 & -0.35 & 1.41 & 3.04 & 3.50 \\
\hline 2000Q1 & -2.33 & -0.55 & 1.57 & 3.34 & 3.82 \\
\hline Q2 & -2.45 & -0.65 & -1.62 & 1.37 & 5.76 \\
\hline Q3 & -2.35 & -0.67 & -4.37 & -0.16 & 7.78 \\
\hline Q4 & -2.49 & -0.68 & -8.69 & -2.94 & 10.25 \\
\hline 2001Q1 & -2.33 & -0.73 & -11.74 & -4.87 & 12.07 \\
\hline Q2 & -2.07 & -0.77 & -13.21 & -5.76 & 13.03 \\
\hline Q3 & -2.20 & -0.73 & -15.60 & -7.51 & 14.03 \\
\hline Q4 & -2.04 & -0.70 & -15.43 & -7.43 & 13.90 \\
\hline 2002Q1 & -1.75 & -0.64 & -13.95 & -6.35 & 13.31 \\
\hline Q2 & -1.83 & -0.53 & -15.51 & -7.41 & 14.11 \\
\hline Q3 & -1.60 & -0.51 & -18.06 & -9.13 & 15.40 \\
\hline Q4 & -1.32 & -0.52 & -18.62 & -9.49 & 15.76 \\
\hline 2003Q1 & -1.22 & -0.51 & -20.44 & -10.96 & 16.27 \\
\hline Q2 & -1.45 & -0.49 & -21.16 & -11.71 & 16.18 \\
\hline Q3 & -1.10 & -0.47 & -18.31 & -9.78 & 14.77 \\
\hline Q4 & -1.61 & -0.35 & -18.61 & -10.12 & 14.70 \\
\hline
\end{tabular}

Note: The point estimates are obtained conditional on the realised values of oil prices, US equity prices and US short and long-term interest rates over the period 1999Q1-2003Q4. The figures for the interest rate are percent per annum. 
Table 11 shows the effect on UK and EA output and prices as percentage changes between the with entry and without entry cases. The effects are quite small. The maximum reduction in UK output per quarter as a result of entry is $-0.54 \%$ in $1999 \mathrm{Q} 2$, the maximum increase is less than $1 \%$. The reductions in EA GDP as a result of entry are less than $1 \%$. Entry causes UK prices to be $3 \%$ lower and EA prices $3 \%$ higher after 5 years; the effects on annual inflation rates would be barely noticeable.

Table 11: Conditional Point Estimates of the Effects of UK Entry on UK and EA Output and Prices under Entry at par at Beginning of 1999Q1

\begin{tabular}{|c|c|c|c|c|}
\hline \multirow[b]{2}{*}{ Year } & \multicolumn{2}{|c|}{ Output (\%) } & \multicolumn{2}{|c|}{ Prices (\%) } \\
\hline & UK & EA & UK & EA \\
\hline 1999Q1 & -0.25 & -0.26 & -0.54 & -0.09 \\
\hline Q2 & -0.54 & -0.55 & -1.71 & -0.05 \\
\hline Q3 & -0.48 & -0.81 & -1.91 & 0.15 \\
\hline Q4 & -0.35 & -0.84 & -2.23 & 0.30 \\
\hline $2000 \mathrm{Q} 1$ & -0.19 & -0.79 & -2.67 & 0.45 \\
\hline Q2 & -0.19 & -0.80 & -2.87 & 0.63 \\
\hline Q3 & -0.11 & -0.83 & -3.08 & 0.84 \\
\hline Q4 & -0.04 & -0.78 & -3.20 & 1.04 \\
\hline 2001Q1 & 0.05 & -0.73 & -3.34 & 1.26 \\
\hline Q2 & 0.22 & -0.67 & -3.39 & 1.50 \\
\hline Q3 & 0.30 & -0.55 & -3.40 & 1.66 \\
\hline Q4 & 0.36 & -0.45 & -3.56 & 1.79 \\
\hline 2002Q1 & 0.52 & -0.37 & -3.64 & 1.96 \\
\hline Q2 & 0.63 & -0.30 & -3.65 & 2.11 \\
\hline Q3 & 0.64 & -0.27 & -3.67 & 2.29 \\
\hline Q4 & 0.78 & -0.25 & -3.53 & 2.50 \\
\hline $2003 \mathrm{Q} 1$ & 0.83 & -0.18 & -3.49 & 2.66 \\
\hline Q2 & 0.78 & -0.12 & -3.43 & 2.78 \\
\hline Q3 & 0.83 & -0.11 & -3.64 & 2.91 \\
\hline Q4 & 0.80 & -0.08 & -3.58 & 3.01 \\
\hline
\end{tabular}

Note: The point estimates are obtained conditional on the realised values of oil prices, US equity prices and US short and long-term interest rates over the period 1999Q1-2003Q4.

\section{Swedish Entry}

For comparison we conducted exactly the same set of exercises for Sweden. The tables and figures, which match those for the UK are available on request. Starting with the baseline case of entry at par in 1999, Sweden like the UK would probably have had lower interest rates, though the probabilities are a little higher in Sweden. However, the EA trajectory for the probability of lower interest rate is very different in the two cases. With UK entry it started at 
zero and rose to $94 \%$ after a year, then fell back to $44 \%$. With Swedish entry it starts at $85 \%$, falls to $34 \%$ then rises to $48 \%$. The probability that output is higher in Sweden with entry starts at $65 \%$, rises to $84 \%$ and then declines to $69 \%$. The probability that prices are lower starts at $27 \%$, rises to $48 \%$, then drops to $32 \%$ before finishing at $35 \%$. Thus Sweden is likely to have had higher output and prices with entry. For the EA, Swedish entry gives an initial probability of higher output of $69 \%$, which rises to $80 \%$ and falls back to $53 \%$. The EA probability that prices are lower is between $10 \%$ and $20 \%$ throughout the sample. Whereas UK entry would probably lower EA GDP, Swedish entry would raise it. Conditioning on observed values of oil prices, US interest rates and US equity prices adds a lot of volatility to the Swedish output probability estimates, but raises the probability of the effect of entry having a positive effect on output towards the end of the sample. In the case of the UK starting in 2004Q1 made very little difference, in the case of Sweden it does make a difference. The probability that output is higher with Swedish entry in 2004 starts at $46 \%$ rising to $61 \%$ at the end of the sample, a little below the $69 \%$ at the end of the 1999 entry sample. For the EA it starts at $30 \%$ and rises to $53 \%$, the same value as at the end of the 1999 sample. Once the effect of the initial conditions has worn off, the probabilities of the two become very similar. In terms of the effect on output, 1999 would have been a better time for Sweden to enter than 2004, both from the Swedish and EA points of view. However, in terms of prices, the probability that Swedish entry would lower prices is higher for both Sweden and the EA for 2004 entry than for 1999 entry. So later entry would tend to lower both output and prices relative to earlier entry.

We now consider the four entry exchange rate cases. The effects on interest rates is very different from the UK. In the UK the probability of lower interest rates starts out at one and declines roughly linearly in all four cases, with final probabilities of lower interest rates between $70 \%$ (10\% appreciation) and $88 \%$ (30\% depreciation). In Sweden initially, like the UK, the 30\% depreciation case has the highest probability of lower interest rates (71\%) and $10 \%$ appreciation the lowest (66\%), but the probabilities cross in 1999Q3 and the order is reversed with final probabilities between 68\% (10\% appreciation) and $62 \%$ (30\% depreciation). At the beginning entry with a $30 \%$ depreciation gives the highest probability of lower interest rates (100\%) and 10\% appreciation the lowest $(45 \%)$. At the end of the sample appreciation gives the highest probability of lower interest rates (52\%) and 30\% depreciation the lowest (37\%). For the UK, entry with depreciation made lower EA interest rates more likely, for Sweden entry with appreciation makes lower EA interest rates more likely. For GDP appreciation reduces the probability that entry will increase Swedish output and depreciation increases the probability. At the beginning the differences are very large with a probability of higher Swedish output $15 \%$ with a $10 \%$ appreciation and $100 \%$ for a $30 \%$ depreciation, but by the end of the sample the differences are smaller, ranging from $65 \%$ to $79 \%$, respectively. Exactly the same pattern holds for the EA. Swedish entry with depreciation increases the probability EA output will be higher. This is the reverse of the pattern for the UK, where appreciation increases the probability that EA output will be higher. Except 
for the first period, when the order is reversed, entry with appreciation has the highest probability of giving lower prices ( $51 \%$ at the end of the period) and $30 \%$ depreciation the lowest ( $8 \%$ at the end of the period). This is the order one would expect, rather than the reverse order found in the UK. The same order holds for the EA: entry with appreciation has the highest probability of lower prices, entry with depreciation the lowest. However, even with appreciation the highest probability of lower prices is only $27 \%$.

Looking at the size of the effects rather than the probabilities, the effect of entry on Swedish interest rates is much larger than the effect on UK interest rates, the maximum reduction, in 2003Q2, is 7.38 percentage points. The effect on EA interest rates is much smaller for Swedish entry than for UK entry. Whereas entry causes appreciation relative to no entry for the UK, for Sweden entry causes depreciation relative to no entry. Swedish entry, like UK entry causes the EA effective rate to depreciate in the medium term. The size of the output effects of entry are much larger in Sweden than the UK, reaching a maximum of $3.76 \%$ higher in 2003Q3. The effects on EA output are small as are the effects on Swedish prices. The effect of Swedish entry on EA prices is rather larger than the effect of UK entry, EA prices are about $8 \%$ higher at the end of the sample, compared to only $3 \%$ in the case of the UK.

\section{Conclusion}

This paper has a methodological and a substantive objective. The methodological objective is to provide a consistent approach to estimating the probability distribution for the effects of a regime change which can take account of international interdependence and observed global shocks. The substantive objective is to estimate the probability that output would be higher and prices lower in the UK and the EA if the UK had joined the euro.

UK entry to the euro in 1999Q1 at 1998Q4 exchange rates would probably have reduced UK GDP in the short term and raised it in the longer term, but the effects are small. UK entry would have probably caused EA GDP to be lower. Entry would have probably caused UK prices to be lower and EA prices to be higher. UK entry would have been bad for the EA, because of lower output and higher prices, though the effects are small. For the UK the welfare effect is ambiguous, depending on the discount rate used, and on the relative weights given to output and inflation. This conclusion seems quite robust to alternative scenarios, including conditioning on observed global shocks over the period 1999Q1 to 2003Q4 and entering with different initial conditions in 2004Q1.

Much of the discussion has emphasised the importance of the exchange rate at which the UK joined the euro and our experiments confirm the importance of this. The probabilities change when one allows for a permanent appreciation or depreciation of the sterling-euro rate on entry. With a large depreciation on entry, the probability of entry having a positive effect on UK output becomes greater. 
We also made a comparison with Sweden, where entry to the euro in 1999 would probably have increased output and raised prices, so again no unambiguous welfare conclusion is possible. However, the Swedish results differed in a number of important respects from the UK results. This is not surprising as they are rather different economies.

There are a number of other issues that might merit investigation. These include the effect of parameter and model uncertainty. Our conclusion about the effect of UK entry can only be tentative until the robustness of the result to parameter and model uncertainty has been analysed, using techniques such as those applied in Garratt et al. (2003) in the context of a macroeconometric model of the UK. There are also other channels such as national debt and budget deficits that could be important for the analysis of the UK entry. The GVAR model used in this paper assumes that the fiscal implications of the UK entry will, to a large extent, be picked up by the term premium and their differences across the UK and the EA. But a more explicit analysis of the fiscal effects of the UK entry within the GVAR framework would be of interest. 


\section{APPENDIX}

\section{Transforming the GVAR: Prices and Nominal Exchange Rates}

Assume that inflation, $p_{i t}-p_{i, t-1}$, is the first variable in $\stackrel{\circ}{\mathbf{x}}_{i t}$, in all country models and, with the exception of the US, the second and third entries in $\mathbf{x}_{i t}$ are the real exchange rate, $e_{i t}-p_{i t}$, and the short term interest rate, $r_{i t}^{S}$. The rest of the variables in $\stackrel{\circ}{i t}_{i t}$ will be denoted by the $\left(k_{i}-3\right) \times 1$ vector $\mathbf{x}_{i t}^{\text {rest }}$ for the non-US models, and by the $\left(k_{0}-2\right) \times 1$ vector $\mathbf{x}_{0 t}^{\text {rest }}$ for the US model. More specifically we have

$$
\stackrel{\mathrm{x}}{0 t}_{0}=\left(\begin{array}{c}
p_{0 t}-p_{0, t-1} \\
r_{0 t}^{S} \\
\mathbf{x}_{0 t}^{r e s t}
\end{array}\right) \text {, and } \stackrel{\mathrm{x}}{i t}_{i t}=\left(\begin{array}{c}
p_{i t}-p_{i, t-1} \\
e_{i t}-p_{i t} \\
r_{i t}^{S} \\
\mathbf{x}_{i t}^{r e s t}
\end{array}\right) \text { for } i=1,2, \ldots, N .
$$

The GVAR model in these variables as set above

$$
\stackrel{\circ}{\mathbf{x}}_{t}=\mathbf{a}_{0}+\mathbf{a}_{1} t+\mathbf{G}_{1} \stackrel{\circ}{\mathbf{x}}_{t-1}+\mathbf{G}_{2} \stackrel{\circ}{\mathbf{x}}_{t-2}+\stackrel{\circ}{\mathbf{v}}_{t},
$$

where $\stackrel{\circ}{\mathbf{x}}_{t}=\left(\stackrel{\circ}{\mathbf{x}}_{0 t}^{\prime}, \stackrel{\circ}{\mathbf{x}}_{1 t}^{\prime}, \ldots, \stackrel{\circ}{\mathbf{x}}_{N t}^{\prime}\right)^{\prime}$, and $\mathbf{a}_{0}, \mathbf{a}_{1}, \mathbf{G}_{1}, \mathbf{G}_{2}$ are defined in terms of the country-specific models as in Section 3.

Since our aim is to fix UK's nominal exchange rate and short term interest rate to the ones in the euro area, we need to work with a GVAR in the levels of these variables. Assume that $\stackrel{\circ}{\mathbf{x}}_{1 t}$ and $\stackrel{\circ}{\mathbf{x}}_{2 t}$ refer to the endogenous variables of the models for the euro area and the UK, respectively, and denote the $k_{i} \times 1$ vector of the endogenous variables in $p_{i t}$ and $e_{i t}$ by $\mathbf{x}_{i t}$. More specifically

$$
\mathbf{x}_{0 t}=\left(\begin{array}{c}
p_{0 t} \\
r_{0 t}^{S} \\
\mathbf{x}_{0 t}^{r e s t}
\end{array}\right) \text {, and } \mathbf{x}_{i t}=\left(\begin{array}{c}
p_{i t} \\
e_{i t} \\
r_{i t}^{S} \\
\mathbf{x}_{i t}^{r e s t}
\end{array}\right) \text { for } i=1,2, \ldots, N
$$

The relationships between $\mathbf{x}_{i t}$ and $\stackrel{\circ}{\mathbf{x}}_{i t}$ are given by the following dynamic identities

$$
\mathbf{x}_{i t}=\mathcal{B}_{i} \stackrel{\circ}{\mathbf{x}}_{i t}+\mathcal{C}_{i} \mathbf{x}_{i, t-1}, \text { for } i=0,1, . . N
$$

where

and

$$
\mathcal{B}_{0}=\mathbf{I}_{k_{0}}, \mathcal{C}_{0}=\left(\begin{array}{cc}
1 & \mathbf{0}_{1 \times\left(k_{0}-1\right)} \\
\mathbf{0}_{\left(k_{0}-1\right) \times 1} & \mathbf{0}_{\left(k_{0}-1\right) \times\left(k_{0}-1\right)}
\end{array}\right)
$$

$$
\begin{aligned}
\mathcal{B}_{i} & =\left(\begin{array}{ccc}
1 & 0 & \mathbf{0}_{2 \times\left(k_{i}-2\right)} \\
1 & 1 & \mathbf{I}_{k_{i}-2}
\end{array}\right), \\
\boldsymbol{O}_{\left(k_{i}-2\right) \times 2} & =\left(\begin{array}{ccc}
1 & 0 & \mathbf{0}_{2 \times\left(k_{i}-2\right)} \\
1 & 0 & \mathbf{0}_{\left(k_{i}-2\right) \times\left(k_{i}-2\right)}
\end{array}\right) .
\end{aligned}
$$


Hence

$$
\mathbf{x}_{t}=\mathcal{B} \dot{\mathbf{x}}_{t}+\mathcal{C} \mathbf{x}_{t-1}
$$

where

$$
\mathcal{B}=\left(\begin{array}{ccccc}
\mathbf{I}_{k_{0}} & \mathbf{0} & \ldots & & \mathbf{0} \\
\mathbf{0} & \mathcal{B}_{1} & & & \mathbf{0} \\
\vdots & & \ddots & & \vdots \\
\mathbf{0} & \mathbf{0} & & \mathcal{B}_{N-1} & \mathbf{0} \\
\mathbf{0} & \mathbf{0} & \ldots & \mathbf{0} & \mathcal{B}_{N}
\end{array}\right)
$$

and

$$
\mathcal{C}=\left(\begin{array}{ccccc}
\mathcal{C}_{0} & \mathbf{0} & \ldots & & \mathbf{0} \\
\mathbf{0} & \mathcal{C}_{1} & & & \mathbf{0} \\
\vdots & & \ddots & & \vdots \\
\mathbf{0} & \mathbf{0} & & \mathcal{C}_{N-1} & \mathbf{0} \\
\mathbf{0} & \mathbf{0} & \ldots & \mathbf{0} & \mathcal{C}_{N}
\end{array}\right)
$$

It is clear that $\mathcal{B}$ is non-singular and its inverse is given by

$$
\mathcal{B}^{-1}=\left(\begin{array}{ccccc}
\mathbf{I}_{k_{0}} & \mathbf{0} & \cdots & & \mathbf{0} \\
\mathbf{0} & \mathcal{B}_{1}^{-1} & & & \mathbf{0} \\
\vdots & & \ddots & & \vdots \\
\mathbf{0} & \mathbf{0} & & \mathcal{B}_{N-1}^{-1} & \mathbf{0} \\
\mathbf{0} & \mathbf{0} & \ldots & \mathbf{0} & \mathcal{B}_{N}^{-1}
\end{array}\right)
$$

where

$$
\mathcal{B}_{i}^{-1}=\left(\begin{array}{ccc}
1 & 0 & \mathbf{0}_{2 \times\left(k_{i}-2\right)} \\
-1 & 1 & \mathbf{I}_{k_{i}-2}
\end{array}\right), \text { for } i=1,2, \ldots, N
$$

and

$$
\stackrel{\circ}{\mathbf{x}}_{t}=\mathcal{B}^{-1}\left(\mathbf{x}_{t}-\mathcal{C} \mathbf{x}_{t-1}\right) .
$$

Using this result in (A.1) we have

$$
\mathcal{B}^{-1}\left(\mathbf{x}_{t}-\mathcal{C} \mathbf{x}_{t-1}\right)=\mathbf{a}_{0}+\mathbf{a}_{1} t+\mathbf{G}_{1} \mathcal{B}^{-1}\left(\mathbf{x}_{t-1}-\mathcal{C} \mathbf{x}_{t-2}\right)+\mathbf{G}_{2} \mathcal{B}^{-1}\left(\mathbf{x}_{t-2}-\mathcal{C} \mathbf{x}_{t-3}\right)+\stackrel{\circ}{\mathbf{v}}_{t},
$$

or

$$
\begin{aligned}
\mathbf{x}_{t}= & \mathcal{B}\left(\mathbf{a}_{0}+\mathbf{a}_{1} t\right)+\left(\mathcal{C}+\mathcal{B} \mathbf{G}_{1} \mathcal{B}^{-1}\right) \mathbf{x}_{t-1}- \\
& \left(\mathcal{B} \mathbf{G}_{1} \mathcal{B}^{-1} \mathcal{C}-\mathcal{B} \mathbf{G}_{2} \mathcal{B}^{-1}\right) \mathbf{x}_{t-2}-\mathcal{B} \mathbf{G}_{2} \mathcal{B}^{-1} \mathcal{C} \mathbf{x}_{t-3}+\mathbf{v}_{t}
\end{aligned}
$$

where

$$
\mathbf{v}_{t}=\mathcal{B} \stackrel{\circ}{t}_{t}
$$

Note that (A.3) can be written as

$$
\mathbf{x}_{t}=\mathbf{b}_{0}+\mathbf{b}_{1} t+\mathbf{F}_{1} \mathbf{x}_{t-1}+\mathbf{F}_{2} \mathbf{x}_{t-2}+\mathbf{F}_{3} \mathbf{x}_{t-3}+\mathbf{v}_{t}
$$


where

$$
\mathbf{b}_{0}=\mathcal{B} \mathbf{a}_{0}, \mathbf{b}_{1}=\mathcal{B} \mathbf{a}_{1}
$$

and

$$
\mathbf{F}_{1}=\left(\mathcal{C}+\mathcal{B} \mathbf{G}_{1} \mathcal{B}^{-1}\right), \mathbf{F}_{2}=\mathcal{B}\left(\mathbf{G}_{2} \mathcal{B}^{-1}-\mathbf{G}_{1} \mathcal{B}^{-1} \mathcal{C}\right), \mathbf{F}_{3}=-\mathcal{B}_{2} \mathcal{B}^{-1} \mathcal{C}
$$

Suppose that the characteristic equation of the model in inflation and real exchange rates, defined by (A.1), lie on or inside the unit circle. Let $\lambda$ be the characteristic root of the model in price levels and nominal exchange rates as specified by (A.3) and note that

$$
\left|\mathbf{I}_{k}-\left(\mathcal{C}+\mathcal{B} \mathbf{G}_{1} \mathcal{B}^{-1}\right) \lambda+\left(\mathcal{B G}_{1} \mathcal{B}^{-1} \mathcal{C}-\mathcal{B G}_{2} \mathcal{B}^{-1}\right) \lambda^{2}+\mathcal{B} \mathbf{G}_{2} \mathcal{B}^{-1} \mathcal{C} \lambda^{3}\right|=0
$$

where $k=\sum_{i=0}^{N} k_{i}$. Since $\mathcal{B}$ is non-singular we also have

$$
\begin{aligned}
\left|\mathbf{I}_{k}-\left(\mathcal{B}^{-1} \mathcal{C B}+\mathbf{G}_{1}\right) \lambda+\left(\mathbf{G}_{1} \mathcal{B}^{-1} \mathcal{C B}-\mathbf{G}_{2}\right) \lambda^{2}+\mathbf{G}_{2} \mathcal{B}^{-1} \mathcal{C B} \lambda^{3}\right| & = \\
\left|\left(\mathbf{I}_{k}-\mathbf{G}_{1} \lambda-\mathbf{G}_{2} \lambda^{2}\right)\left(\mathbf{I}_{k}-\mathcal{B}^{-1} \mathcal{C B} \lambda\right)\right| & = \\
\left|\left(\mathbf{I}_{k}-\mathbf{G}_{1} \lambda-\mathbf{G}_{2} \lambda^{2}\right)\right|\left|\left(\mathbf{I}_{k}-\mathcal{B}^{-1} \mathcal{C B} \lambda\right)\right| & =0 .
\end{aligned}
$$

Hence, the characteristic roots of (A.4) are given by the solutions to

$$
\left|\left(\mathbf{I}_{k}-\mathbf{G}_{1} \lambda-\mathbf{G}_{2} \lambda^{2}\right)\right|=0
$$

which is the characteristic equation of (A.1), and

$$
\left|\left(\mathbf{I}_{k}-\mathcal{B}^{-1} \mathcal{C B} \lambda\right)\right|=0 \text {. }
$$

However, it is easily seen that

$$
\mathcal{B}^{-1} \mathcal{C B}=\left(\begin{array}{ccccc}
\mathcal{C}_{0} & \mathbf{0} & \ldots & & \mathbf{0} \\
\mathbf{0} & \mathcal{B}_{1}^{-1} \mathcal{C}_{1} \mathcal{B}_{1} & & & \mathbf{0} \\
\vdots & & \ddots & & \vdots \\
\mathbf{0} & \mathbf{0} & & \mathcal{B}_{N-1}^{-1} \mathcal{C}_{N-1} \mathcal{B}_{N-1} & \mathbf{0} \\
\mathbf{0} & \mathbf{0} & \ldots & \mathbf{0} & \mathcal{B}_{N}^{-1} \mathcal{C}_{N} \mathcal{B}_{N}
\end{array}\right)
$$

with

$$
\mathcal{B}_{i}^{-1} \mathcal{C}_{i} \mathcal{B}_{i}=\left(\begin{array}{ccc}
1 & 0 & \mathbf{0}_{2 \times\left(k_{i}-2\right)} \\
-1 & 1 & \mathbf{I}_{k_{i}-2}
\end{array}\right)\left(\begin{array}{ccc}
1 & 0 & \mathbf{0}_{2 \times\left(k_{i}-2\right)} \\
1 & 0 & \mathbf{0}_{\left(k_{i}-2\right) \times 2}
\end{array}\right)\left(\begin{array}{ccc}
1 & 0 & \mathbf{0}_{2 \times\left(k_{i}-2\right)} \\
1 & 1 & \mathbf{I}_{\left(k_{i}-2\right) \times 2} \\
\mathbf{0}_{\left(k_{i}-2\right) \times\left(k_{i}-2\right)}
\end{array}\right)
$$

or

$$
\mathcal{B}_{i}^{-1} \mathcal{C}_{i} \mathcal{B}_{i}=\left(\begin{array}{ccc}
1 & 0 & \mathbf{0}_{2 \times\left(k_{i}-2\right)} \\
0 & 0 & \mathbf{0}_{\left(k_{i}-2\right) \times\left(k_{i}-2\right)}
\end{array}\right)
$$

The eigenvalues of $\mathcal{B}^{-1} \mathcal{C B}$ are given by those of $\mathcal{C}_{0}$ and $\mathcal{B}_{i}^{-1} \mathcal{C}_{i} \mathcal{B}_{i}$ for $i=1,2, \ldots, N$, which are zero or unity. Therefore, the characteristic roots of (A.3) are the same as the characteristics of (A.1) plus the roots of (A.6) which are either zero or unity. 
What if the UK had Joined the Euro in 1999? An Empirical Evaluation using a Global VAR

M. Hashem Pesaran

University of Cambridge
L. Vanessa Smith

University of Cambridge

May, 2005
Ron P. Smith

Birkbeck College, London

Supplementary Tables for the Sweden Euro Entry Experiments 
Table S1: Probability Estimates that SE and EA Short-Term Interest Rates are Lower under Entry at par at Beginning of 1999Q1

\begin{tabular}{rcc}
\hline \hline & \multicolumn{2}{c}{ Probability } \\
\cline { 2 - 3 } Year & SE & EA \\
\hline 1999Q1 & 0.67 & 0.85 \\
Q2 & 0.69 & 0.89 \\
Q3 & 0.75 & 0.86 \\
Q4 & 0.75 & 0.72 \\
2000Q1 & 0.76 & 0.50 \\
Q2 & 0.75 & 0.40 \\
Q3 & 0.71 & 0.35 \\
Q4 & 0.69 & 0.34 \\
2001Q1 & 0.69 & 0.34 \\
Q2 & 0.68 & 0.35 \\
Q3 & 0.67 & 0.37 \\
Q4 & 0.66 & 0.38 \\
2002Q1 & 0.66 & 0.40 \\
Q2 & 0.66 & 0.41 \\
Q3 & 0.66 & 0.43 \\
Q4 & 0.66 & 0.44 \\
2003Q1 & 0.66 & 0.45 \\
Q2 & 0.66 & 0.46 \\
Q3 & 0.66 & 0.47 \\
Q4 & 0.67 & 0.48 \\
\hline
\end{tabular}

Table S2: Probability Estimates that Output is Higher and Prices are Lower, separately and jointly in SE and EA under Entry at par at Beginning of 1999Q1

\begin{tabular}{|c|c|c|c|c|c|c|}
\hline \multirow[b]{2}{*}{ Year } & \multicolumn{2}{|c|}{ Output } & \multicolumn{2}{|c|}{ Prices } & \multicolumn{2}{|c|}{ Output \& Prices } \\
\hline & SE & EA & SE & EU & SE & EU \\
\hline 1999Q1 & 0.65 & 0.69 & 0.27 & 0.18 & 0.08 & 0.08 \\
\hline Q2 & 0.76 & 0.75 & 0.33 & 0.15 & 0.11 & 0.04 \\
\hline Q3 & 0.80 & 0.79 & 0.48 & 0.14 & 0.31 & 0.04 \\
\hline Q4 & 0.83 & 0.80 & 0.44 & 0.13 & 0.32 & 0.03 \\
\hline $2000 \mathrm{Q} 1$ & 0.84 & 0.79 & 0.44 & 0.12 & 0.34 & 0.02 \\
\hline Q2 & 0.83 & 0.78 & 0.41 & 0.12 & 0.33 & 0.02 \\
\hline Q3 & 0.81 & 0.76 & 0.39 & 0.13 & 0.31 & 0.02 \\
\hline Q4 & 0.79 & 0.74 & 0.37 & 0.13 & 0.29 & 0.01 \\
\hline 2001Q1 & 0.78 & 0.71 & 0.34 & 0.13 & 0.27 & 0.01 \\
\hline Q2 & 0.76 & 0.69 & 0.33 & 0.14 & 0.26 & 0.01 \\
\hline Q3 & 0.75 & 0.66 & 0.32 & 0.14 & 0.26 & 0.01 \\
\hline Q4 & 0.73 & 0.64 & 0.32 & 0.15 & 0.26 & 0.01 \\
\hline 2002Q1 & 0.73 & 0.62 & 0.32 & 0.15 & 0.26 & 0.01 \\
\hline Q2 & 0.72 & 0.60 & 0.32 & 0.16 & 0.26 & 0.01 \\
\hline Q3 & 0.71 & 0.59 & 0.32 & 0.17 & 0.27 & 0.01 \\
\hline $\mathrm{Q} 4$ & 0.71 & 0.57 & 0.33 & 0.17 & 0.27 & 0.01 \\
\hline 2003Q1 & 0.70 & 0.56 & 0.33 & 0.18 & 0.28 & 0.01 \\
\hline Q2 & 0.70 & 0.55 & 0.34 & 0.19 & 0.29 & 0.01 \\
\hline Q3 & 0.70 & 0.54 & 0.35 & 0.19 & 0.29 & 0.01 \\
\hline Q4 & 0.69 & 0.53 & 0.35 & 0.20 & 0.30 & 0.01 \\
\hline
\end{tabular}


Table S3: Conditional Probability Estimates that SE and EA Short-Term Interest Rates are Lower under Entry at par at Beginning of 1999Q1

\begin{tabular}{rcc}
\hline \hline & \multicolumn{2}{l}{ Probability } \\
\cline { 2 - 3 } Year & SE & EA \\
\hline 1999Q1 & 0.57 & 0.71 \\
Q2 & 0.55 & 0.75 \\
Q3 & 0.63 & 0.76 \\
Q4 & 0.63 & 0.74 \\
2000Q1 & 0.61 & 0.67 \\
Q2 & 0.67 & 0.67 \\
Q3 & 0.65 & 0.65 \\
Q4 & 0.77 & 0.67 \\
2001Q1 & 0.83 & 0.69 \\
Q2 & 0.83 & 0.69 \\
Q3 & 0.86 & 0.71 \\
Q4 & 0.84 & 0.70 \\
2002Q1 & 0.81 & 0.68 \\
Q2 & 0.86 & 0.66 \\
Q3 & 0.91 & 0.65 \\
Q4 & 0.93 & 0.64 \\
2003Q1 & 0.94 & 0.65 \\
Q2 & 0.94 & 0.66 \\
Q3 & 0.90 & 0.64 \\
Q4 & 0.91 & 0.62 \\
\hline
\end{tabular}

Note: The probability estimates are obtained conditional on the realised values of oil prices, US equity prices and US short and long-term interest rates over the period 1999Q1-2003Q4.

Table S4: Conditional Probability Estimates that Output is Higher and Prices are Lower, separately in SE and EA under Entry at par at Beginning of 1999Q1

\begin{tabular}{rccccc}
\hline \hline & \multicolumn{2}{c}{ Output } & & \multicolumn{2}{c}{ Prices } \\
\cline { 2 - 3 } \cline { 6 - 7 } Year & SE & EA & & SE & EA \\
\hline 1999Q1 & 0.59 & 0.75 & & 0.30 & 0.26 \\
Q2 & 0.61 & 0.72 & & 0.39 & 0.28 \\
Q3 & 0.62 & 0.67 & & 0.43 & 0.26 \\
Q4 & 0.65 & 0.62 & & 0.39 & 0.24 \\
2000Q1 & 0.65 & 0.60 & & 0.51 & 0.24 \\
Q2 & 0.65 & 0.56 & & 0.46 & 0.22 \\
Q3 & 0.71 & 0.52 & & 0.49 & 0.22 \\
Q4 & 0.74 & 0.48 & & 0.49 & 0.20 \\
2001Q1 & 0.83 & 0.46 & & 0.43 & 0.18 \\
Q2 & 0.85 & 0.47 & & 0.50 & 0.16 \\
Q3 & 0.85 & 0.48 & & 0.56 & 0.15 \\
Q4 & 0.85 & 0.49 & & 0.59 & 0.15 \\
2002Q1 & 0.83 & 0.51 & & 0.66 & 0.14 \\
Q2 & 0.84 & 0.51 & & 0.67 & 0.14 \\
Q3 & 0.89 & 0.48 & & 0.64 & 0.13 \\
Q4 & 0.93 & 0.50 & & 0.67 & 0.12 \\
2003Q1 & 0.94 & 0.54 & & 0.73 & 0.11 \\
Q2 & 0.94 & 0.56 & & 0.75 & 0.11 \\
Q3 & 0.94 & 0.60 & & 0.80 & 0.10 \\
Q4 & 0.92 & 0.62 & & 0.81 & 0.10 \\
\hline
\end{tabular}

Note: The probability estimates are obtained conditional on the realised values of oil prices, US equity prices and US short and long-term interest rates over the period 1999Q1-2003Q4. 
Table S5: Probability Estimates that Output is Higher and Prices are Lower, separately in SE and EA under Entry at par at Beginning of 2004Q1

\begin{tabular}{rlllll}
\hline \hline & \multicolumn{2}{l}{ Output } & & \multicolumn{2}{c}{ Prices } \\
\cline { 2 - 3 } \cline { 6 - 7 } Year & SE & EA & & SE & EA \\
\hline 2004Q1 & 0.46 & 0.30 & & 0.43 & 0.49 \\
Q2 & 0.49 & 0.33 & & 0.49 & 0.46 \\
Q3 & 0.47 & 0.39 & & 0.68 & 0.46 \\
Q4 & 0.52 & 0.43 & & 0.67 & 0.44 \\
2005Q1 & 0.55 & 0.46 & & 0.70 & 0.44 \\
Q2 & 0.56 & 0.48 & & 0.70 & 0.44 \\
Q3 & 0.58 & 0.50 & & 0.70 & 0.44 \\
Q4 & 0.59 & 0.51 & & 0.69 & 0.44 \\
2006Q1 & 0.60 & 0.52 & & 0.68 & 0.44 \\
Q2 & 0.60 & 0.53 & & 0.67 & 0.44 \\
Q3 & 0.60 & 0.53 & & 0.66 & 0.44 \\
Q4 & 0.60 & 0.53 & & 0.65 & 0.44 \\
2007Q1 & 0.61 & 0.53 & & 0.64 & 0.43 \\
Q2 & 0.61 & 0.53 & & 0.63 & 0.43 \\
Q3 & 0.61 & 0.53 & & 0.62 & 0.43 \\
Q4 & 0.61 & 0.53 & & 0.61 & 0.43 \\
2008Q1 & 0.61 & 0.53 & & 0.61 & 0.43 \\
Q2 & 0.61 & 0.53 & & 0.60 & 0.43 \\
Q3 & 0.61 & 0.53 & & 0.60 & 0.43 \\
Q4 & 0.61 & 0.53 & & 0.59 & 0.43 \\
\hline
\end{tabular}

Table S6: Probability Estimates that SE and EA Short-Term Interest Rates are Lower under Entry at par at Beginning of 1999Q1 for Alternative Exchange Rates

\begin{tabular}{|c|c|c|c|c|c|c|c|c|}
\hline \multirow[b]{3}{*}{ Year } & \multicolumn{4}{|c|}{$\overline{\mathrm{SE}}$} & \multicolumn{4}{|c|}{ EA } \\
\hline & \multirow{2}{*}{$\begin{array}{c}\text { Appreciation } \\
10 \%\end{array}$} & \multirow{2}{*}{$\frac{\text { At par }}{0 \%}$} & \multicolumn{2}{|c|}{ Depreciation } & \multirow{2}{*}{$\begin{array}{c}\text { Appreciation } \\
10 \%\end{array}$} & \multirow{2}{*}{$\frac{\text { At par }}{0 \%}$} & \multicolumn{2}{|c|}{ Depreciation } \\
\hline & & & $10 \%$ & $30 \%$ & & & $10 \%$ & $30 \%$ \\
\hline 1999Q1 & 0.66 & 0.67 & 0.69 & 0.71 & 0.45 & 0.85 & 0.98 & 1.00 \\
\hline Q2 & 0.67 & 0.69 & 0.71 & 0.74 & 0.58 & 0.89 & 0.98 & 1.00 \\
\hline Q3 & 0.75 & 0.75 & 0.75 & 0.75 & 0.84 & 0.86 & 0.88 & 0.91 \\
\hline Q4 & 0.76 & 0.75 & 0.74 & 0.73 & 0.84 & 0.72 & 0.57 & 0.30 \\
\hline 2000Q1 & 0.77 & 0.76 & 0.74 & 0.71 & 0.69 & 0.50 & 0.32 & 0.11 \\
\hline Q2 & 0.77 & 0.75 & 0.73 & 0.69 & 0.57 & 0.40 & 0.25 & 0.09 \\
\hline Q3 & 0.73 & 0.71 & 0.68 & 0.64 & 0.51 & 0.35 & 0.23 & 0.08 \\
\hline Q4 & 0.72 & 0.69 & 0.66 & 0.62 & 0.47 & 0.34 & 0.23 & 0.10 \\
\hline 2001Q1 & 0.71 & 0.69 & 0.66 & 0.62 & 0.45 & 0.34 & 0.25 & 0.13 \\
\hline Q2 & 0.71 & 0.68 & 0.65 & 0.61 & 0.45 & 0.35 & 0.27 & 0.16 \\
\hline Q3 & 0.69 & 0.67 & 0.64 & 0.60 & 0.45 & 0.37 & 0.29 & 0.18 \\
\hline Q4 & 0.69 & 0.66 & 0.64 & 0.60 & 0.46 & 0.38 & 0.32 & 0.21 \\
\hline 2002Q1 & 0.69 & 0.66 & 0.64 & 0.60 & 0.47 & 0.40 & 0.34 & 0.24 \\
\hline Q2 & 0.69 & 0.66 & 0.64 & 0.60 & 0.48 & 0.41 & 0.36 & 0.26 \\
\hline Q3 & 0.68 & 0.66 & 0.64 & 0.61 & 0.49 & 0.43 & 0.37 & 0.29 \\
\hline Q4 & 0.68 & 0.66 & 0.64 & 0.61 & 0.49 & 0.44 & 0.39 & 0.31 \\
\hline 2003Q1 & 0.68 & 0.66 & 0.64 & 0.61 & 0.50 & 0.45 & 0.40 & 0.32 \\
\hline Q2 & 0.68 & 0.66 & 0.65 & 0.62 & 0.51 & 0.46 & 0.42 & 0.34 \\
\hline Q3 & 0.68 & 0.66 & 0.65 & 0.62 & 0.51 & 0.47 & 0.43 & 0.36 \\
\hline Q4 & 0.68 & 0.67 & 0.65 & 0.62 & 0.52 & 0.48 & 0.44 & 0.37 \\
\hline
\end{tabular}


Table S7: Probability Estimates that SE and EA Output is Higher under Entry at par at Beginning of 1999Q1 for Alternative Exchange Rates

\begin{tabular}{|c|c|c|c|c|c|c|c|c|}
\hline \multirow[b]{3}{*}{ Year } & \multicolumn{4}{|c|}{ SE } & \multicolumn{4}{|c|}{$\overline{\text { EA }}$} \\
\hline & \multirow{2}{*}{$\begin{array}{c}\text { Appreciation } \\
10 \%\end{array}$} & \multirow{2}{*}{$\frac{\text { At par }}{0 \%}$} & \multicolumn{2}{|c|}{ Depreciation } & \multirow{2}{*}{$\begin{array}{c}\text { Appreciation } \\
10 \%\end{array}$} & \multirow{2}{*}{$\begin{array}{c}\text { At par } \\
0 \%\end{array}$} & \multicolumn{2}{|c|}{ Depreciation } \\
\hline & & & $10 \%$ & $30 \%$ & & & $10 \%$ & $30 \%$ \\
\hline 1999Q1 & 0.15 & 0.65 & 0.95 & 1.00 & 0.01 & 0.69 & 1.00 & 1.00 \\
\hline Q2 & 0.58 & 0.76 & 0.88 & 0.97 & 0.16 & 0.75 & 0.99 & 1.00 \\
\hline Q3 & 0.63 & 0.80 & 0.90 & 0.98 & 0.42 & 0.79 & 0.96 & 1.00 \\
\hline Q4 & 0.71 & 0.83 & 0.91 & 0.98 & 0.52 & 0.80 & 0.94 & 1.00 \\
\hline 2000Q1 & 0.74 & 0.84 & 0.90 & 0.97 & 0.57 & 0.79 & 0.92 & 0.99 \\
\hline Q2 & 0.74 & 0.83 & 0.89 & 0.96 & 0.60 & 0.78 & 0.89 & 0.98 \\
\hline Q3 & 0.73 & 0.81 & 0.87 & 0.94 & 0.61 & 0.76 & 0.86 & 0.96 \\
\hline Q4 & 0.71 & 0.79 & 0.84 & 0.92 & 0.61 & 0.74 & 0.83 & 0.94 \\
\hline 2001Q1 & 0.71 & 0.78 & 0.83 & 0.90 & 0.60 & 0.71 & 0.80 & 0.91 \\
\hline Q2 & 0.70 & 0.76 & 0.81 & 0.88 & 0.58 & 0.69 & 0.77 & 0.88 \\
\hline Q3 & 0.69 & 0.75 & 0.80 & 0.87 & 0.57 & 0.66 & 0.74 & 0.84 \\
\hline Q4 & 0.68 & 0.73 & 0.78 & 0.85 & 0.56 & 0.64 & 0.71 & 0.81 \\
\hline 2002Q1 & 0.67 & 0.73 & 0.77 & 0.84 & 0.55 & 0.62 & 0.68 & 0.78 \\
\hline Q2 & 0.66 & 0.72 & 0.76 & 0.83 & 0.54 & 0.60 & 0.66 & 0.75 \\
\hline Q3 & 0.66 & 0.71 & 0.75 & 0.82 & 0.53 & 0.59 & 0.64 & 0.72 \\
\hline Q4 & 0.66 & 0.71 & 0.75 & 0.81 & 0.52 & 0.57 & 0.62 & 0.70 \\
\hline 2003Q1 & 0.65 & 0.70 & 0.74 & 0.80 & 0.51 & 0.56 & 0.60 & 0.68 \\
\hline Q2 & 0.65 & 0.70 & 0.74 & 0.80 & 0.50 & 0.55 & 0.59 & 0.66 \\
\hline Q3 & 0.65 & 0.70 & 0.73 & 0.79 & 0.50 & 0.54 & 0.58 & 0.64 \\
\hline Q4 & 0.65 & 0.69 & 0.73 & 0.79 & 0.49 & 0.53 & 0.57 & 0.63 \\
\hline
\end{tabular}

Table S8: Probability Estimates that SE and EA Prices are Lower under Entry at par at Beginning of 1999Q1 for Alternative Exchange Rates

\begin{tabular}{|c|c|c|c|c|c|c|c|c|}
\hline \multirow[b]{3}{*}{ Year } & \multicolumn{4}{|c|}{$\overline{\mathrm{SE}}$} & \multicolumn{4}{|c|}{$\overline{\text { EA }}$} \\
\hline & \multirow{2}{*}{$\begin{array}{c}\text { Appreciation } \\
10 \%\end{array}$} & \multirow{2}{*}{$\begin{array}{c}\text { At par } \\
0 \%\end{array}$} & \multicolumn{2}{|c|}{ Depreciation } & \multirow{2}{*}{$\begin{array}{c}\text { Appreciation } \\
10 \%\end{array}$} & \multirow{2}{*}{$\begin{array}{c}\text { At par } \\
0 \%\end{array}$} & \multicolumn{2}{|c|}{ Depreciation } \\
\hline & & & $10 \%$ & $30 \%$ & & & $10 \%$ & $30 \%$ \\
\hline 1999Q1 & 0.21 & 0.27 & 0.32 & 0.43 & 0.25 & 0.18 & 0.13 & 0.06 \\
\hline Q2 & 0.59 & 0.33 & 0.15 & 0.02 & 0.18 & 0.15 & 0.13 & 0.09 \\
\hline Q3 & 0.82 & 0.48 & 0.18 & 0.01 & 0.19 & 0.14 & 0.10 & 0.05 \\
\hline Q4 & 0.73 & 0.44 & 0.20 & 0.02 & 0.17 & 0.13 & 0.09 & 0.05 \\
\hline 2000Q1 & 0.71 & 0.44 & 0.21 & 0.03 & 0.18 & 0.12 & 0.09 & 0.04 \\
\hline Q2 & 0.71 & 0.41 & 0.17 & 0.02 & 0.18 & 0.12 & 0.08 & 0.03 \\
\hline Q3 & 0.68 & 0.39 & 0.17 & 0.02 & 0.19 & 0.13 & 0.08 & 0.03 \\
\hline Q4 & 0.65 & 0.37 & 0.16 & 0.02 & 0.20 & 0.13 & 0.08 & 0.03 \\
\hline 2001Q1 & 0.61 & 0.34 & 0.15 & 0.02 & 0.21 & 0.13 & 0.09 & 0.03 \\
\hline Q2 & 0.58 & 0.33 & 0.15 & 0.02 & 0.21 & 0.14 & 0.09 & 0.04 \\
\hline Q3 & 0.56 & 0.32 & 0.15 & 0.02 & 0.22 & 0.14 & 0.09 & 0.04 \\
\hline Q4 & 0.55 & 0.32 & 0.16 & 0.03 & 0.22 & 0.15 & 0.10 & 0.04 \\
\hline 2002Q1 & 0.53 & 0.32 & 0.16 & 0.03 & 0.23 & 0.15 & 0.10 & 0.05 \\
\hline Q2 & 0.52 & 0.32 & 0.17 & 0.04 & 0.23 & 0.16 & 0.11 & 0.05 \\
\hline Q3 & 0.52 & 0.32 & 0.18 & 0.04 & 0.24 & 0.17 & 0.11 & 0.05 \\
\hline Q4 & 0.51 & 0.33 & 0.19 & 0.05 & 0.24 & 0.17 & 0.12 & 0.06 \\
\hline 2003Q1 & 0.51 & 0.33 & 0.20 & 0.06 & 0.25 & 0.18 & 0.13 & 0.06 \\
\hline Q2 & 0.51 & 0.34 & 0.21 & 0.07 & 0.26 & 0.19 & 0.13 & 0.07 \\
\hline Q3 & 0.51 & 0.35 & 0.22 & 0.07 & 0.26 & 0.19 & 0.14 & 0.08 \\
\hline $\mathrm{Q} 4$ & 0.51 & 0.35 & 0.23 & 0.08 & 0.27 & 0.20 & 0.15 & 0.08 \\
\hline
\end{tabular}


Table S9: Conditional Point Estimates of the Effects of SE Entry on SE and EA ShortTerm Interest Rate, the SEK/Euro Rate and Effective Exchange Rate under Entry at par at Beginning of 1999Q1

\begin{tabular}{|c|c|c|c|c|c|}
\hline \multirow{3}{*}{ Year } & \multicolumn{2}{|c|}{ Short-Term } & \multicolumn{3}{|c|}{ Exchange Rate (\%) } \\
\hline & \multicolumn{2}{|c|}{ Interest Rate (\%) } & \multirow{2}{*}{$\begin{array}{l}\text { Spote Rate } \\
\text { SEK/Euro }\end{array}$} & \multicolumn{2}{|c|}{ Effective Rate } \\
\hline & SE & EA & & SE & EA \\
\hline 1999Q1 & -0.38 & -0.05 & 2.49 & 2.16 & -0.17 \\
\hline Q2 & -0.29 & -0.08 & 5.88 & 5.00 & -0.58 \\
\hline Q3 & -0.86 & -0.11 & 8.36 & 7.15 & -0.72 \\
\hline Q4 & -0.93 & -0.13 & 10.16 & 8.84 & -0.45 \\
\hline 2000Q1 & -0.83 & -0.12 & 12.41 & 10.91 & -0.24 \\
\hline $\mathrm{Q} 2$ & -1.41 & -0.15 & 13.83 & 12.44 & 0.41 \\
\hline Q3 & -1.26 & -0.17 & 15.70 & 14.40 & 1.18 \\
\hline $\mathrm{Q} 4$ & -2.49 & -0.23 & 17.00 & 16.07 & 2.40 \\
\hline 2001Q1 & -3.40 & -0.29 & 18.64 & 18.11 & 3.79 \\
\hline Q2 & -3.64 & -0.33 & 19.82 & 19.71 & 5.22 \\
\hline Q3 & -4.25 & -0.39 & 19.05 & 19.73 & 7.03 \\
\hline Q4 & -4.00 & -0.41 & 18.71 & 20.03 & 8.62 \\
\hline 2002Q1 & -3.74 & -0.38 & 19.20 & 20.92 & 9.88 \\
\hline Q2 & -4.62 & -0.36 & 17.97 & 20.62 & 11.93 \\
\hline Q3 & -5.94 & -0.36 & 16.51 & 20.46 & 14.74 \\
\hline $\mathrm{Q} 4$ & -6.75 & -0.36 & 17.40 & 22.15 & 17.03 \\
\hline 2003Q1 & -7.13 & -0.40 & 17.70 & 23.03 & 18.79 \\
\hline Q2 & -7.38 & -0.45 & 17.57 & 23.38 & 20.19 \\
\hline Q3 & -6.48 & -0.39 & 19.10 & 24.79 & 20.75 \\
\hline Q4 & -6.84 & -0.34 & 17.61 & 23.88 & 22.10 \\
\hline
\end{tabular}

Note: The point estimates are obtained conditional on the realised values of oil prices, US equity prices and US short and long-term interest rates over the period 1999Q1-2003Q4. The figures for the interest rate are percent per annum.

Table S10: Conditional Point Estimates of the Effects of SE Entry on SE and EA Output and Prices under Entry at par at Beginning of 1999Q1

\begin{tabular}{rccccc}
\hline \hline & \multicolumn{2}{c}{ Output (\%) } & & \multicolumn{2}{c}{ Prices $(\%)$} \\
\cline { 2 - 3 } \cline { 6 - 7 } Year & SE & EA & & SE & EA \\
\hline 1999Q1 & 0.14 & 0.06 & & 0.12 & 0.10 \\
Q2 & 0.26 & 0.11 & & 0.08 & 0.18 \\
Q3 & 0.33 & 0.13 & & 0.06 & 0.29 \\
Q4 & 0.45 & 0.12 & & 0.11 & 0.45 \\
2000Q1 & 0.51 & 0.12 & & -0.01 & 0.60 \\
Q2 & 0.55 & 0.08 & & 0.05 & 0.81 \\
Q3 & 0.82 & 0.02 & & 0.01 & 1.03 \\
Q4 & 1.02 & -0.03 & & 0.01 & 1.33 \\
2001Q1 & 1.58 & -0.07 & & 0.14 & 1.72 \\
Q2 & 1.80 & -0.05 & & -0.01 & 2.10 \\
Q3 & 1.86 & -0.04 & & -0.15 & 2.50 \\
Q4 & 1.97 & -0.03 & & -0.24 & 2.94 \\
2002Q1 & 1.92 & 0.02 & & -0.49 & 3.31 \\
Q2 & 2.08 & 0.02 & & -0.60 & 3.72 \\
Q3 & 2.59 & -0.04 & & -0.52 & 4.30 \\
Q4 & 3.20 & -0.01 & & -0.71 & 4.90 \\
2003Q1 & 3.56 & 0.10 & & -1.06 & 5.50 \\
Q2 & 3.62 & 0.17 & & -1.25 & 6.15 \\
Q3 & 3.76 & 0.31 & & -1.66 & 6.70 \\
Q4 & 3.39 & 0.35 & & -1.85 & 7.26 \\
\hline
\end{tabular}

Note: The point estimates are obtained conditional on the realised values of oil prices, US equity prices and US short and long-term interest rates over the period 1999Q1-2003Q4. 
Figure S1: SE and EA Nominal Short-Term Interest Rates at Annual Percentage Rates

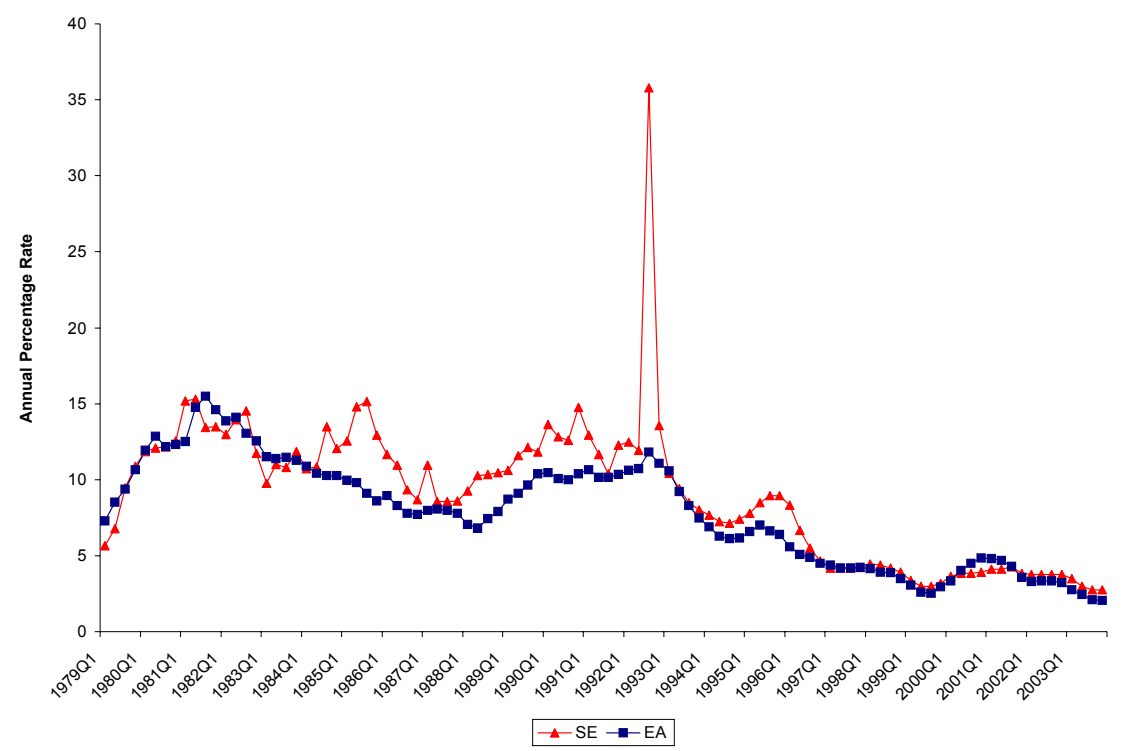

Figure S2: Quarterly Percentage Changes in SE and EA Exchange Rates

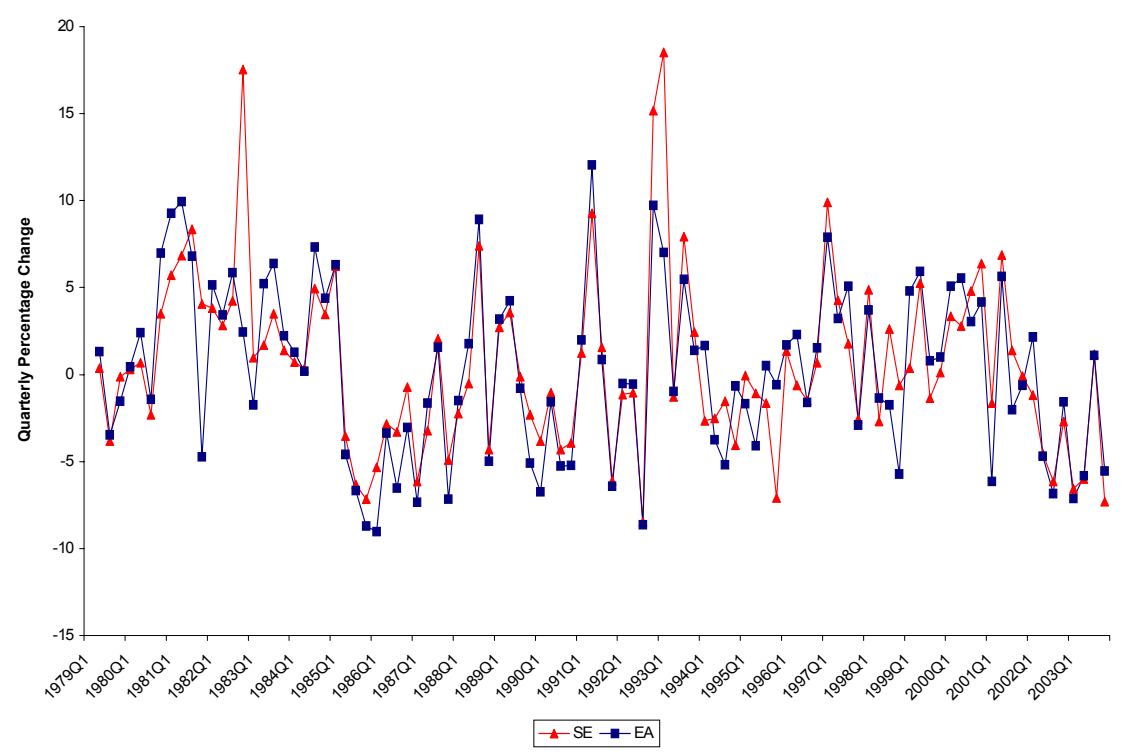


Figure S3: Probability Estimates that SE and EA Short-Term Interest Rates are Lower under Entry at par at Beginning of 1999Q1

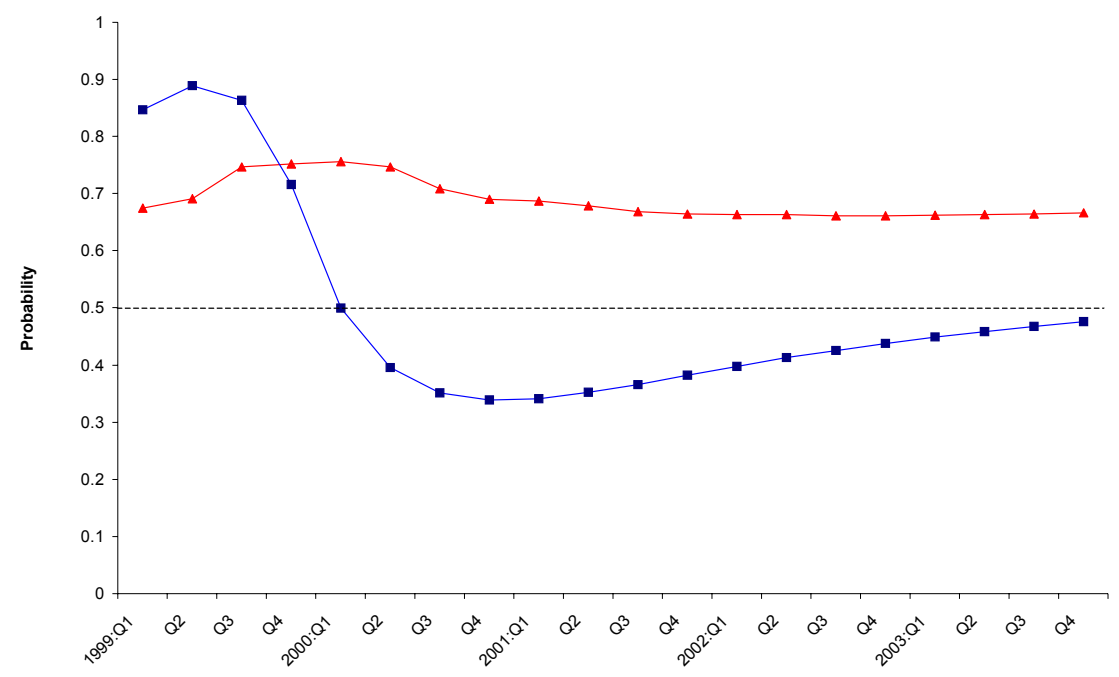

$\neg$ SE $\rightarrow-\mathrm{EA}$

Figure S4: Probability Estimates that SE and EA Output is Higher under Entry at par at Beginning of 1999Q1

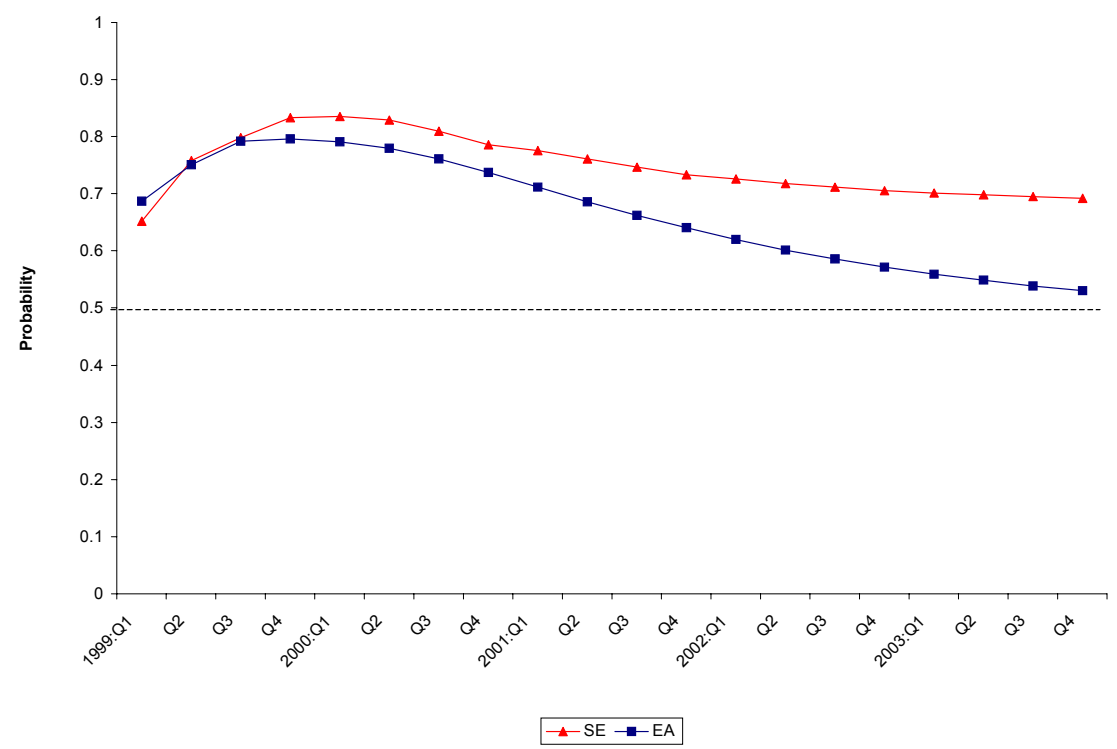


Figure S5: Probability Estimates that SE and EA Prices are Lower under Entry at par at Beginning of 1999Q1

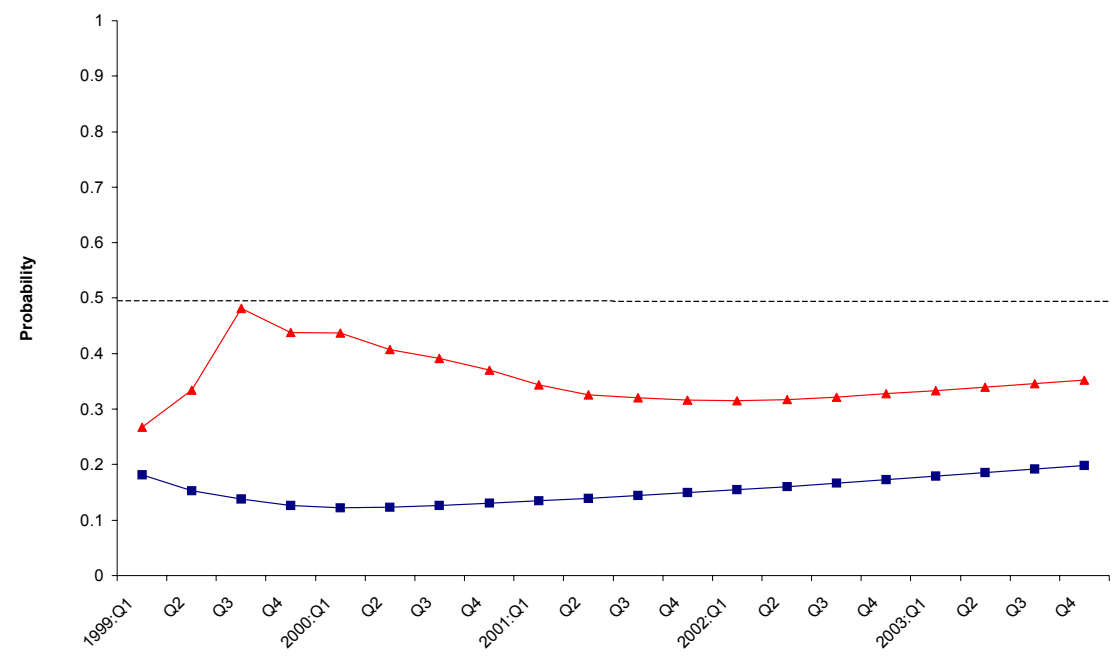

$\neg-\mathrm{SE} \rightarrow \mathrm{EA}$

Figure S6: Conditional and Unconditional Probability Estimates that SE and EA Output is Higher under Entry at par at Beginning of 1999Q1

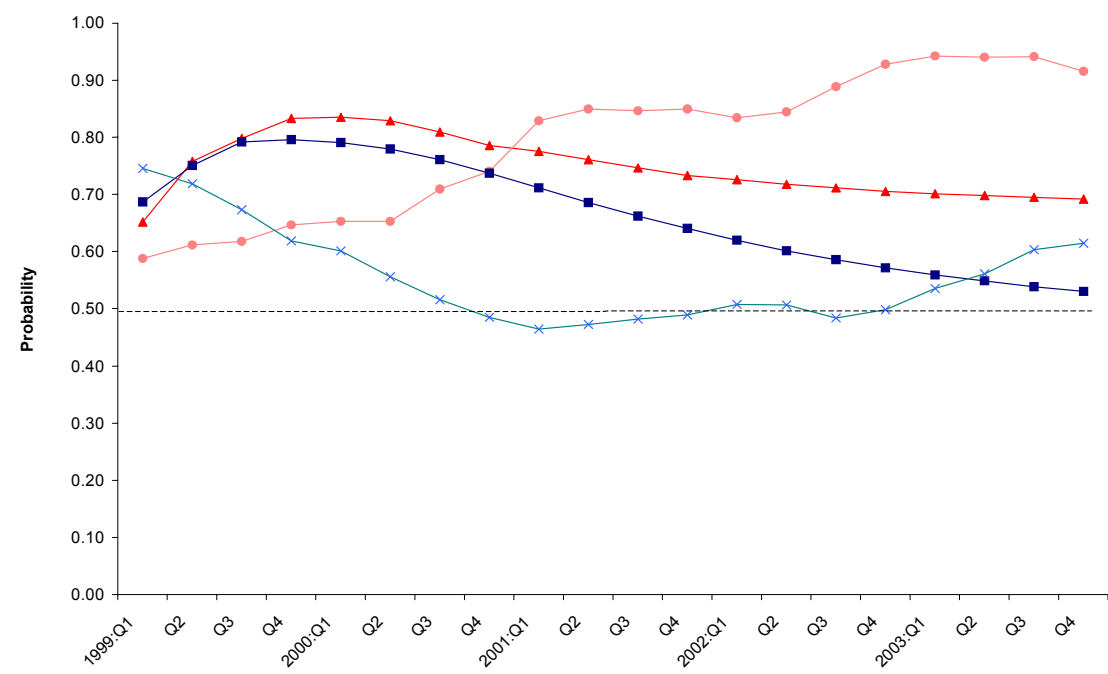

$\neg$ SE Unconditional $\rightarrow-$ SE Conditional $\rightarrow$-EA Unconditional $*$ EA Conditional

Note: The probability estimates are obtained conditional on the realised values of oil prices, US equity prices and US short and long-term interest rates over the period 1999Q1-2003Q4. 
Figure S7: Probability Estimates that SE and EA Output is Higher under Entry at par at Beginning of 1999Q1 and at Beginning of 2004Q1, by Quarters after Entry

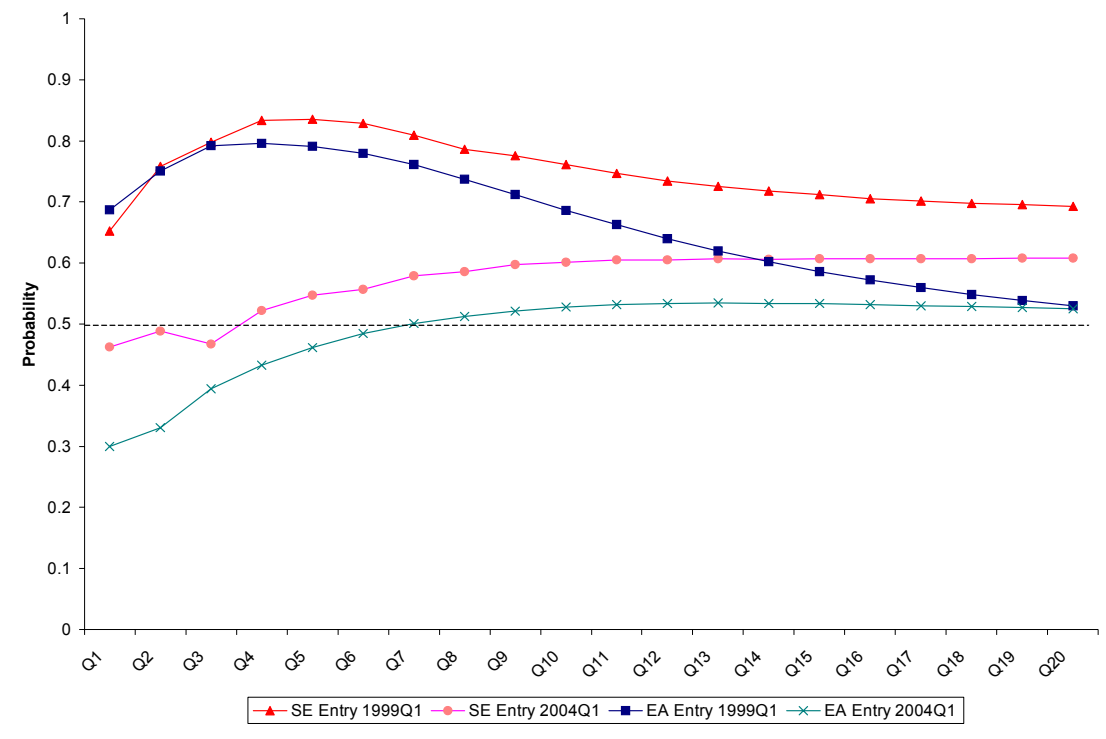

Figure S8: Probability Estimates that SE Output is Higher under Entry at Beginning of 1999Q1 for Alternative Exchange Rates

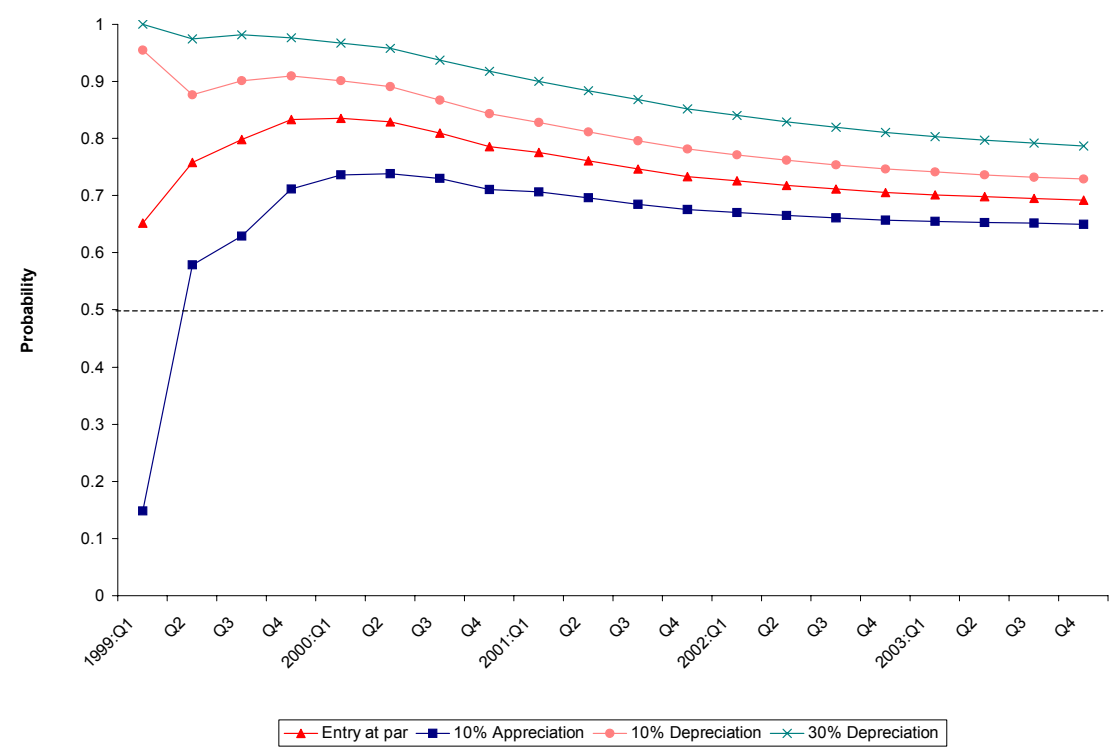


Figure S9: Probability Estimates that EA Output is Higher under Entry at Beginning of 1999Q1 for Alternative Exchange Rates

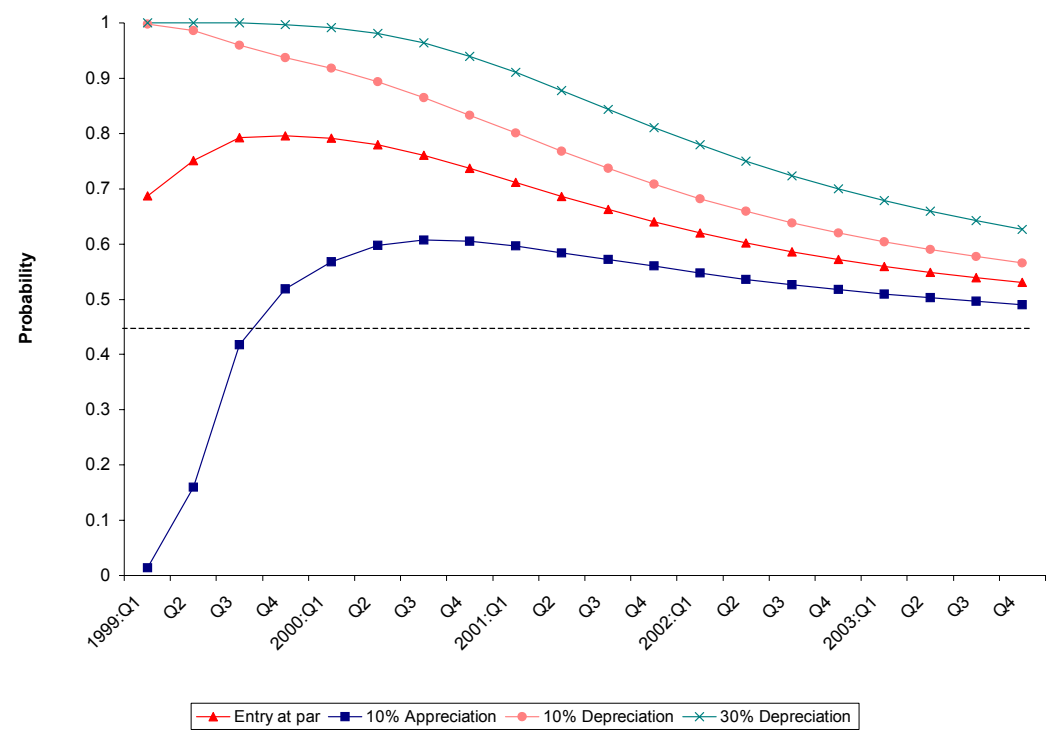




\section{References}

[1] Dees, S., F. di Mauro, M. H. Pesaran and L. V. Smith (2005), "Exploring the International Linkages of the Euro Area: A Global VAR Analysis", CESifo Working Paper No. 1425. Presented at CESifo Area Conference on Macro, Money and International Finance, February 2005.

[2] Doan, T., Litterman, R., and C. Sims (1984), "Forecasting and Conditional Projection Using Realistic Prior Distributions," Econometric Reviews, 3, $1-100$.

[3] Fogel, R.W. (1964), Railroads and American Economic Growth, Baltimore, Johns Hopkins Press.

[4] Garratt, A., K. Lee, M.H. Pesaran, Y. Shin (2003), "Forecast Uncertainties in Macroeconometric Modelling: An Application to the UK Economy", Journal of the American Statistical Association, Applications and Case Studies, 98, 829-838.

[5] Heckman, J.J. (2000), "Causal Parameters and Policy Analysis in Economics: A Twentieth Century Retrospective", Quarterly Journal of Economics, 115, 45-98.

[6] HMT (2003), UK Membership of the Single Currency: Assessment of the Five Economic Tests, H.M. Treasury, June.

[7] Keegan, W. (2003), The Prudence of Mr Gordon Brown, Wiley.

[8] Neyman, J. (1935), "Statistical Problems in Agricultural Experiments", Supplement to the Journal of the Royal Statistical Society, II, 107-180.

[9] Pesaran, M.H., T. Shuermann, and S.M. Weiner (2004), "Modelling Regional Interdependencies Using a Global Error-Correcting Macroeconometric Model", Journal of Business and Economic Statistics, 22, 129-162.

[10] Waggoner, D.F., and T. Zha, (1999), "Conditional Forecasts in Dynamic Multivariate Models," The Review of Economics and Statistics, 81(4), 639651. 


\section{CESifo Working Paper Series}

(for full list see www.cesifo-group.de)

1413 Gil S. Epstein and Shmuel Nitzan, Lobbying and Compromise, February 2005

1414 Marcel F. M. Canoy, Jan C. van Ours and Frederick van der Ploeg, The Economics of Books, February 2005

1415 Eric A. Hanushek and Ludger Wößmann, Does Educational Tracking Affect Performance and Inequality? Differences-in-Differences Evidence across Countries, February 2005

1416 George Kapetanios and M. Hashem Pesaran, Alternative Approaches to Estimation and Inference in Large Multifactor Panels: Small Sample Results with an Application to Modelling of Asset Returns, February 2005

1417 Samuel Mühlemann, Jürg Schweri, Rainer Winkelmann and Stefan C. Wolter, A Structural Model of Demand for Apprentices. February 2005

1418 Giorgio Brunello and Lorenzo Rocco, Educational Standards in Private and Public Schools, February 2005

1419 Alex Bryson, Lorenzo Cappellari and Claudio Lucifora, Why so Unhappy? The Effects of Unionisation on Job Satisfaction, March 2005

1420 Annalisa Luporini, Relative Performance Evaluation in a Multi-Plant Firm, March 2005

1421 Giorgio Bellettini and Carlotta Berti Ceroni, When the Union Hurts the Workers: A Positive Analysis of Immigration Policy, March 2005

1422 Pieter Gautier, Michael Svarer and Coen Teulings, Marriage and the City, March 2005

1423 Ingrid Ott and Stephen J. Turnovsky, Excludable and Non-Excludable Public Inputs: Consequences for Economic Growth, March 2005

1424 Frederick van der Ploeg, Back to Keynes?, March 2005

1425 Stephane Dees, Filippo di Mauro, M. Hashem Pesaran and L. Vanessa Smith, Exploring the International Linkages of the Euro Area: a Global VAR Analysis, March 2005

1426 Hans Pitlik, Friedrich Schneider and Harald Strotmann, Legislative Malapportionment and the Politicization of Germany’s Intergovernmental Transfer System, March 2005

1427 Konstantinos Angelopoulos and Apostolis Philippopoulos, The Role of Government in Anti-Social Redistributive Activities, March 2005

1428 Ansgar Belke and Daniel Gros, Asymmetries in the Trans-Atlantic Monetary Policy Relationship: Does the ECB follow the Fed?, March 2005 
1429 Sören Blomquist and Luca Micheletto, Optimal Redistributive Taxation when Government’s and Agents’ Preferences Differ, March 2005

1430 Olof Åslund and Peter Fredriksson, Ethnic Enclaves and Welfare Cultures - QuasiExperimental Evidence, March 2005

1431 Paul De Grauwe, Roberto Dieci and Marianna Grimaldi, Fundamental and NonFundamental Equilibria in the Foreign Exchange Market. A Behavioural Finance Framework, March 2005

1432 Peter Egger, Stefan Gruber, Mario Larch and Michael Pfaffermayr, Knowledge-Capital Meets New Economic Geography, March 2005

1433 George Economides and Apostolis Philippopoulos, Should Green Governments Give Priority to Environmental Policies over Growth-Enhancing Policies?, March 2005

1434 George W. Evans and Seppo Honkapohja, An Interview with Thomas J. Sargent, March 2005

1435 Helge Berger and Volker Nitsch, Zooming Out: The Trade Effect of the Euro in Historical Perspective, March 2005

1436 Marc-Andreas Muendler, Rational Information Choice in Financial Market Equilibrium, March 2005

1437 Martin Kolmar and Volker Meier, Intra-Generational Externalities and InterGenerational Transfers, March 2005

1438 M. Hashem Pesaran and Takashi Yamagata, Testing Slope Homogeneity in Large Panels, March 2005

1439 Gjermund Nese and Odd Rune Straume, Industry Concentration and Strategic Trade Policy in Successive Oligopoly, April 2005

1440 Tomer Blumkin and Efraim Sadka, A Case for Taxing Education, April 2005

1441 John Whalley, Globalization and Values, April 2005

1442 Denise L. Mauzerall, Babar Sultan, Namsoug Kim and David F. Bradford, Charging $\mathrm{NO}_{x}$ Emitters for Health Damages: An Exploratory Analysis, April 2005

1443 Britta Hamburg, Mathias Hoffmann and Joachim Keller, Consumption, Wealth and Business Cycles in Germany, April 2005

1444 Kohei Daido and Hideshi Itoh, The Pygmalion Effect: An Agency Model with Reference Dependent Preferences, April 2005

1445 John Whalley, Rationality, Irrationality and Economic Cognition, April 2005

1446 Henning Bohn, The Sustainability of Fiscal Policy in the United States, April 2005 
1447 Torben M. Andersen, Is there a Role for an Active Fiscal Stabilization Policy? April 2005

1448 Hans Gersbach and Hans Haller, Bargaining Power and Equilibrium Consumption, April 2005

1449 Jerome L. Stein, The Transition Economies: A NATREX Evaluation of Research, April 2005

1450 Raymond Riezman, John Whalley and Shunming Zhang, Metrics Capturing the Degree to which Individual Economies are Globalized, April 2005

1451 Romain Ranciere, Aaron Tornell and Frank Westermann, Systemic Crises and Growth, April 2005

1452 Plutarchos Sakellaris and Focco W. Vijselaar, Capital Quality Improvement and the Sources of Growth in the Euro Area, April 2005

1453 Kevin Milligan and Michael Smart, Regional Grants as Pork Barrel Politics, April 2005

1454 Panu Poutvaara and Andreas Wagener, To Draft or not to Draft? Efficiency, Generational Incidence, and Political Economy of Military Conscription, April 2005

1455 Maurice Kugler and Hillel Rapoport, Skilled Emigration, Business Networks and Foreign Direct Investment, April 2005

1456 Yin-Wong Cheung and Eiji Fujii, Cross-Country Relative Price Volatility: Effects of Market Structure, April 2005

1457 Margarita Katsimi and Thomas Moutos, Inequality and Relative Reliance on Tariffs: Theory and Evidence, April 2005

1458 Monika Bütler, Olivia Huguenin and Federica Teppa, Why Forcing People to Save for Retirement may Backfire, April 2005

1459 Jos Jansen, The Effects of Disclosure Regulation of an Innovative Firm, April 2005

1460 Helge Bennmarker, Kenneth Carling and Bertil Holmlund, Do Benefit Hikes Damage Job Finding? Evidence from Swedish Unemployment Insurance Reforms, May 2005

1461 Steffen Huck, Kai A. Konrad and Wieland Müller, Merger without Cost Advantages, May 2005

1462 Louis Eeckhoudt and Harris Schlesinger, Putting Risk in its Proper Place, May 2005

1463 Hui Huang, John Whalley and Shunming Zhang, Trade Liberalization in a Joint Spatial Inter-Temporal Trade Model, May 2005

1464 Mikael Priks, Optimal Rent Extraction in Pre-Industrial England and France - Default Risk and Monitoring Costs, May 2005 
1465 François Ortalo-Magné and Sven Rady, Heterogeneity within Communities: A Stochastic Model with Tenure Choice, May 2005

1466 Jukka Pirttilä and Sanna Tenhunen, Pawns and Queens Revisited: Public Provision of Private Goods when Individuals make Mistakes, May 2005

1467 Ernst Fehr, Susanne Kremhelmer and Klaus M. Schmidt, Fairness and the Optimal Allocation of Ownership Rights, May 2005

1468 Bruno S. Frey, Knight Fever - Towards an Economics of Awards, May 2005

1469 Torberg Falch and Marte Rønning, The Influence of Student Achievement on Teacher Turnover, May 2005

1470 John Komlos and Peter Salamon, The Poverty of Growth with Interdependent Utility Functions, May 2005

1471 Hui Huang, Yi Wang, Yiming Wang, John Whalley and Shunming Zhang, A Trade Model with an Optimal Exchange Rate Motivated by Current Discussion of a Chinese Renminbi Float, May 2005

1472 Helge Holden, Lars Holden and Steinar Holden, Contract Adjustment under Uncertainty, May 2005

1473 Kai A. Konrad, Silent Interests and All-Pay Auctions, May 2005

1474 Ingo Vogelsang, Electricity Transmission Pricing and Performance-Based Regulation, May 2005

1475 Spiros Bougheas and Raymond Riezman, Trade and the Distribution of Human Capital, June 2005

1476 Vesa Kanniainen, Seppo Kari and Jouko Ylä-Liedenpohja, The Start-Up and Growth Stages in Enterprise Formation: The "New View" of Dividend Taxation Reconsidered, June 2005

1477 M. Hashem Pesaran, L. Vanessa Smith and Ron P. Smith, What if the UK had Joined the Euro in 1999? An Empirical Evaluation Using a Global VAR, June 2005 